\title{
A STUDY OF SUBSTRATE REMOVAL \\ IN A MICROBIAL FILM REACTOR
}

BY

NICHOLAS PAUL HARRIS

Submitted to the University of Cape Town in fulfilment of the requirements for the degree of Master of Science in Engineering

April 1975

Copyright by the University of Cape Town

The copyright of this thesis is held by the University of Capo Town.

Reproduction of the whole or any part may be made for study purposes only, and not for publication. 
The copyright of this thesis vests in the author. No quotation from it or information derived from it is to be published without full acknowledgement of the source. The thesis is to be used for private study or noncommercial research purposes only.

Published by the University of Cape Town (UCT) in terms of the non-exclusive license granted to UCT by the author. 


\section{ACKNOWLEDGEMENTS}

The author wishes to express his sincere appreciation and thanks to Dr. G.S. Hansford for his valuable guidance throughout the course of this work, and to Professor A.D. Carr for his frequent advice and helpful suggestions.

Thanks go also to Mr. G.P.A. Corewijn for the time and effort he devoted to the construction of the experimental apparatus, and to Mrs. Cousins for her rapid and efficient typing.

Finally the generous financial support of A.E. \& C.I. is gratefully acknowledged. 
CHAPTER 1 - BACKGROUND 1

1.1 Introduction 1

1.1.1 Historical Development 1

1.1 .2 Objectives 2

1.2 Literature Survey 3

1.2.1 Correlations and Empirical 3 Models

1.2.1.1 Stone Filters 3

1.2.1.2 Plastic-Media Filters 5

1.2.2 Theoretical Treatments 6

1.2.3 Summary 13

CHAPTER 2 - THEORY 14

2. I Formulation of the Mathematical Model 14

2.1.1 Introduction 14

2.1.2 Assumptions 14

2.1.3 Derivation of Equations 16

2.1.4 Summary of Model Equations 19

2.2 Technique of Solution 20

2.2.I Introduction 20

2.2.2 Trial and Error Procedure 20

2.3 Selection of Parameter Values 22

2.4 The Effect of Temperature 26

$\begin{array}{ll}2.5 \text { Summary } & 27\end{array}$

CHAPTER 3 - EXPERIMENTAL APPARATUS AND METHOD 28

3.I Experimental Apparatus 28

3.1.1 Apparatus used by Other 28

3.1.2 Description of Experimental 28

Apparatus

3.1.2.1 Introduction 28

3.1.2.3 The Plate 29

3.1.2.3 The Overflow Weir 31

3.1.2.4 The Feed System 31

3.2 Operating Technique 33

3.2.1 Startup 33

3.2.2 Choice of Variable Ranges 33

3.2.3 Reactor Operation 36 
CHAPTER 4 - RESULTS 39

4.1 Experimental Results 39

4.1.1 Presentation and Discussion 39

4.1.2 Error Analysis 40

4.2 Theoretical Results 46

4.2.1 COD Removal 46

4.2.2 Active Depth - Oxygen and 51

4.2.3 Choosing Filter Design 55

Parameters

CHAPTER $5-$ CONCLUSIONS AND RECOMMENDATIONS 57

LITERATURE CITED $\quad$ • 59

APPENDICES

A On Mass Transfer of Oxygen from the air to a falling film of liquid

B Fortran program listing with sample output

C Detalls of the Synthetic Feed Composition and Makeup

D Temperature measurements in the falling film

E Experimental results 


\section{IIST OF FIGURES}

page

2.1 Schematic Diagram Showing an Element of

Microbial Slime with Substrate and oxygen

Profiles

2.2 Block Diagram Showing Procedure for Solution

of the Model Equations

3.1 Bottom Section of the plate Showing Retaining 30

Strips and Thermocouple Grooves

3.2 Enlarged Side and End Elevation of the Over- 30 flow Knife-edge

3.3 The Overflow Weir

3.4 The Microbial Film Reactor Assembly

3.5 Flow Diagram of the Feed System

3.6 Dynamic Response of Microbial Film Reactor After Removal of Superficial slime

4.I Experimentally Determined COD Removals per $40 \mathrm{~cm}$

4.2 Experimentally Determined COD Removals per $40 \mathrm{~cm}$

4.3 Cell Yield vs Applied COD

4.4 COD Removal Rate vs Applied COD

4.5 Predicted Curves for $6 \mathrm{l} / \mathrm{hr}$ at $15^{\circ} \mathrm{C}$ and $25^{\circ} \mathrm{C}$

4. 6 Predicted Curves for $12 \mathrm{l} / \mathrm{hr}$ at $15^{\circ} \mathrm{C}$ and $25^{\circ} \mathrm{C} \quad 48$

4.7 Predicted Curves for $18 \mathrm{l} / \mathrm{hr}$ at $15^{\circ} \mathrm{C}$ and $25^{\circ} \mathrm{C} \quad 49$

4.8 Predicted Curves for $24 \mathrm{l} / \mathrm{hr}$ at $15^{\circ} \mathrm{C}$ and $25^{\circ} \mathrm{C} 50$

4.9 Variation in Active Depth with Applied COD 53

4.10 Typical Oxygen and Substrate Concentration 54 Profiles in the Bioslime

4.I1 COD Decrease with Reactor Length 
A mathematical model is formulated describing the mechanism of substrate removal by a microbial slime over which a film of liquid, containing the substrate as dissolved biodegradable material, is flowing. It is assumed that a lack of either organic carbon, oxygen, or both simultaneously, can limit the overall rate of the process. Basic chemical engineering principles of interfacial mass transfer, diffusion and biochemical reaction are used in the formulation of the model and the resulting set of equations is solved by digitial computer using typical kinetic parameters taken from the literature. Predictions of whether organic carbon, oxygen, or both simultaneously, limit the process, the substrate removal rate, and the active depth of the biofilm are made.

Data were obtained in support of the model by measuring substrate removals on a vertically mounted experimental biofilm reactor over a range of hydraulic and organic loadings typical of industrial-scale operation. Good agreement between the experimental results and the model predictions was obtained with the exception of the data pertaining to hydraulic loadings approaching the minimum wetting rate. These data showed a marked deviation from the predicted values indicating that under conditions of low hydraulic load the model is unsatisfactory for describing the system. 


\section{NOMENCLATURE}

$\mathrm{C}_{\mathrm{B}} \quad$ Bulk oxygen concentration in the falling liquid film, $\left(\mathrm{mg} / \mathrm{cm}^{3}\right)$.

$C^{*} \quad$ Concentration of oxygen in the liquid at the gasliquid interface, $\left(\mathrm{mg} / \mathrm{cm}^{3}\right)$.

C Dissolved oxygen concentration in equilibrium with an oxygen partial pressure of $\mathrm{P},\left(\mathrm{mg} / \mathrm{cm}^{3}\right)$.

$\mathrm{D}_{\mathrm{O}} \quad$ Diffusivity of oxygen in the biological slime, $\left(\mathrm{cm}^{2} / \mathrm{sec}\right)$.

$D_{S} \quad$ Diffusivity of glucose in the biological slime, $\left(\mathrm{cm}^{2} / \mathrm{sec}\right)$.

F Constant factor relating the quantities of glucose and oxygen utilized in the aerobic metabolism process,

$\mathrm{H}$ Henry's Law constant, (atm./mole fraction).

$\mathrm{k}_{\text {LO }}$ Liquid phase oxygen mass transfer coefficient referring to transfer from the bulk of the liquid to the slime-liquid interface, ( $\mathrm{cm} / \mathrm{sec})$.

$k_{\text {LS }}$ Liquid phase substrate (glucose) mass transfer coefficient, $(\mathrm{cm} / \mathrm{sec})$.

$k_{G} \quad$ Gas-side mass transfer coefficient, (cm/sec).

$k_{L} \quad$ Liquid side mass transfer coefficient, (cm/sec).

$K_{G} \quad$ Overall mass transfer coefficient based on the gas side, $(\mathrm{cm} / \mathrm{sec})$.

$\mathrm{K}_{\mathrm{L}} \quad$ Overall mass transfer coefficient based on the liquid side, $(\mathrm{cm} / \mathrm{sec})$.

$\mathrm{K}_{\mathrm{S}}, \mathrm{K}_{\mathrm{O}}$ Half-velocity kinetic coefficients for substrate and oxygen respectively, $\left(\mathrm{mg} / \mathrm{cm}^{3}\right)$.

$\mathrm{K}_{1}, \mathrm{~K}_{2}$ Half-velocity kinetic coefficients for reactants 1 and 2 respectively, $\left(\mathrm{mg} / \mathrm{cm}^{3}\right)$.

$\mathrm{L}$ Active thickness of the biological film, (cm).

$\mathrm{N}$ Mass flux of oxygen, (mg/ $\left.\mathrm{cm}^{2}-\mathrm{sec}\right)$.

o Oxygen concentration in the biological film, $\left(\mathrm{mg} / \mathrm{cm}^{3}\right)$.

$0 *$ Oxygen concentration at the slime-liquid interface, $\left(\mathrm{mg} / \mathrm{cm}^{3}\right)$.

$\mathrm{O}_{\mathrm{S}}$ oxygen concentration in the saturated liquid film, $\left(\mathrm{mg} / \mathrm{cm}^{3}\right)$. 
P Partial pressure of oxygen in the air, (KPa).

$\mathrm{P}^{*} \quad$ Partial pressure of oxygen at the air-liquid interface, (KPa).

$P_{B} \quad$ Partial pressure of oxygen in equilibrium with a dissolved oxygen concentration in the liquid of $C_{B}$, (KPa).

Q Liquid flow rate, $\left(\mathrm{cm}^{3} / \mathrm{cm}-\mathrm{sec}\right)$.

$R_{1}, R_{2}$ Concentration of reactants 1 and 2 respectively, $\left(\mathrm{mg} / \mathrm{cm}^{3}\right)$.

S Substrate concentration in the biological slime, $\left(\mathrm{mg} / \mathrm{cm}^{3}\right)$.

$S_{1} \quad$ Bulk substrate concentration in the liquid entering the control element, ( $\left.\mathrm{mg} / \mathrm{cm}^{3}\right)$.

$\mathrm{S}_{2} \quad$ Bulk substrate concentration in the liquid leaving the control element, $\left(\mathrm{mg} / \mathrm{cm}^{3}\right)$.

$\mathrm{S}^{*} \quad$ Substrate concentration at the slime-liquid interface, $\left(\mathrm{mg} / \mathrm{cm}^{3}\right)$.

$\mathrm{x}$ Cell concentration in the biological slime, $\left(\mathrm{mg} / \mathrm{cm}^{3}\right)$.

$\mathbf{x}$ Distance measured into the slime from the interface, (cm).

$\Delta \mathrm{x} \quad$ Thickness of elemental slice in the slime, (cm).

$\Delta \mathbf{z}$ Length of reactor control element, (cm).

Y Cell yield.

$z$ Distance measured from the top of the reactor, (cm).

$\mu \quad$ Specific growth rate of organisms, $\left(\sec ^{-1}\right)$.

$\hat{\hat{\mu}} \quad$ Maximum specific growth rate of organisms, $\left(\sec ^{-1}\right)$.

$\delta$ Liquid film thickness, (cm). 
1. INTRODUCTION

\subsection{Historical Development}

The origin of the trickling filter as a process for the treatment of domestic sewage is obscure but it seems probable, as suggested by Lohmeyer [1], that the first step occurred in 1871 with the design, by Franklin, of an intermittent sand filter. This filter, in which settled sewage was allowed to pass through a bed of sand about three feet high produced, by biological breakdown, a good quality water, but had the disadvantages of frequent clogging and large area requirements lone acre of bed per 1400 people). In an effort to reduce the prohibitive size of the filter a "contact bed" was introduced whereby sewage was allowed to stand for several hours in a tank containing small rocks. Gross inefficiency, however, resulted in the abandonment of this system. In 1889 the first experimental trickling filters were built and operated at the Lawrence Experiment station of the Massachusitts state Board of Health. This study produced the following fundamental principle of trickling filter operation which today remains essentially unchanged : "A slow movement of sewage over biological slimes would produce an increase in the stability of the dissolved and finely divided solids." 1893 saw the introduction by Joseph Corbett of spray distribution and the raising of the stone bed to allow ventilation from below. This not only improved the efficiency of organic removal but also prevented clogging at the bottom of the filter. For the next half-century trickling filter design and operation technology remained fairly stagnant and it was not until the mid nineteen-fifties that a major upheaval occurred with the advent of moulded plastic media as a replacement for the conventional stone and slag. There 
are currently several designs of plastic media commercially available which, although dissimilar in appearance, have three principal structural advantages over their stone counterparts. Briefly these are:-

(i) Light weight; enabling units to be constructed to greater heights thereby reducing the land area required.

(ii) Extremely high surface area to volume ratio; thus achieving vast areas of slime-liquid contact in relatively small units.

(iii) Large voidage fraction (> 90\%) which ensures an adequate draught of air through the media as well as eliminating blockage.

These characteristics make it possible to subject plastic media filters to much higher organic and hydraulic loadings than an equivalent volume of conventional medium and also allow them to cope more easily with shock loads. This versatility and high performance capacity has led to a large-scale spread in the use of plastic media to many industries experiencing problems with disposal of high concentration biodegradable effluents.

\section{2 objectives}

Since the earliest days of controlled biological wastewater treatment in the latter half of the nineteenth century, design and operation of trickling filters has been almost exclusively the role of Civil engineers. Criteria for design were based on decades of field experience and were found to be quite satisfactory for sewage fed stone media filters. The recent explosion in the use of plastic media for high-rate bio-filtration, however, has highlighted the need for a more rational design procedure based on fundamental theoretical principles and it was at this stage that the field began to attract interest from Chemical engineers. The objectives of the work described herein were, therefore:-

(i) To produce a niathematical mocel., based on established chemical engineering principles, describing the mechanisin of substrate uptake and utilization in a bio- 
logical film, this with a view to better understanding the various processes involved and,

(ii) To confirm the validity of the model by means of an experimental investigation.

\section{IITERATURE SURVEY}

\subsection{Correlations and Enpirical Models}

\subsubsection{Stone Filters}

Although stone media trickling filters were in common use well before the Second World War, it appears that the first attempt to develop a mathematical model describing their performance occurred only in 1946. It was in this year that the National Research Council (NRC), having analysed data gathered from sewage treatment plants serving military installations in the United states, published an empirical formula relating the fractional BOD removal in a combined filter-settler to the applied organic loading, the volume of filter medium, and the ratio of recirculated to influent flow [2]. Two years later Velz [3] formulated his basic law for the performance of biological filters, i.e. "The rate of extraction of organic material per interval of depth of a biological bed is proportional to the remaining concentration of organic matter." Following directly from this law he proposed an equation giving the fraction of BOD remaining as a function of filter depth and a temperaturedependent removal rate constant.

Realising that "no trickling process, its operation or its efficiency can be completely defined on the basis of one design variable or loading," Geber [4], in 1954, proposed using a dimensionless group incorporating hydraulic loading, filter depth, and BOD reaction rate constant to correlate the fraction of BOD removed. He was, however, largely unsuccessful, obtaining a linear correlation for only very specific conditions.

Fairall [5], using data gathered from a large number 
of field installations, obtained correlations relating the fraction of 5-day $B O D$ remaining in following clarifier effluents to various process variables (gross volume of media, hydraulic loading and recirculation ratio) for filters both with and without recycle. No theoretical justification of the correlations, however, was attempted.

By assuming:- (i) a trickling filter is a selfregenerating absorbtion tower; (ii) each unit depth of the filter will remove a constant fraction of the removable BOD applied to it; and (iii), the quantity of BOD that can be absorbed per unit volume has a maximum limit, Stack [6] was able, by theoretical analysis, to extend Velz's formula. He derived equations giving the fraction of BOD renoved for filters operating both with and without recirculation, and also developed a graphical technique for their solution. Good agreement was obtained with results from experimental filters but the usefulness of the equations remained unclear.

Eckenfelder [7] assumed the BOD removal to be related to hydraulic loading and depth and to follow a retardant type reaction (i.e. one whose rate decreases with increasing time and decreasing substrate concentration). Using multiple regression analysis on various published filter data he was able to develop a generalised design equation for the removal efficiency of stone filters treating domestic sewage.

Galler and Gotaas [8] similarly employed multiple regression analysis on extensive field data but included recirculation, temperature, and organic loading rate together with depth and hydraulic rate as independent variables. The mathematical model which emerged from this work indicated that hydraulic rate was not a significant variable and, since temperature could not be controlled, the equation was reduced to a three variable design formula.

More detailed surveys of the development of stone filter technology are given by Baker and Graves [10], 
Chase [61], and Roberts [9], the latter containing, in addition, a brief summary of some of the theoretical considerations proposed by researchers examining filter behaviour.

\subsubsection{Plastic-media Filters}

Anong the pioneers of plastic-media trickling filters was Bryan [11] who, in 1955, published one of the first papers dealing with the use of plastic support packings. The results he obtained using filters packed with corrugated sheet-type polystyrene treating botin phenol and settled domestic sewage were encouraging, but no attempt was made to formulate any mathematical models.

Schulze [12, 13], experimenting with vertical screen filters operated at various hydraulic and organic loadings, produced, by means of curve-fitting, an equation for the efficiency similar to that proposed by Velz [3]. Also, from careful observation of the biological slime, he was prompted to suggest the possible existence of distinct aerobic and anaerobic zones.

Using data from experiments undertaken by the Dow Chemical Company on "Surfpac" plastic medium, Germain [14] obtained a formula describing the performance of the filters similar in form to those proposed by Velz and stack. The results indicated that recirculation had no major effect on the removal of BOD.

Eckenfelder [15], by assurning soluble BOD removal in a trickling filter to be analogous with that in the activated sludge process, derived a model incorporating both recirculation and media characteristics. Gromiec et al. [16] effected slight modifications to this equation and attempted to verify it by experimenting on a filter packed with "Surfpac" plastic medium. They concluded that the filter performance could be represented adequately by their model. 


\subsection{Theoretical Treatments}

Arnes et al.[17], using a theoretical approach similar to that used in chemical engineefing treatments of packed bed reactors, derived fundamental equations describing the transient operation of trickling filters. Their analysis was basea on several postulates of operation, these being : mass transfer from the liquid to the slime by absorbtion; first-order biochemical reaction; linear equilibrium relation between interface $B O D$ and $B O D$ in the slime, and constant filter parameters. Although it was recognised that oxygen is an essential requirement for efficient filter operation, the supply was assumed to exceed the demand. From the results for transient operation steady-state design equations were developed incorporating basic filter parameters, i.e. depth, hydraulic load, media characteristics, oxygen concentration, mass transfer coefficient, reaction rate constant, equilibrium constant, and liquid density. This theory has been further extended by Roberts [9] who examined the factors influencing absorbtion and the effects of flow rate on tine liquid phase mass transfer coefficient.

Atkinson et al.[18], assuming that trickling filter operation could be modelled by film flow in contact with a vertical wall, attempted a mathematical analysis qualified by the following assumptions : (i) steady-state operation; (ii) rate limitation by biochemical reaction; (iii) first order irreversible kinetics; (iv) reaction occurs at the liquid-solid interfaces throughout the liquid film as though the liquid was flowing through a spongy mass (pseudo-homogeneous reaction model), and ( $v$ ) the slime does not influence the liquid film thickness.

By rejecting the pseudo-homogeneous reaction model in favour of one involving heterogeneous reaction at the slime-liquiä interface, Swilley anä Atikinson [19] derived theoretical models for situations in which firstly reaction, and secondly diffusion of substrate in the liquid film, were controlling. Oxygen transfer through the 
liquid to the bacterial slime was assumed to be nonlimiting in both cases.

Maier et al [20], using an inclined flat surface covered with biological slime as a physical model of trickling filter operation, developed a theoretical description assuming substrate mass transfer and biochemical reaction rate to be the principal factors affecting substrate removal. The resulting second-order partial differential equation was analytically solved for the case of mass transfer limitation which experiments indicated to be the rate determining step.

To determine whether substrate uptake by slime organisims is dependent on the external velocity field, and hence on diffusional mass transfer, Gulevich [21] examined the flux of substrate to slimes grown on rotating disks, these presenting the simplest conditions for mathematical analysis. Experimenting with glucose as substrate and laminar flow he concluded that, in the range studied, the rate of substrate uptake was of the same order as the theoretical diffusional mass transfer rate. This implied that the operation of the biological film was independent of reaction rate.

Grieves [46] formulated a dynamic mathematical model for the rotating biological disk reactor by considering the microbial film to be composed of two parts, a variable active depth and an inactive region. Substrate removal from the feed solution was modelled as mass transfer across the liquid-solid interface followed by utilization in the active region. A lonod saturation function was used to describe the microbial kinetics. Simpler pseudohomogeneous dynamic and steady state models were developed from the heterogeneous model, solved by numerical computing methods, and the results compared with data from an experimental reactor. Parameters in the model were adjusted until the theoretical and experimental results co-incided as closely as possible.

Kornegay and Andrews [22] developed a model for the kinetics of fixed biological films on the basis of the 
following assumptions: (i) complete mixing is achieved in the liquid phase; (ii) substrate utilization occurs in the biological phase only; and (iii) removal of substrate is described by a saturation function which incorporates the effects of both diffusion and growth rate. Results of experiments conducted in completely mixed annular reactors were used to determine the model parameters. Measurements of substrate removal rates during the transient period of film buildup indicated the existence of a constant "active depth", independent of the total film thickness, thereby lending some confirmation to Schulze's suggestion of aerobic and anaerobic zones. By assuming trickling filters to operate as plug-flow units, and that a series of completely mixed reactors adequately simulates plug-flow behaviour, the authors extended their theoretical analysis to apply to the trickling filter process [23]. The equation which results relates substrate removal to flow rate, depth, cross-sectional area, specific surface area of the media, and a lumped parameter made up of constants characteristic of the biological phase. A graphical technique for evaluating this parameter is outlined.

Atkinson et al. [24] have used a slime covered inclined perspex plate to examine the practical applicability of the pseudo-homogeneous and heterogeneous models previously proposed by Atkinson et al. [18] and Swilley and Atkinson [19]. Experiments were performed in a nitrogen atmosphere with potassium nitrate, used in double the stoichiometric requirement to ensure adequate availability, as an electron acceptor. From the results it was concluded that: (i) mathematical models derived on a heterogeneous basis are applicable to the biological film reactor, and (ii), liquid phase diffusion has considerable influence on the reactor performance.

By using an approach wherein microbial masses are described by a model analogous to a catalyst particle, Atkinson and Daoud [25] derived theoretical equations for the substrate flux at the interface jetween the microorganisms and adjacent solution. The equations were shown 
to be in general agreement with available experimental evidence and further indicated that, for slimes above a certain minimum thickness, the flux remained constant.

As an extension to previous work $[24,25]$, Atkinson et al.[26] developed a theory incorporating diffusion in both the liquid and "solid" phases which allows prediction of biological film reactor performance on the basis of physical and biological variables. The theory, it is clained, may be used for designing film reactors and is logically extendable to reactors employing flocculated micro-organisins. Data, collected by Atkinson and Daoud [27] working with an inclined plate on which a constant thickness of slime was maintained by means of a grid within which the growth developed, agreed well with the theoretical predictions.

Kehrberger [28] has analysed the effect of recirculation on removal of soluble organic carbon for three theoretical film flow models, the heterogeneous, the reactioncontrolled, and the pseudo-homogeneous. Experiments, both aerobic and anaerobic (nitrate electron acceptor), using an inclined acrylic plastic plate, indicated that the reactor behaved as a heterogeneous model. Conclusions drawn from the study were: (i) for heterogeneous film flow reactors recirculation has a detrimental effect on soluble organic carbon removal and (ii), for pseudohomogeneous reactors recirculation enhances organic carbon removal.

Monadjemi [29], in formulating his theoretical model, considered the trickling filter in terms of individual elements of filter media over which laninar flow occurs. The basic steps of substrate removal in each element were proposed to be molecular diffusion of substrate in the liquid, removal of substrate across the liquid-slime interface, and biochemical oxidation within the slime respectively. This final step was thought not to be rate limiting. Experimental results were applied to the mathematical model in order to determine the mass transfer coefficient. 
Frorn theoretical considerations Lamb and Owen [30] developed an equation relating the influent and effluent strength to and from a biological filter to the flow of sewage, volume of medium, specific surface area of the mediur, and temperature. Various published data from both stone and plastic media filters showed good agreement with the model.

Atkinson and Williams [31] have suggested that trickling filter efficiency is influenced by the hold-up of microbial mass in the filter. This was examined experimentally in laboratory-scale filters wherein the hold-up was controlled by periodic washing. A slightly modified version of the theory devised by Atkinson et al. [26] was used to describe the performance characteristics of the filter and it was concluded that performance was independent of oxygen transfer but influenced by diffusional limitations in both the biological and liquid films.

Assuming diffusion of oxygen through the liquid to the bacterial sites to be the overall rate-determining step, Hehta et al. [32] developed a mathematical model which relates the BOD removed to the hydraulic loading, filter depth, packing characteristics, and physical properties of the waste-water. Their theoretically predicted results compared well with results taken from operating plants. It was noted, however, that in some situations mass transfer of organic substrate may becorne rate limiting.

Quirk [33] formulated theoretical models for biooxidation in trickling filters using an inclined sheet flow reactor with a fixed biological film. He assumed plug-flow hydraulics and employed several assumptions for BOD removal kinetics including zero order, first order, Michaelis-Menton and retardant mechanisms. Data to substantiate the theory were obtained from laboratory experiments. Calculation techniques for scale-up are presented and verified by means of a comparison between computed and observed rate constants for full-scale plastic media towers operating on a variety of effluents. 
Pirt [34] regarded a packed column with attached microorganisms as a series of compartments in each of winth the flowing liquid medium remained an equal time. The biomass was assumed to have an "active layer" whose thickness was determined by the kinetics of diffusion of the limiting substrate which, for aerobic processes, was taken to be oxygen. Expressions were derived for the amounts of substrate consumed in both aerated and non-aerated columns and the theory was applied to calculate some trickling filter parameters. Ready verification of the theory was possible since it involved only measurable and meaningful microbial growth parameters.

Saunders and Bazin [35] have modified and extended Pirt's theory to include a consideration of two-species systems. Equations were derived to describe the fate of a substrate when the substrate itself is limiting microbial growth and when oxygen is limiting. The experimental data available indicated that microbial growth limitation by surface area availability was unlikely but yielded inconclusive results when applied to the "active layer" theory.

A mechanistic model of substrate removal in trickling filters having plastic media of the film flow type, operated at high organic and hydraulic loadings, has been proposed by Jank and Drynan [36]. Transfer of both substrate and oxygen in the liquid and slime layers was considered. The concepts of the model were incorporated into the filter performance equation derived by Kornegay and Andrews [23] and experimentation carried out on a vertically mounted, slime covered, perspex plate to evaluate the parameters of the combined relationship.

Vaughan et al. [37] studied mass transfer and reaction using an inclined plane as a simulation of the trickling filter process. Atternpts were made to relate the data obtained to various mathematical theories but with little success, this being attributed to the lack of consideration of liquid film hydrodynamics. It was found that by including the hydrodynamics better agreement between the data and theoretical predictions was obtained. 
By introducing the concept of an efiectiveness factor, Atkinson and Davies [38] devised a pseudo-analytical equation describing simultaneous diffusion and biochemical reaction of a single limiting substrate in microbial flocs and films. The equation expressed the overall rate of substrate uptake in terms of three kinetic coefficients whose values depended on the types of micro-organisms present, the particular substrate, and the physical environment (temperature, $\mathrm{pH}$, etc.). Experimental studies, undertaken by Atkinson and How [39] to examine the influence of nitrogen concentration and microbial film thickness on the rate of substrate uptaise using an inclined plate reactor, were found to partially suistantiate tire proposed pseudo-analytical equation.

Williamson and McCarty [40] have presented a mathematical model for substrate utilization within biofilms based on biological kinetic constants; the biofilm depti; the deptin of the stagment liquid layer adjacent to the biofilm; the substrate diffusion coefficients in the biofilm and water; the biofilm density, and the bulk liquid substrate concentration. Implicit in the model is the assumption that the concentration of substrate, considered to be either the electron-donor or electronacceptor species, linits the metabolic rate throughout the biofilm. Concepts of "flux-limitation" and "substrate liritation" are introduced together with theoretical relationsinips developed to determine which of the species is rate limiting, electron-donor or electron-acceptor. It was realised that a change of limiting species could occur between the iniler and outer portions of the biofilm but, having constrained the work to treatment of one limiting substrate only, this possibility was not mathematically explored. BY concentrating dispersed nitrifying organisms onto memorane filters the authors were able to produce test biofilms of desired depths having measurable kinetic coeficients [41]. Experiments conducted on these films showed that the biofilm model gave accurate predictions of substrate utilization rates for deso films which are eitner electron-donor or electron-acceptor Iimited. 


\subsection{Summary}

Tine literature survey revealed that a substantial amount of theoretical work, much of it backed by experimental investigations, has been done on aspects of substrate removal and kinetics in biological films. In all the analyses reviewed either one or more of the following processes were assumed to limit the overall rate of substrate removal : liquid phase mass transfer, diffusion in the biological film, and biological reaction rate. These processes, however, were applied to one reactant only, the so-called "limiting substrate", which was taiken to be either organic carbon or the electron-acceptor. Identification of this "Iimiting substrate" was either by qualified assumption or, as done by Williamson and McCarty [40], by means of a simple calculation procedure. The apparent lack of published literature dealing with modelling of substrate uptake in biological films simultaneously limited by both organic carbon and the oxidizing agent motivated the work described herein. 


\subsection{FORMULATION OF THE MATHEIATICAL MODEL}

\subsubsection{Introduction}

Although the actual processes occurring in a microbial slime are extremely complicated and at present not well understood, a mechanism can be postulated, with the aid of certain simplifying assumptions, which is readily susceptible to mathematical description and analysis. By employing fundamental chemical engineering principles of interfacial mass transfer, diffusion, and reaction, the mathematical model presented here constitutes an attempt to achieve this with the ultinate purpose of predicting the amount of substrate removed by the slime when it is subjected to various hydraulic and organic loadings.

\subsubsection{Assumptions}

(i) The microbial film is made up of two regions, an aerobic zone whose thickness is determined by the depth to which oxygen can penetrate in concentrations high enough so as not to inhibit aerobic metabolism, and an anaerobic zone stretching from the limit of the aerobic zone to the support surface. (see fig. 2.1). This two-zone concept, first observed and documented by schulze [21] in 1957, has since become almost universally accepted in the field of aeroijc microbial slime research $[20,22,42,43,44$, $45]$.

(ii) A survey of the relevant literature conducted by Grieves [46] revealed values for the maximum specific growth rates of aerobic micro-organisms, growing on glucose, ranging from $0,2 \mathrm{hr}^{-1}$ to $0,54 \mathrm{hr}^{-1}$. Richter [47], on the other hand, found values for anaerobic growth varying from $0,0028 \mathrm{hr}^{-1}$ to $0,0078 \mathrm{hr}^{-1}$. Since the difference between these maximum specific growth rates is in the region. of two orders of magnitude it was assumed that the 
amount of substrate utilized in the anaerobic zone is negligible.

(iii) The liquid film flowing down the reactor is assumed to be laminar with negligible edge effects.

(iv) No longitudinal diffusion of either substrate or oxygen occurs in the biological phase.

(v) The influent liquid feeding onto the slime is taken to be free of microbial activity and substrate utilization is assumed to occur in the biological phase only.

(vi) Growth limiting substrates are assumed to be organic carbon, in the form of glucose, and oxygen, all other essential nutrients being available in excess throughout the slime.

(vii) The rate of aerobic biological reaction is assumed to be a saturation function of the growth limiting substrates, rising to a finite constant value when these substrates are available in excess. A modified form of the expression proposed by Monod [48] for biological growth kinetics is used which incorporates the possibility of reaction retardation caused by a lack of either or both of two reactants, $R_{1}$ and $R_{2}$.

$$
\begin{aligned}
& \text { Monod: } \mu=\hat{\mu}\left(\frac{R_{1}}{K_{1}+R_{1}}\right), \\
& \text { Modified expression : } \mu=\hat{\mu}\left(\frac{R_{1}}{K_{1}+R_{1}}\right)\left(\frac{R_{2}}{K_{2}+R_{2}}\right)
\end{aligned}
$$

Experiments on microbial growth kinetics at low oxygen concentrations reported by Johnson [49] and Longmuir [50] showed that the rate remained unaffected until the dissolved oxygen level dropped below about $2 \mathrm{mg} / \mathrm{l}$, thereafter declining to zero in a fashion described by the Monod function. Nueller et al. [54], experimenting on oxygen utilization by flocculated micro-organisms, have confirmed this. It has therefore been assumed, as done by Ryder and Sinclair [65], that the above modified expression, used 
satisfactorily by Miegee [51] for dual substrate system modelling, can equally well be used for systems in which one of the two limiting substrates is oxygen.

(viii) The rate of consumption of oxygen by organisms in the slime is directly proportional to the rate of substrate utilization. When considering aerobic metabolism this type of behaviour is predicted and has indeed been observed by several researchers $[7,16,29,34,43,49$, 52 ].

(ix) Oxygen transport from the air to the falling liquid film is sufficiently fast to ensure that the bulk of the liquid remains saturated with oxygen at all times. The calculations and reasoning employed in substantiating this assumption are presented in Appendix A.

(x) The diffusivities of substrate and oxygen in the slime do not vary with position or time.

(xi) The organism density in the slime, the maximum specific growth rate and the cell yield are independent of depth.

(xii) The bulk substrate concentration in the liquid film over an element of reactor length is equal to the average of the bulk inlet and outlet concentrations to and from that element.

(xiii) Substrate and oxygen mass transfer coefficients are constant over the complete length of the reactor.

(xiv) Film sloughing and endogenous respiration are not considered.

\subsubsection{Derivation of Equations}

The equations derived below pertain to a small control element of reactor length, as illustrated in fig. 2.1, and 


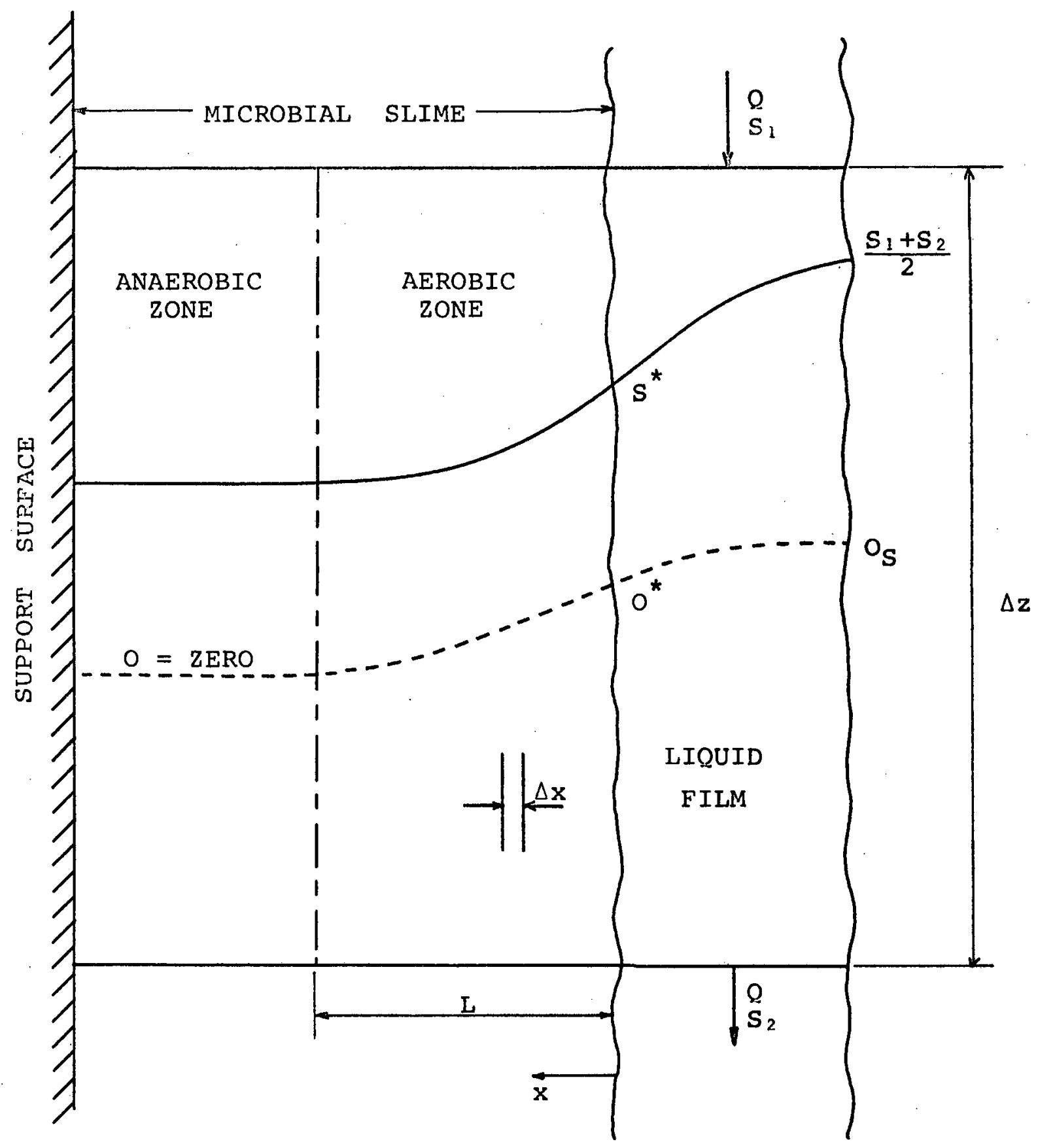

FIGURE 2.1. Schematic Diagram Showing an Element of Microbial slime with substrate and oxygen Profiles. 
apply to steady state conditions only. In order to avoid the introduction of an additional dimension into the equations, the width of the element was taken to be unity.

A material balance on the substrate in the falling liquid film may be written as follows:$\left[\begin{array}{c}\text { substrate } \\ \text { inflow }\end{array}\right]=\left[\begin{array}{c}\text { substrate } \\ \text { outflow }\end{array}\right]+\left[\begin{array}{c}\text { substrate transferred from } \\ \text { the bulk of the liquid to } \\ \text { the slime-liquid interface }\end{array}\right]$

i.e. $\quad Q S_{1}=Q S_{2}+k_{L S} \Delta z\left(\frac{S_{1}}{2}+\frac{S_{2}}{2}-S^{*}\right)$.

By the law of mass conservation the quantity of substrate moving to the interface must, at steady state, equal the quantity diffusing into the biological slime. Assuming Fick's diffusion law to be applicable this may be expressed mathematically as

$$
\mathrm{k}_{\mathrm{LS}} \Delta \mathrm{z}\left(\frac{\mathrm{S}_{1}}{2}+\frac{\mathrm{S}_{2}}{2}-\mathrm{S}^{*}\right)=-\left.\mathrm{D}_{\mathrm{S}} \Delta \mathrm{z} \frac{\mathrm{dS}}{\mathrm{dx}}\right|_{\mathrm{x}=0} .
$$

Similarly the transfer of oxygen from the bulk of the liquid, which is assumed to be saturated, into the slime may be described by

$$
\mathrm{k}_{\mathrm{LO}} \Delta \mathrm{z}\left(\mathrm{O}_{\mathrm{S}}-\mathrm{O}^{*}\right)=-\left.\mathrm{D}_{\mathrm{O}} \Delta \mathrm{z} \frac{\mathrm{dO}}{\mathrm{dx}}\right|_{\mathrm{x}=0} .
$$

Equations describing the substrate and oxygen profiles within the biofilm are derived by taking mass balances over an elemental slice of thickness $\Delta x$ as shown in fig. 2.1 .

$$
\left[\begin{array}{l}
\text { influx by } \\
\text { diffusion }
\end{array}\right]=\left[\begin{array}{l}
\text { efflux by } \\
\text { diffusion }
\end{array}\right]+\left[\begin{array}{ll}
\text { consumption } \\
\text { by } & \text { reaction }
\end{array}\right]
$$

For substrate this becomes

$$
\left.D_{S} \Delta z \frac{d S}{d x}\right|_{x}=\left.D_{S} \Delta z \frac{d S}{d x}\right|_{x+\Delta x}+\frac{\hat{\mu} x \Delta z \Delta x}{Y}\left(\frac{S}{K_{S}+S}\right)\left(\frac{0}{K_{O}+0}\right)
$$

which, when $\Delta x$ becomes infinitely small, reduced to 


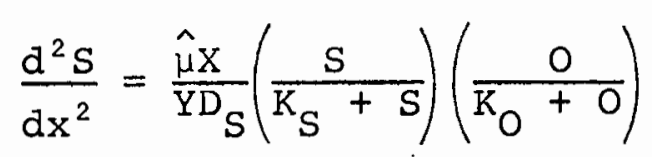

By using the assumed linear relationship between substrate and oxygen utilization rates, the differential equation for oxygen may be derived in a similar manner.

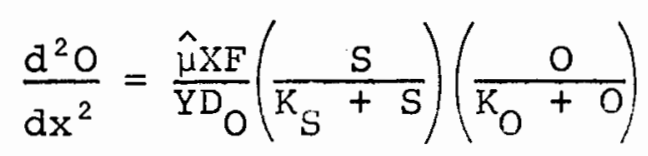

Equations (2.1) through (2.5) together constitute the proposed mathematical model and are summarised below.

$$
\begin{aligned}
& 2.1 .4 \text { Summary of model equations } \\
& \mathrm{QS}_{1}=\mathrm{QS}_{2}+\mathrm{k}_{\mathrm{LS}} \Delta \mathrm{z}\left(\frac{\mathrm{S}_{1}}{2}+\frac{\mathrm{S}_{2}}{2}-\mathrm{S}^{*}\right) \\
& \mathrm{k}_{\mathrm{LS}} \Delta \mathrm{z}\left(\frac{\mathrm{S}_{1}}{2}+\frac{\mathrm{S}_{2}}{2}-\mathrm{S}^{*}\right)=-\left.\mathrm{D}_{S \Delta z} \frac{\mathrm{dS}}{\mathrm{dx}}\right|_{\mathrm{x}=0} \\
& \mathrm{k}_{L O^{\Delta}}\left(\mathrm{O}_{\mathrm{S}}-\mathrm{O}^{*}\right)=-\left.\mathrm{D}_{\mathrm{O}} \Delta \mathrm{z} \frac{\mathrm{dO}}{\mathrm{dx}}\right|_{\mathrm{x}=0} \\
& \frac{\mathrm{d}^{2} \mathrm{~s}}{\mathrm{dx^{2 }}}=\frac{\hat{\mu} \mathrm{X}}{\mathrm{YD} \mathrm{S}}\left(\frac{\mathrm{s}}{\mathrm{K}_{\mathrm{S}}+\mathrm{s}}\right)\left(\frac{\mathrm{O}}{\mathrm{K}_{\mathrm{O}}+0}\right) \\
& \frac{\mathrm{d}^{2} \mathrm{O}}{\mathrm{dx^{2 }}}=\frac{\hat{\mu} X F}{\mathrm{YD}_{\mathrm{O}}}\left(\frac{\mathrm{s}}{\mathrm{K}_{\mathrm{S}}+\mathrm{s}}\right)\left(\frac{\mathrm{O}}{\mathrm{K}_{\mathrm{O}}+\mathrm{O}}\right)
\end{aligned}
$$

The boundary conditions for equations (2.4) and (2.5) are:-

$$
\begin{aligned}
\text { (i) At } x=0, & S=S^{*} \\
\text { (ii) At } x=0, & 0=0 * \\
\text { (iii) At } x=I, & \frac{d S}{d x}=0 \text { and } \frac{d O}{d x}=0 \\
\text { (iv) At } x=I, & S \text { and/or o equal zero. }
\end{aligned}
$$

The third and fourth boundary conditions mean that at the limit of the active depth, when $x=L$, all metabolism has ceased as a result of there being a lack of sufficient substrate and/or oxygen present. 


\subsection{TECHNIQUE OF SOLUTION}

\section{2 .1 Introduction}

The principal objective of the model was to calculate $S_{2}$, the substrate concentration in the liquid leaving the control element, knowing the value of $\mathrm{S}_{1}$. An explicit solution, however, was impossible owing to the unavailability of analytical solutions to the two differential equations, and therefore a trial-and-error numerical technique had to be employed. Several numerical methods were investigated and, by virtue of its ready applicability to non-linear simultaneous ordinary differential equations of high order, that of Range-Kutta [53] was chosen as being the most suitable for the purpose. The execution of the method, however, required four initial conditions (conditions at $\mathrm{x}=0$ ) to be specified, thereby causing boundary conditions (iii) and (iv) above, which are final, to be replaced by the initial gradients of the substrate and oxygen profiles. The displaced final conditions then became criteria for terminating the trial-and-error process which is described below.

\subsubsection{Trial-and-error procedure}

The following stepwise trial-and-error procedure was used for solving the above set of model equations:-

(i) A value of $s_{2}$ was chosen such that $s_{1}-s_{2}$ equalled $0,5 \mathrm{mg} / \mathrm{l}$ (an arbitrarily chosen small value).

(ii) From the model equations the four initial conditions $S^{*}, O^{*},\left.\frac{d S}{d x}\right|_{x=0}$ and $\left.\frac{d O}{d x}\right|_{x=0}$ were calculated.

(iii) Using these initial conditions the equations (2.4) and (2.5) were simultaneously solved by the RangeKutta numerical method. This method calculated the oxygen ana substrate profiles by means of a succession of incremental steps commencing at the slime-liquid interface and progressing into the slime. Termination of the profile calculations occurred when their gradients had fallen to zero, i.e. satisfying boundary condition (iii) 
above.

(iv) The concentration levels of substrate and oxygen at the ends of the profiles were then examined. If either or both were zero, then the initially chosen value for $\mathrm{S}_{2}$ was the correct solution, while if they were both greater than zero a new value of $\mathrm{S}_{2}$, smaller than the previous one, was chosen and the whole procedure repeated. (use of boundary condition (iv).)

For sufficiently small values of the difference $s_{1}-s_{2}$, both the substrate and oxygen profiles were found to level off at positive concentrations, the values of which decreased as $s_{1}-s_{2}$ increased. Therefore, by initiating the trial-and-error process with $\mathrm{S}_{2}$ only slightly less than $s_{1}$ and thereafter decreasing it by small steps, it was possible to ensure that the solution was found before either of the profiles went negative.

In order to carry out step (ii) in the above procedure it was first necessary to derive explicit equations for $S^{*}, O^{*},\left.\frac{d S}{d x}\right|_{x=0}$ and $\left.\frac{d O}{d x}\right|_{x=0}$ in terms of $S_{1}$ and $S_{2}$. The manipulations required for achieving this are shown below:-

Rearranging equation (2.1) gives

$$
S^{*}=\frac{S_{1}}{2}+\frac{S_{2}}{2}-\frac{Q}{k_{L S} \Delta z}\left(S_{1}-S_{2}\right)
$$

while equation (2.2), on substitution into (2.1) yields

$$
\left.\frac{\mathrm{dS}}{\mathrm{dx}}\right|_{x=0}=-\frac{Q}{D_{S} \Delta z}\left(S_{1}-S_{2}\right)
$$

The flux of substrate entering the bioslime is given by $-\left.D_{S} \Delta z \frac{d S}{d x}\right|_{x=0}$ while that of oxygen is $-\left.D_{O} \Delta z \frac{d O}{d x}\right|_{x=0}$

Since at steady state there is no accumulation, these fluxes are equal to the respective utilization rates of substrate and oxygen within the bioslime which, as previously mentioned, are related by the stoichiometric factor $\mathrm{F}$ i.e., 


$$
\begin{aligned}
& \left.D_{O} \Delta z \frac{d O}{d x}\right|_{x=0}=\left.F D_{S} \Delta z \frac{d S}{d x}\right|_{x=0} \\
& \text { or }\left.\quad \frac{d O}{d x}\right|_{x=0}=\frac{F D_{S}}{D_{O}}\left[\left.\frac{d S}{d x}\right|_{x=0}\right]
\end{aligned}
$$

Finally the equation for $O *$ is obtained by substituting for $\left.\frac{\mathrm{dO}}{\mathrm{dx}}\right|_{\mathrm{x}=0}$ into equation $(2.3)$ and rearranging to give

$$
O^{*}=O_{S}-\frac{Q F}{k_{L O} \Delta z}\left(S_{1}-S_{2}\right) \text {. }
$$

Using the above technique solutions to the model equations were obtained with the aid of a UNIVAC 1106 digital computer. A listing of the fortran program developed for this purpose, together with a sample output, is given in appendix $B$ while the block diagram in fig. 2,2 conveniently summarises the logic and sequence of the solution procedure.

\subsection{SELECTION OF PARAMETER VALUES}

$D_{S}$ - The diffusivity of glucose in bacterial films has not, as far as the author can ascertain, been measured. Considering the porous nature of the slime, however, it was deemed reasonable to follow the examples set by Grieves [46] and Pirt [34] who have taken the diffusivity of glucose in water, $0,69 \times 10^{-5} \mathrm{~cm}^{2} / \mathrm{sec}[56]$, as an estimate of the value in the slime. This has been confirmed by Atkinson and Davies [38] who, using data collected by Atkinson and Daoud [25], calculated the diffusivity in the slime to be $110 \%$ of that in water.

$$
\mathrm{D}_{\mathrm{O}} \text { - Oxygen diffusivities in biological aggregates }
$$
have been measured and reported by several researchers. These are summarised in table 2.1 . 


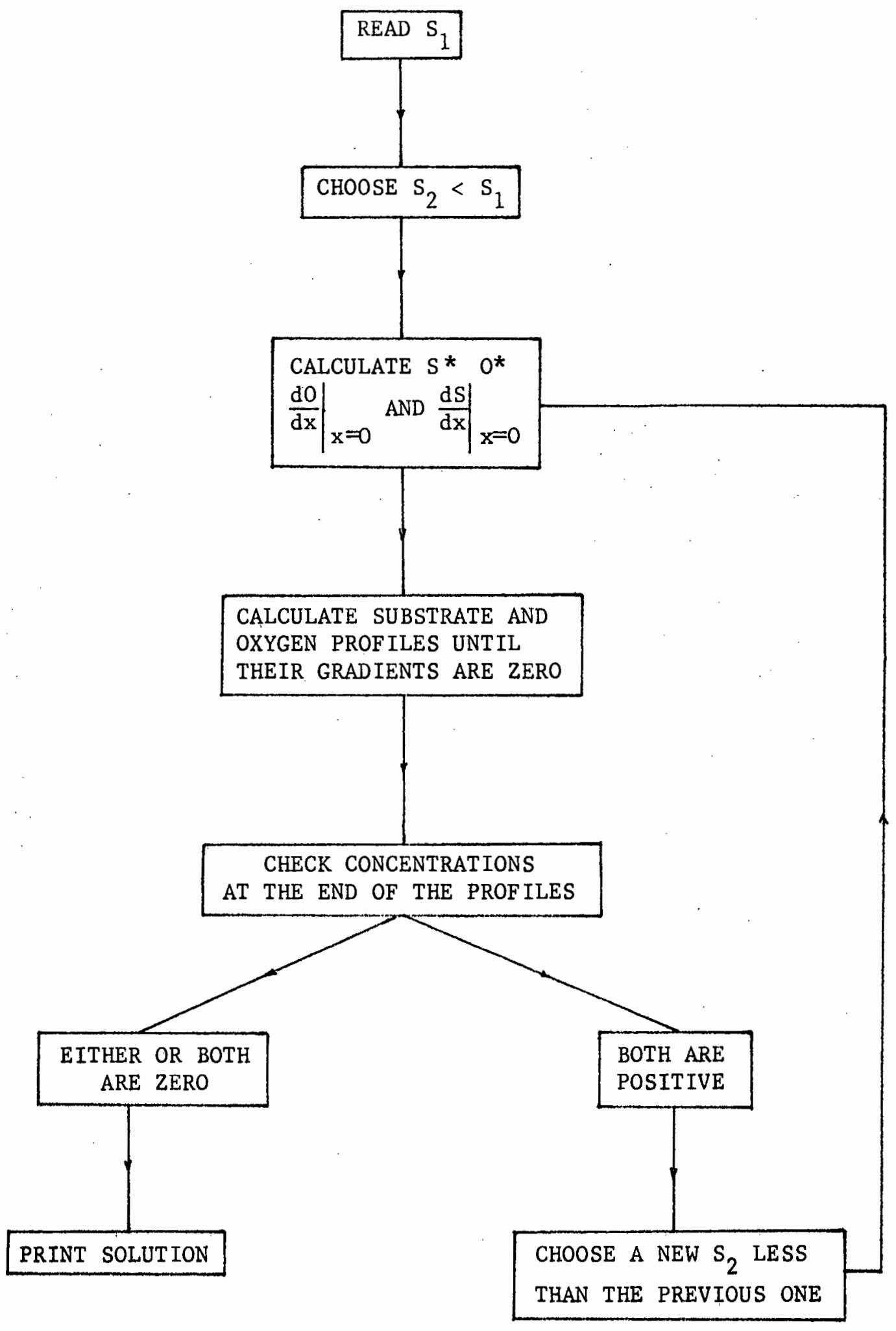

FIGURE 2.2 - BLOCK DIAGRAM SHOWING PROCEDURE FOR SOLUTION OF THE MODEL EQUATIONS 
TABLE 2.1 - OXYGEN DIFFUSIVITIES

\begin{tabular}{|l|cr|c|}
\hline \multicolumn{1}{|c|}{ Type of Aggregate } & Diffusivity $\times 10^{5}$ & Reference \\
\hline Film grown with sewage & 1,5 & $\mathrm{~cm}^{2} / \mathrm{sec}$ & 44 \\
Film grown with glucose & 22,0 & $\mathrm{~cm}^{2} / \mathrm{sec}$ & 44 \\
Not specified & 0,04 & $\mathrm{~cm}^{2} / \mathrm{sec}$ & 60 \\
Concentrated nitrifying & 2,5 & $\mathrm{~cm}^{2} / \mathrm{sec}$ & 41 \\
bacteria & & & 54 \\
Flocs grown with glucose & 0,07 to $0,44 \mathrm{~cm}^{2} / \mathrm{sec}$ & 5 \\
\hline
\end{tabular}

From the wide variation in these results it is clear that a reliable estimate of the oxygen diffusivity is not available. It was decided, therefore, to use the diffusivity of oxygen in pure water, $2,5 \times 10^{-5} \mathrm{~cm}^{2} / \mathrm{sec}[56]$, as the model parameter, firstly because it lies within the experimentally measured range, and secondly it provides a standardised basis from which to work.

$\hat{\mu}$ - As mentioned in section 2.1 .2 , values of the maximum specific growth rate varying from $0,2 \mathrm{hr}^{-1}$ to $0,54 \mathrm{hr}^{-1}$ have been quoted by Grieves [46]. For use in the model a value of $0,45 \mathrm{hr}^{-1}$ was chosen.

$x$ - Measurement of the density of the active film is difficult because of its minute thickness ( $<200 \mu)$. Kornegay and Andrews [22], however, have reported a value of $95 \mathrm{mg} / \mathrm{l}$ while Hoehn [45] showed that $X$ varied from 20 to $105 \mathrm{mg} / \mathrm{l}$. A value of $90 \mathrm{mg} / \mathrm{l}$ was taken for the model.

Y. - For organism-substrate systems the yield is usually assumed to be constant, falling in the range 0,26 to $0,64[46]$. Experimental determinations of the organism yield on the film reactor, described in section 4.1 , gave values ranging from 0,4 to 0,26 . 0,3 was therefore chosen as being representative of the slime yield.

$K_{S}$ - The Monod half-velocity coefficient was chosen 
to be $50 \mathrm{mg} / \mathrm{l}$, this $1 y$ ing within the range of values given by Grieves [46] of $4 \mathrm{mg} / \mathrm{l}$ to $150 \mathrm{mg} / \mathrm{l}$.

$\mathrm{K}_{0}$ - It is generally accepted that the aerobic growth of bacteria becomes oxygen limited when the concentration level drops below $2 \mathrm{mg} / \mathrm{l}[49,50,65]$. A value for $\mathrm{k}_{\mathrm{O}}$ of $0,025 \mathrm{mg} / l$ was found to satisfy this condition and was therefore used in the model.

F - As pointed out in section 2.1.2 several researchers have observed a linear relationship between the rates of substrate and oxygen utilization with values of the proportionality constant, F, varying from 0,6 to 0,3 $\mathrm{mg}$ oxygen/mg of substrate $[49,52]$. In the solution of the model equations $F$ was given the value 0,32 .

$O_{S}$ - Although the oxygen concentration in saturated water at atmospheric pressure is $8,96 \mathrm{mg} / \mathrm{l}$, it is shown in appendix $A$ that under conditions of oxygen mass flux through a falling water film this value drops to $7,9 \mathrm{mg} / \mathrm{l}$. In the model, therefore, a value of $8 \mathrm{mg} / l$ was used.

$k_{\text {LO }}$ - No data are available on the values of oxygen mass transfer coefficients between a falling liquid film and a microbial slime. In order to obtain an estimate of this coefficient, therefore, it was assumed that the liquid coefficient for absorbtion of oxygen by a falling liquid film, as evaluated in appendix $A$, applied to the case of oxygen transfer from the liquid to the slime. 0,04 was therefore used in the model solutions. From data' reported by Bungay et al. [42] on oxygen gradients and profiles in microbial slimes bathed with flowing glucose medium it was possible to calculate oxygen mass transfer coefficients using the equation

$$
k_{L O}\left(O_{S}-O^{*}\right)=-\left.D_{O} \frac{d O}{d x}\right|_{x=0}
$$

Values ranged from 0,01 to $0,006 \mathrm{~cm} / \mathrm{sec}$ indicating that the chosen figure of $0,04 \mathrm{~cm} / \mathrm{sec}$, although possibly 
rather high, was of the correct order of magnitude.

$k_{\text {LS }}$ - If the falling liquid film is assumed to be completely laminar, mass transfer of substrate (glucose) from the bulk of the film to the slime-liquid interface will be by molecular diffusion only and the flux will be equal to $D_{S} \frac{C_{B}-C^{*}}{\delta}$. The mass transfer coefficient, therefore, is given by ${ }^{\mathrm{S}} / \delta$ where $\delta$, the liquid film thickness, may be calculated for each liquid flow rate using hydrodynamic theory [66]. Values of the mass transfer coefficient, $\mathrm{k}_{\text {IS }}$, calculated in this way for 6 and $24 \mathrm{l} / \mathrm{hr}$, are 0,0005 and $0,0003 \mathrm{~cm} / \mathrm{sec}$ respectively. For solution of the model the value of $\mathrm{k}_{\mathrm{LS}}$ was taken as $0,0004 \mathrm{~cm} / \mathrm{sec}$.

\subsection{THE EFFECT OF TEMPERATURE}

Temperature is of fundamental importance to the growth of micro-organisms since the metabolic rate is, to a large extent, dependent on it [67]. The range within which microbial activity occurs is limited by upper and lower temperatures above and below which growth becomes seriousIy impaired and, if the condition is extreme enough and maintained for a sufficient period, all activity terminates. The temperature ranges vary from one type of organism to another but in general fall between $0^{\circ} \mathrm{C}$ and $50^{\circ} \mathrm{C}$. It has been observed, and is generally acknowledged $[43,67,68,69,70,71,72]$, that within the above range the rate of growth doubles for every $10^{\circ}$ rise in temperature. In the solution of the model, therefore, the value chosen for $\hat{\mu}$ of $0,45 \mathrm{hr}^{-1}$ was assumed to be for $20^{\circ} \mathrm{C}$ and for solutions at different temperatures it was suitably adjusted either up or down as required.

It was recognised that for microbial slimes temperature has a more far-reaching effect than merely changing the growth rate since both diffusivities and mass transfer coefficients can be expected to be influenced. However, because of the lack of theoretical understanding as to the nature of these effects, as well as to avoid excessive 
and complicated additions to the model, temperature effects were restricted to the growth rate only.

\subsection{SUMMARY}

In this chapter the derivation of the model equations is described together with the assumptions associated with them and the technique employed for their solution. A detailed account is given of the basis on which each parameter in the model was chosen and the effect of temperature is discussed. In the following chapters theoretical results obtained by solution of the model equations are given. 


\subsection{EXPERIMENTAL APPARATUS}

\subsubsection{Apparatus used by other Researchers}

A survey of work published by various researchers involved in the study of biological film characteristics has revealed the use of several different types of experimental apparatus. Most common among these is the inclined plate, differing versions of which have been used by Atkinson [24, 27, 39], Kehrberger [28], Quirk [33], Vaughan et al. [37], and Maier et al.[20]. Sanders et al. [60] chose a continuous flow culture chamber in which to study their films while Kornegay and Andrews [22] used completely mixed annular reactors. Tomlinson and Snaddon [44] studied films grown in an inclined rotating-tube reactor while Jank and Drynan [36] opted for a vertically mounted plate on which to grow theirs. Williamson and McCarty [41], using a somewhat different experimental approach, produced test films by concentrating dispersed nitrifying bacteria on membrane filters.

\subsubsection{Description of Experimental Apparatus}

\section{1 .2 .1 Introduction}

When considering the type of experimental apparatus to be constructed it is essential to have the ultimate objectives towards which the research is directed constantly in mind so that, as far as possible, the most suitable design for the achievement of these ends can be employed. For this project, therefore, it was clearly of importance to design equipment which, together with retaining the high degree of definition and control characteristic of laboratoryscale work, produced conditions sufficiently similar to those in full-scale plastic media filters to allow some practical significance to be attached to the results. A vertically mounted growth support, after the fashion of that used by 
Jank and Drynan, was considered to fulfil adequately the criteria mentioned above for it ensured that:-

(i) The area of the active slime would be well defined.

(ii) Flow characteristics would be similar to those encountered in trickling filters packed with modular-type plastic media, and

(iii) Access to the biological slime for sampling and other purposes would present no difficulty.

\subsubsection{The Plate}

The vertical support surface for organism growth consisted of a flat perspex sheet measuring $180 \times 27 \times 0,6 \mathrm{~cm}$ on which two $2 \mathrm{~cm}$ wide strips were glued, one along the length of each edge, to serve as retainers for both the biological growth and the falling liquid film (see figure 3.1). The size of the area available for slime growth was, therefore, $180 \times 25 \mathrm{~cm}$. Criteria used for determining these dimensions were: (i) sufficient length to ensure an appreciable drop in substrate concentration, thereby diminishing relative errors incurred during the analysis; and (ii) sufficient width to reduce hydrodynamic edge effects originating at the plate boundaries to a minimum. It was felt that a plate of the above dimensions would satisfy both criteria. This was confirmed by experimental evidence for the case of length but no tests on the hydrodynamic effects were performed. However, considering the thickness of the liquid films dealt with $(0.1$ to $0.2 \mathrm{~mm})$ it seemed extremely unlikely that edge effects would be significant over a total width of $25 \mathrm{~cm}$.

In order to facilitate the attachment of micro-organisms to the plate the growth surface was roughened slightly by means of sandblasting.

It was of importance to avoid liquid channelling on the plate by ensuring that the distribution of the overflow was as uniform as possible. For this reason the upper edge was carefully machined into a toothed knife-edge as detailed in figure 3.2 .

Attachment of the plate to the overflow weir was by means of several bolts permanently fastened to the back of 


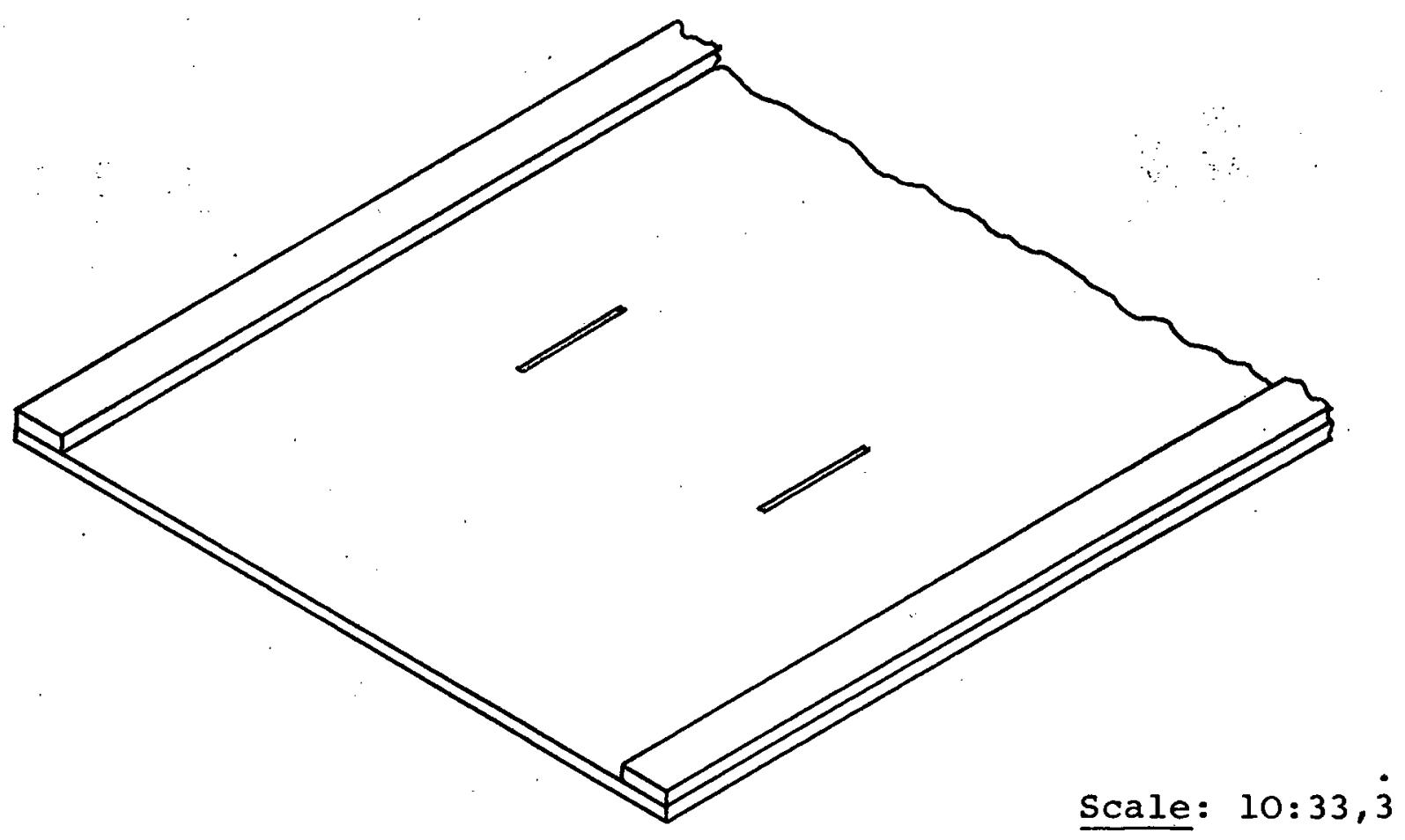

FIGURE 3.1. Bottom Section of the Plate showing Retaining Strips and Thermocouple Grooves.
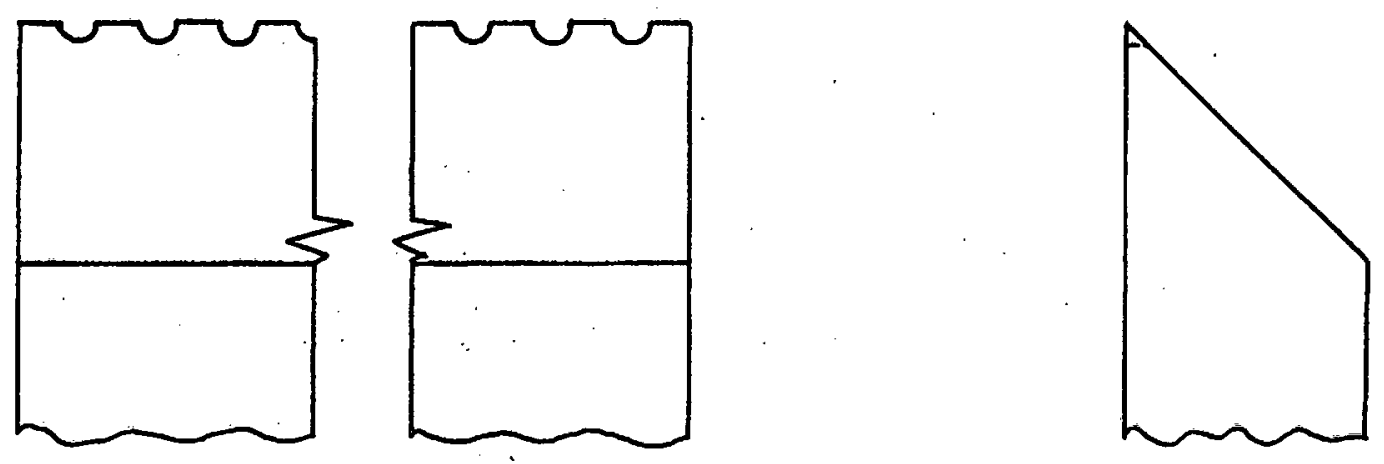

Scale: $4: 1$

FIGURE 3.2. Enlarged Side and End Elevations of the Overflow knife-edge. 


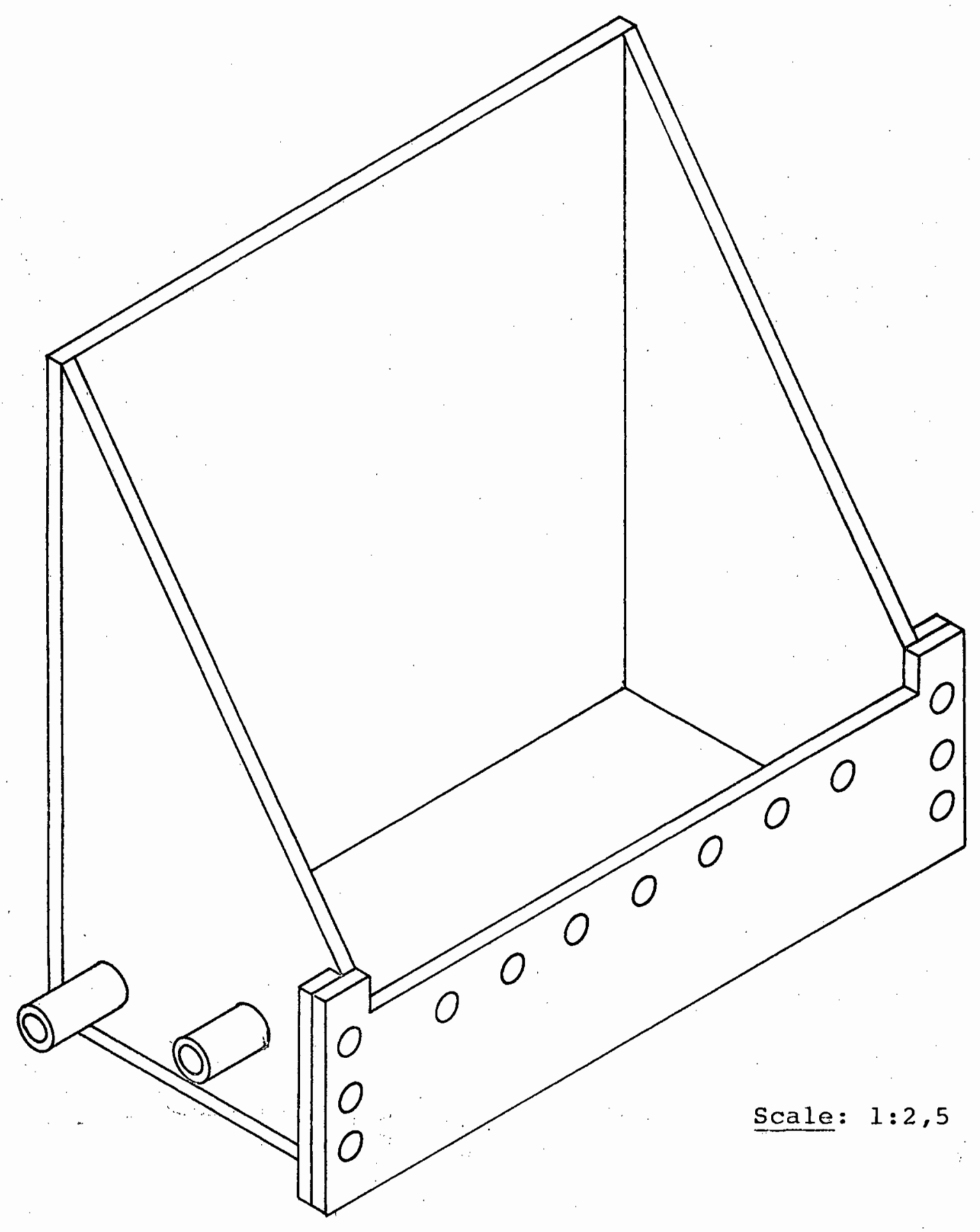

FIGURE 3.3. The Overflow Weir. 
this purpose a variable speed peristaltic pump fitted with flow-rated tygon tubes was used. Mixing of the concentrated solutions with the dilution water, achieved by a combination of turbulence in the inlet manifold and diffusion within the weir, was found to be satisfactory, resulting in the overflow of a homogeneous feed solution. A constant head tank, filled with water from the Cape Town municipal supply network, served as the source of dilution water for the apparatus. From this tank the water flowed through a control valve followed by a rotameter, and thereafter, having been mixed with the concentrated glucose and nutrient solutions, into the overflow weir. For experiments conducted at high glucose concentrations (10 $000 \mathrm{mg} / \mathrm{l}$ COD) the delivery of the peristaltic pump was found to be insufficient and a Huges micro-metering pump was used in its place. A flow diagram of the feed system is shown in figure 3.5 .

\subsection{OPERATING TECHNIQUE}

\subsubsection{Startup}

The attachment and growth of micro-organisms was initiated by mounting the plate on a laboratory work-bench at an angle of about $2^{\circ}$ from horizontal and recirculating a strong glucose solution over it. A small quantity $(500 \mathrm{ml})$ of settled sewage was added to the solution to act as a seed. Within two days growth was visible on the plate although it was somewhat patchy. After two more days the recirculation was stopped and the plate assembly bolted firmly onto its "Dexion" frame, carefully ensuring that it was exactly vertical.

\subsubsection{Choice of variable ranges}

Controlled variables in the experimental system were concentration of the synthetic waste, measured as Chemical Oxygen Demand (COD), and hydraulic loading. Typical. commercial plastic-media units run at hydraulic loadings ranging from 2.2 to $4.1 \mathrm{~m}^{3} / \mathrm{m}^{2}-\mathrm{hr}$ [62] which, when suitably scaled down to the dimensions of the experimental. plate, correspond to loadings of about 0.067 and $0.13 \mathrm{~cm}^{3} / \mathrm{cm}-\mathrm{sec}$ 


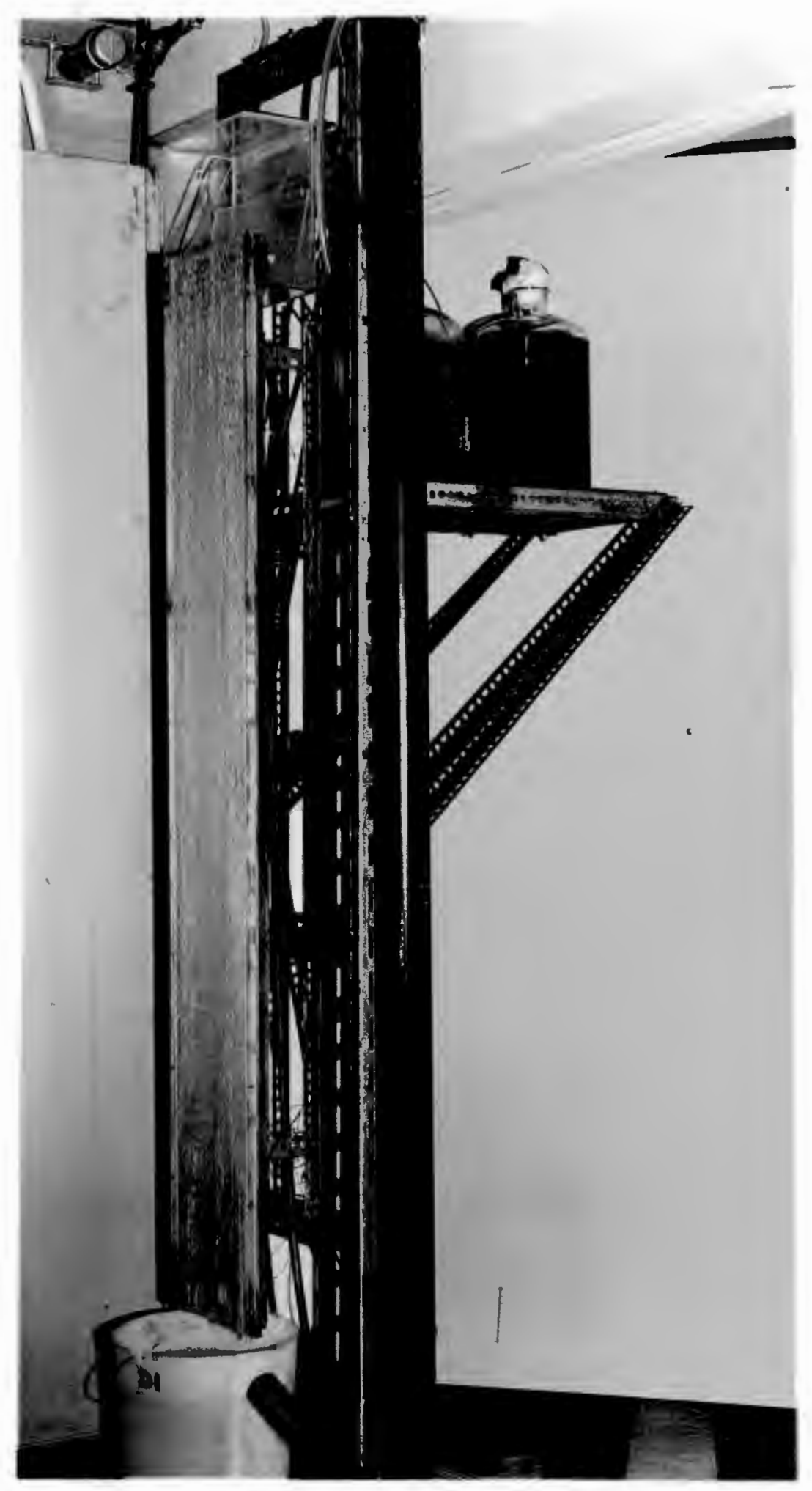

FIGURE 3,4 The Microbial Film Reactor Assembly 


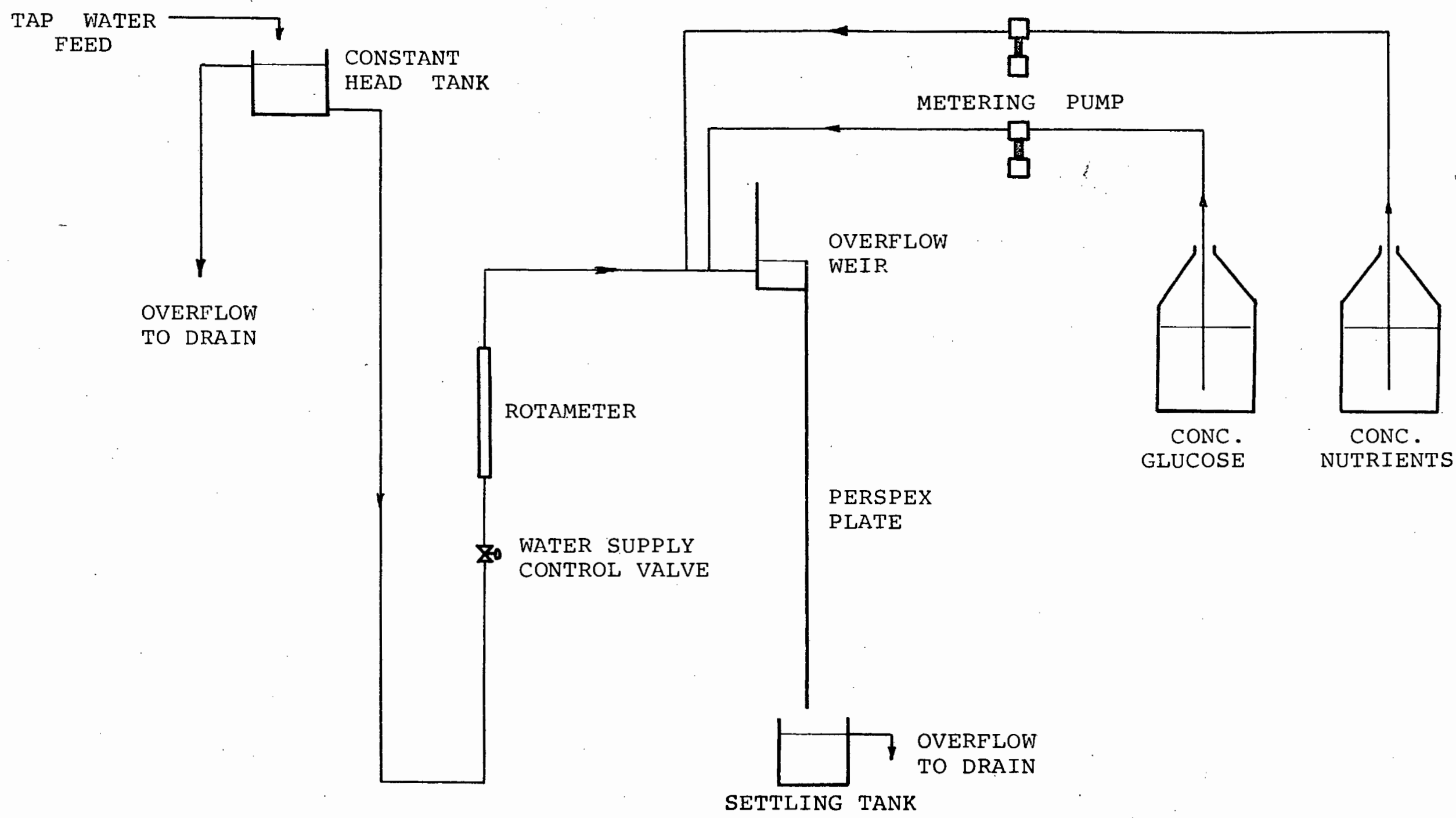

FIGURE 3.5. Flow Diagram of the Feed System. 
or 6 and $12 \mathrm{l} / \mathrm{hr}$. During the experimental program, therefore, flow rates of $6,12,18$ and $24 \mathrm{l} / \mathrm{hr}$ were used in the hope these would give similar hydraulic conditions to those encountered in full-scale filters. As far as concentration levels were concerned industrial units have been known to operate at anything from $100 \mathrm{mg} / \mathrm{l}$ to $2600 \mathrm{mg} / \mathrm{l}$ Biological Oxygen Demand (BOD) [63]. Since the BOD of glucose is typically about 608 of the COD [64], the experimental range covered was from 200 to $10000 \mathrm{mg} / \mathrm{l} \mathrm{COD}$.

Unfortunately the experimental work was not carried out in a temperature controlled environment but it was shown, by means of thermocouple measurements, that the temperature of the falling liquid did not change significantly over the length of the plate (see appendix D). The liquid temperature could therefore be taken as the temperature at which each experiment was performed.

\subsubsection{Reactor Operation}

To obtain the desired flow rates and COD levels adjustments were made firstly to the water supply control valve, and secondly to the delivery rate of the peristaltic pump. In order to maintain a smooth biofilm with even liquid distribution the superficial biological growth was removed daily by means of a scraping instrument run vertically down from the top to the bottom of the plate. An experiment, wherein the rate of COD removal was measured at hourly intervals after scraping, showed that steady state conditions were achieved within 6 hours (figure 3.6). To ensure that samples were taken only at stablized steady state conditions a period of twenty-four hours was allowed to elapse between scraping and sampling. Samples, each consisting of about $100 \mathrm{ml}$ of liquid, were drawn off at various levels starting at the bottom of the reactor using a wedge-shaped tool which, when pushed horizontally into the slime, guided the falling liquid into an attached sample bottle. They were then filtered through whatman 542 paper to remove any suspended solids and micro-organisms which may have been present, diluted if necessary, using a Micromedic Auto- 


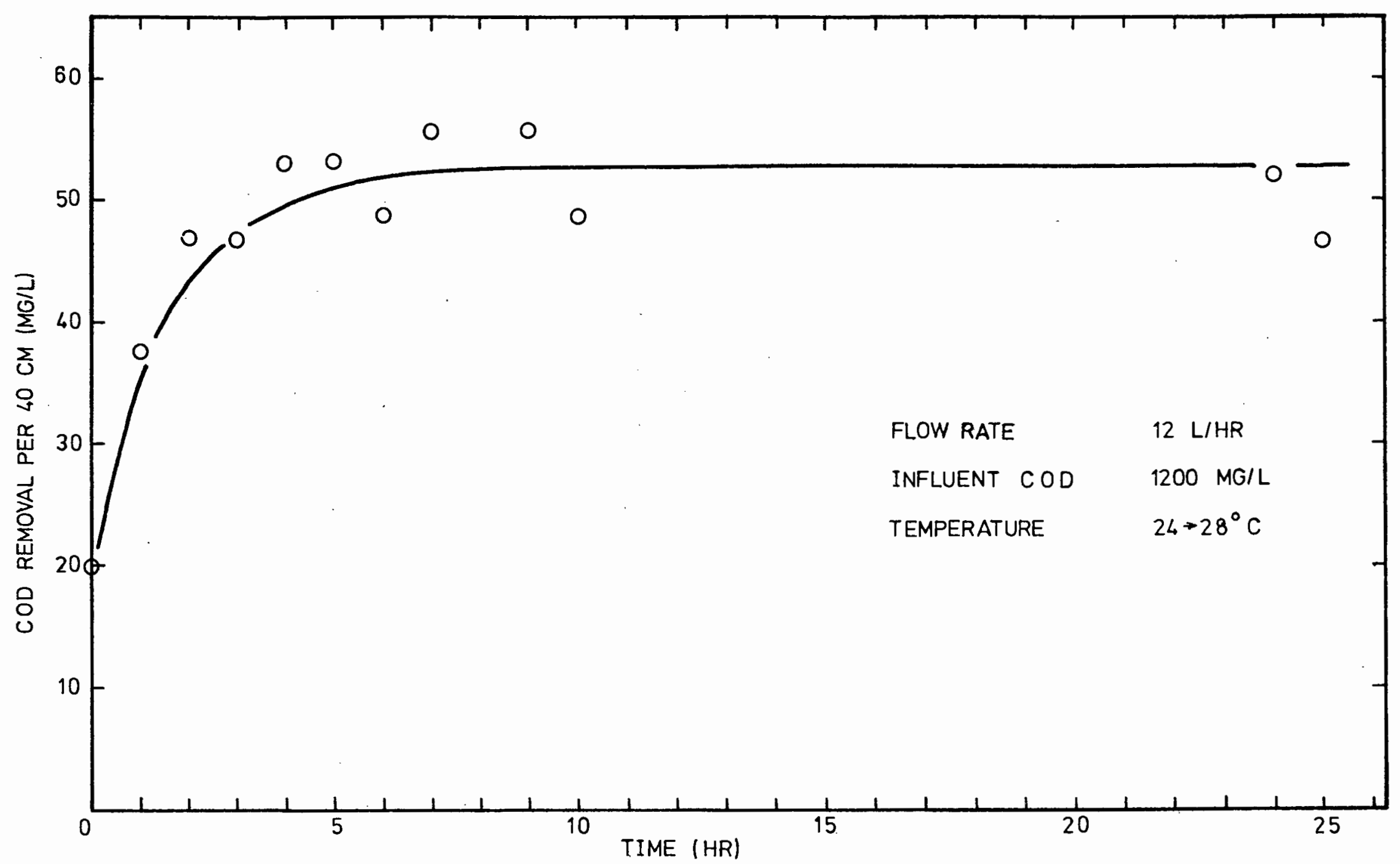

FIG. 3.6-DYNAMIC RESPONSE OF MICROBIAL FILM REACTOR AFTER REMOVAL OF SUPERFICIAL SLIME 
matic Pipette, and analysed for COD on a Techicon AutoAnalyser II. Air temperature, liquid temperature, and $\mathrm{pH}$ were recorded daily, and periodic estimates of the cell yield were made by relating the quantity of COD removed to the dry weight of the slime scraped off. When operating at high COD levels $(10000 \mathrm{mg} / \mathrm{l})$ the precision of the AutoAnalyser was not sufficient to expose any concentration difference between diluted samples taken from the top and bottom of the plate. An approximate value for the rate of COD removal, however, was obtained by measuring the total mass of slime produced over twenty-four hours and, using the yield previously determined at lower COD levels, calculating the corresponding COD consumption. clearly the results obtained in this manner were qualified by the assumption that cell yield is independent of: COD level. 
$\begin{array}{lllllll}C & H & A & P & T & E & R\end{array}$

\section{I EXPERIMENTAL RESULTS}

\subsubsection{Presentation and Discussion}

Figures 4.1 and 4.2 show the experimentally measured COD removals per $40 \mathrm{~cm}$ of reactor length plotted against the applied COD for liquid flow rates of $6,12,18$ and $24 \mathrm{l} / \mathrm{hr}$. Each point represents the average removal determined over a period of several days during which the feed concentration and flow rate were maintained as constant as possible. Detailed results are tabulated in appendix $E$ for each flow rate giving the influent and effluent COD levels, temperature, yield (if determined), average removals per $40 \mathrm{~cm}$, and maximum percentage deviations from this average. In no case did the effluent $\mathrm{pH}$ fall below 6,3. Figure 4.3 shows the experimentally determined cell yields for the various flow rates and applied COD's. No trend is discernable up to a COD of $5000 \mathrm{mg} / \mathrm{l}$ and varying the flow rate appears to have no effect.

In order to determine the steady state COD concentration profile from the top to the bottom of the reactor samples were drawn off during the $18 \mathrm{l} / \mathrm{hr}$ runs at levels of $0,40,80,120$ and $160 \mathrm{~cm}$ below the overflow weir. From these results, also tabulated in appendix $E$, it became clear that even at COD concentrations as low as $200 \mathrm{mg} / \mathrm{l}$ the profile did not deviate significantly from a straight line. In all further experiments, therefore, the profile was assumed to be linear and COD removals were determined by measuring only the influent and effluent concentrations. In section 4.2.3, figure 4.11, it is shown theoretically that this assumption is valid with only a slight deviation from linearity occurring at COD levels below $400 \mathrm{mg} / \mathrm{l}$.

Data reported by Jank and Drynan [36], who measured COD removals on a vertical microbial film at flow rates 
of $4,13,8,26,12,4$ and $17,1 \mathrm{l} / \mathrm{hr}$, have been adjusted by linear interpolation to correspond to 6,12 and $18 \mathrm{l} / \mathrm{hr}$ and the solid lines on figures 4.1 and 4.2 are curves fitted by least-squares analysis through these data. Good agreement between the two sets of data is evident.

The COD removals at 24,18 and $12 \mathrm{l} / \mathrm{hr}$ increased as the applied COD was raised up to about $1000 \mathrm{mg} / \mathrm{l}$ and thereafter became independent of it. This is clearly shown by the point for $12 \mathrm{l} / \mathrm{hr}$ which, at an applied coD of $9900 \mathrm{mg} / \mathrm{l}$, gives the same COD removal as that for an applied COD of $2000 \mathrm{mg} / \mathrm{l}$. The pattern for $6 \mathrm{l} / \mathrm{hr}$, however, was somewhat different with the COD removal steadily increasing as the applied COD was raised. Jank and Drynan observed this same phenomenon but offered no mechanistic explanation, putting it down to scatter in their results. It appears, however, that the process which limits COD removals at 12,18 and $24 \mathrm{l} / \mathrm{hr}$ is not as successful at $6 \mathrm{l} / \mathrm{hr}$, indicating that the hydraulic characteristics of the falling liquid film may be of increasing significance at low flow rates. Vaughan et al,[37], who studied the hydrodynamics of liquid films associated with biological slime reactors, reached a similar conclusion.

Figure 4.4 shows the COD removal rates measured at all four hydraulic loadings plotted against the applied COD. These data show that the capacity of the slime for COD removal is independent of the flow rate and has an upper limit of about $7,5 \mathrm{~g} / \mathrm{m}^{2} \mathrm{hr}$.

\subsubsection{Error Analysis}

From an examination of the data tabulated in appendix $E$ it is evident that the individual results are widely scattered. In this section possible reasons for this scatter are discussed.

Random variations in experimental results, if caused by errors inherent in the experimental and analytical systems used, are impossible to eliminate. It is therefore important to be aware not only of where these errors 


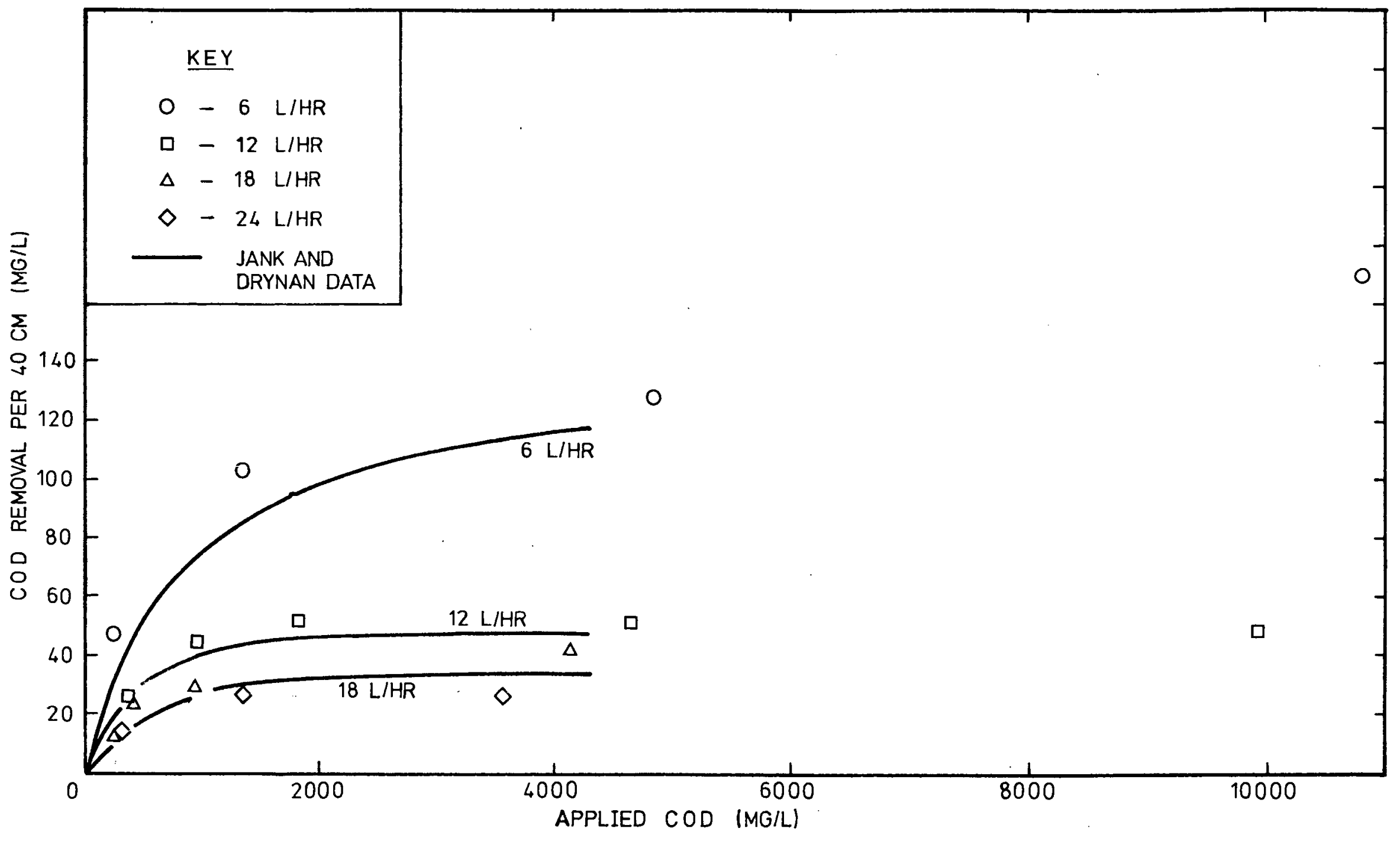

FIG 4.1- EXPERIMENTALLY DETERMINED COD REMOVALS PER $40 \mathrm{CM}$ 


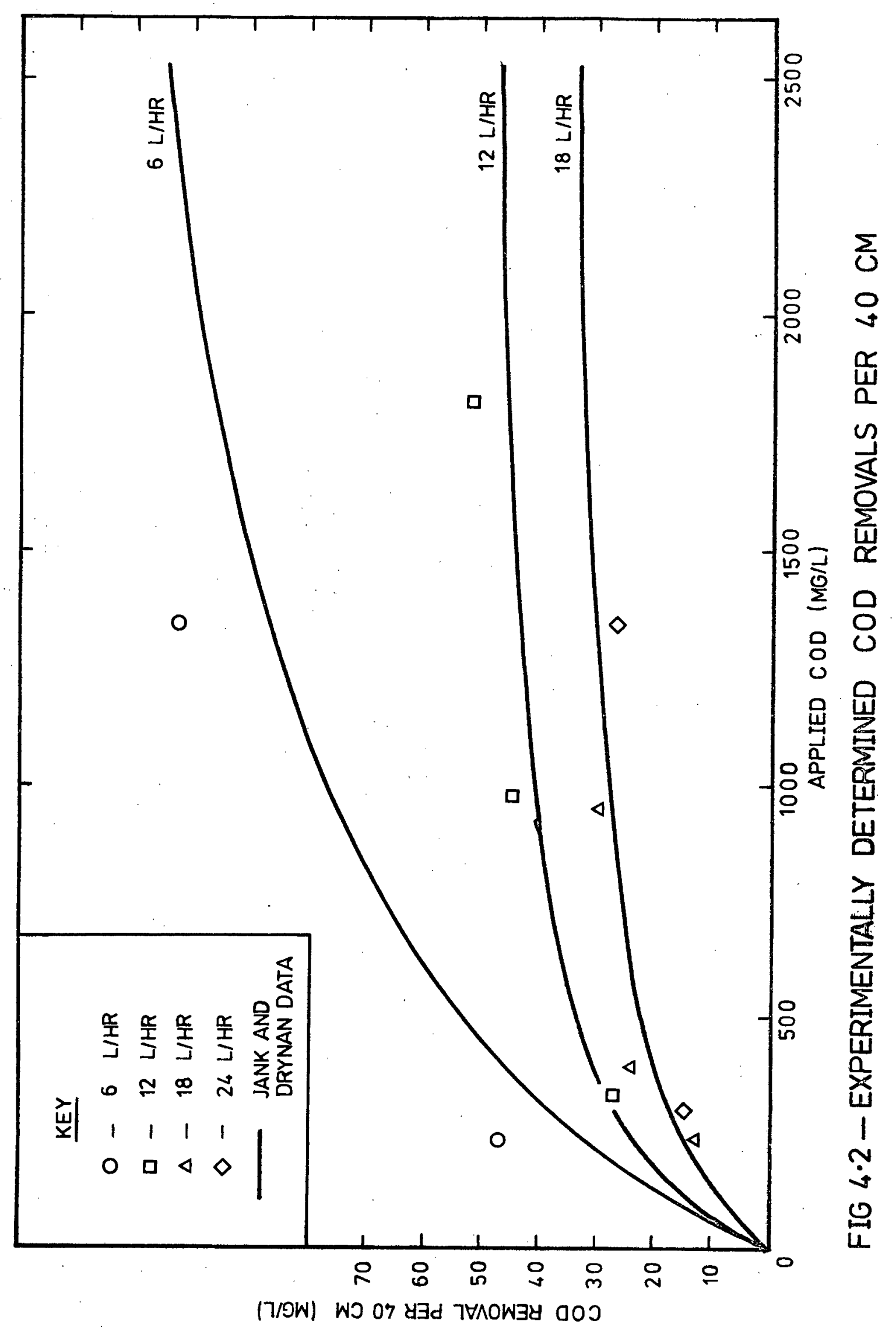




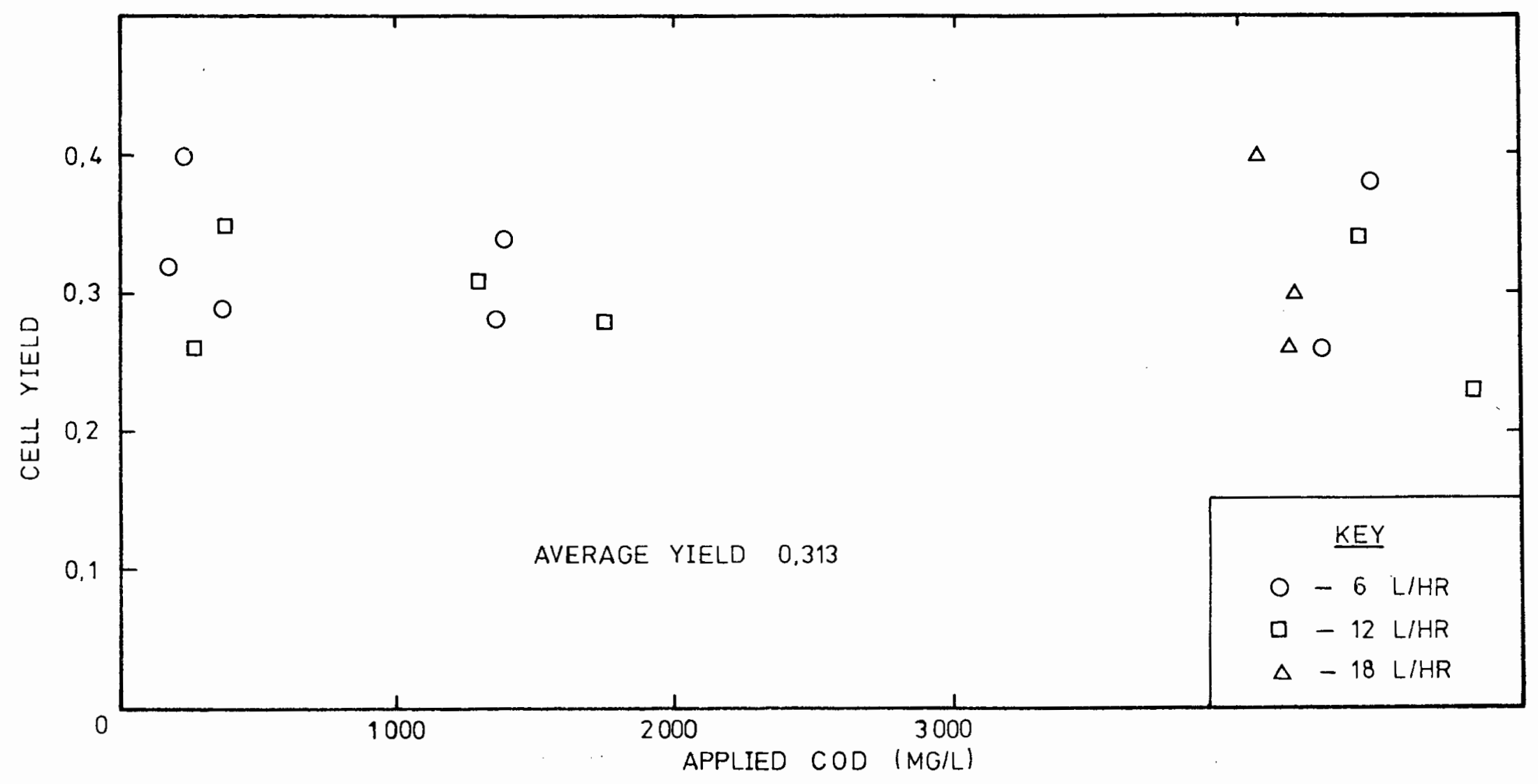

FIG.4.3-CELL YIELD VS APPLIED COD 


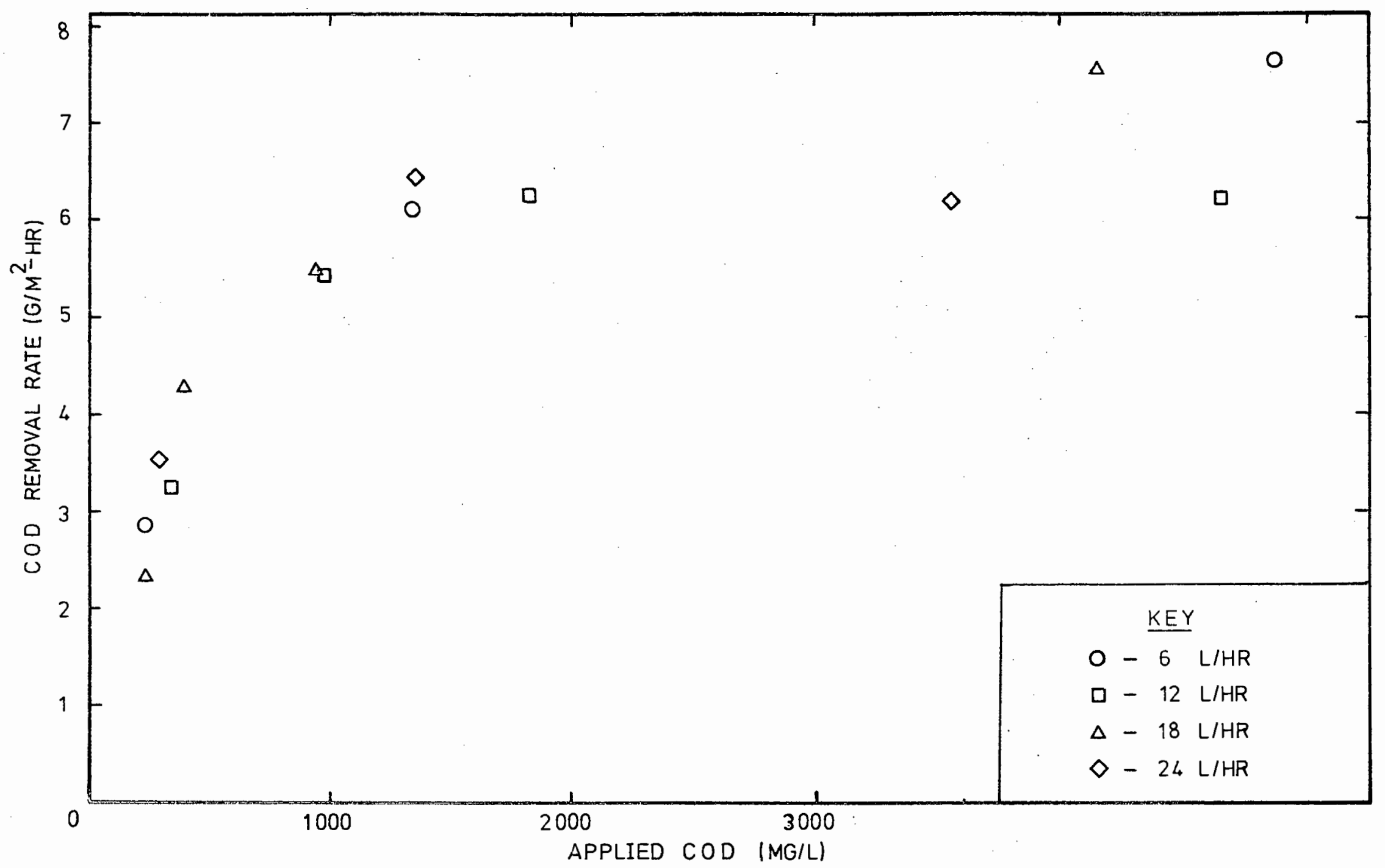

FIG. 4.4 - COD REMOVAL RATE VS APPLIED COD 
can arise, but also of their approximate magnitudes, so that an estimate can be made of the degree of scatter attributable to them. The possible sources of variation inherent in the biofilm reactor system and analytical technique used in this study are listed and discussed below.

(1) The Rotameter

The instrument used was rated to deliver the indicated flow with a variation of $\pm 2 \%$ at constant temperature which, when consideration of a $10^{\circ}$ temperature variation was included, increased to $\pm 5 \%$ of the indicated flow. The effect of this variation on the results could not be expected to be more than $10 \%$ and this only at the lower flow rates where sensitivity is high.

(2) Model 25002 Micromedic Automatic Pipette

In order to make use of the Technicon AutoAnalyser for COD analyses samples first had to be diluted to within the range 30 to $100 \mathrm{mg} / \mathrm{l}$. For this purpose the above automatic pipette was used. The coefficient of variation of the pipette was given by the manufacturers as $0,1 \%$ which, when measuring the concentration difference between two diluted samples, can result in a maximum error of $0,2 \%$. It can therefore be discounted as a significant contributer to the observed scatter.

(3) Technicon AutoAnalyser

Although no coefficient of variation for COD analysis was supplied by the manufacturers, experience showed its value to be approximately 5\%. This meant that the COD difference between two samples, as measured on the AutoAnalyser, could be in error by a maximum of $10 \%$. In an attempt to reduce this error all analyses were repeated in quadruplicate and the results averaged.

The above three possible sources of error, even when occurring simultaneously in the worst case, i.e. all tending to cause either a positive or negative deviation, fall far short of explaining the wide scatter in the results (average maximum deviation from mean removals per $40 \mathrm{~cm}$ of $30 \%$ ). Variations in temperature can be expected to 
cause scatter as shown in section 4.2 but even when the temperature had remained fairly constant over a period of several days the results were spread over a wide range.

A possible explanation for the scattered results is that the liquid film distribution could not be reproduced consistently from one run to the next. Although the superficial sline was removed between runs for the specific purpose of ensuring uniform distribution, a time of 24 hours was allowed to elapse before sampling the liquid. During this time random growth of the biofilm resulted in a non-uniform increase in film thickness, thereby causing an uneven surface and disturbing the liquid distribution. It is inconceivable that two runs could have identical liquid distribution histories and therefore, since the removal of COD is directly related to the area of adequately wetted biofilm, a variation in results from run to run can be expected. At low flow rates $(<6 \mathrm{l} / \mathrm{hr})$ when the liquid film is extremely thin, the effect will be more pronounced. This is confirmed by both the experimental data obtained for $6 \mathrm{l} / \mathrm{hr}$ and those reported by Jank and Drynan for $4,13 \mathrm{l} / \mathrm{hr}$.

\subsection{THEORETICAL RESULTS}

\subsubsection{COD Removal}

Since the temperature at which the experiments were performed was not constant but varied from $14^{\circ} \mathrm{C}$ to $25^{\circ} \mathrm{C}$, Theoretical predictions of the COD removals were computed for both $15^{\circ} \mathrm{C}$ and $25^{\circ} \mathrm{C}$. This was done by changing the value of the maximum specific growth rate, as discussed in section 2,4, from $0,45 \mathrm{hr}^{-1}$ at $20^{\circ} \mathrm{C}$ to $0,3 \mathrm{hr}^{-1}$ for $15^{\circ} \mathrm{C}$ and $0,6 \mathrm{hr}^{-1}$ for $25^{\circ} \mathrm{C}$. Figures 4.5 through 4.8 show the predicted curves together with experimental results for each of the four hydraulic loading rates. The average temperature at which the experiments were done is written alongside each point. A complete list of the parameters used to generate these theoretical curves is given in table 4.1. With the exception of the $6 \mathrm{l} / \mathrm{hr}$ curves agreement between the theoretical and experimental results 


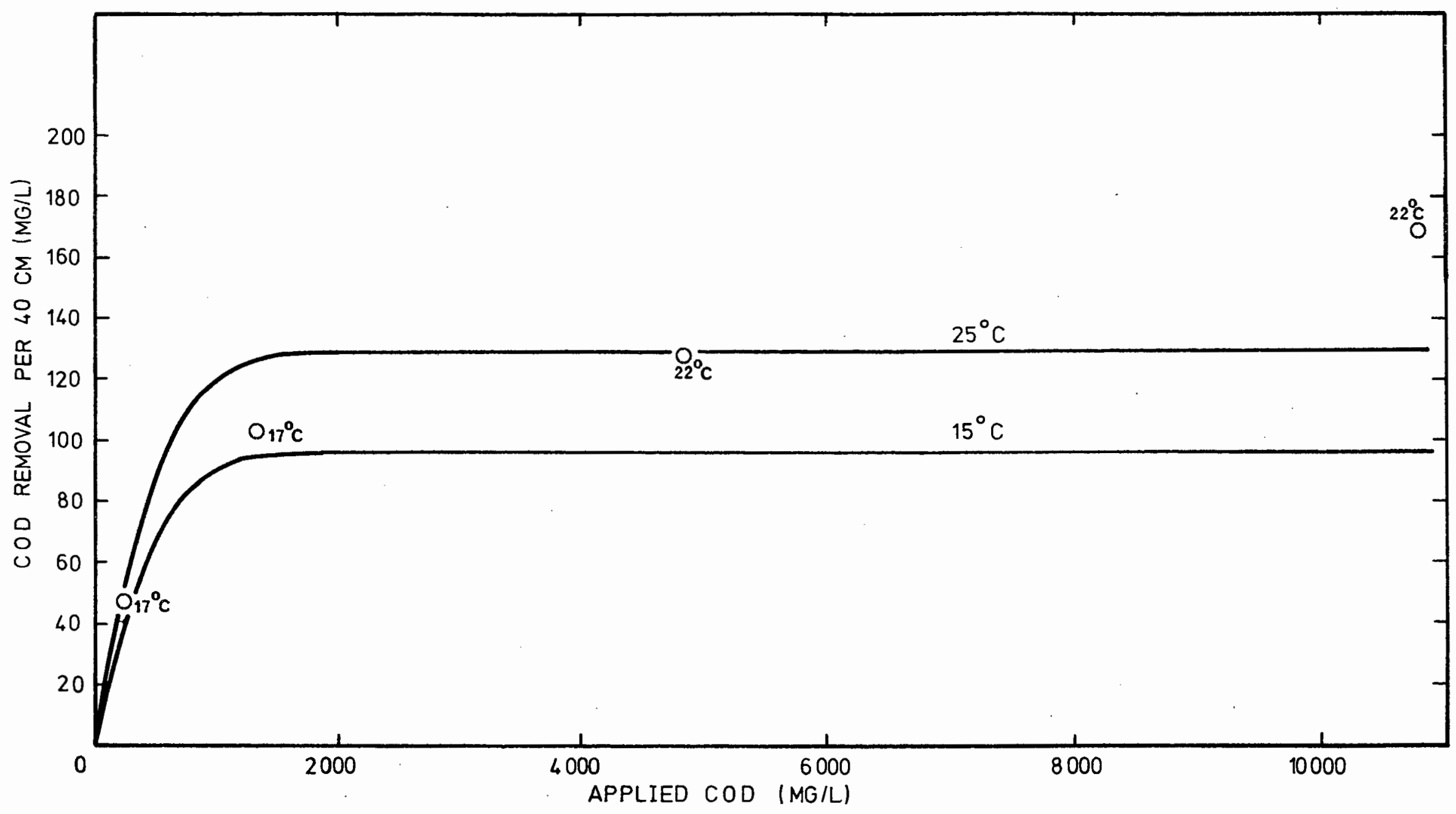

FIG 4.5 - PREDICTED CURVES FOR 6 L/HR AT $15^{\circ} \mathrm{C}$ AND $25^{\circ} \mathrm{C}$ 


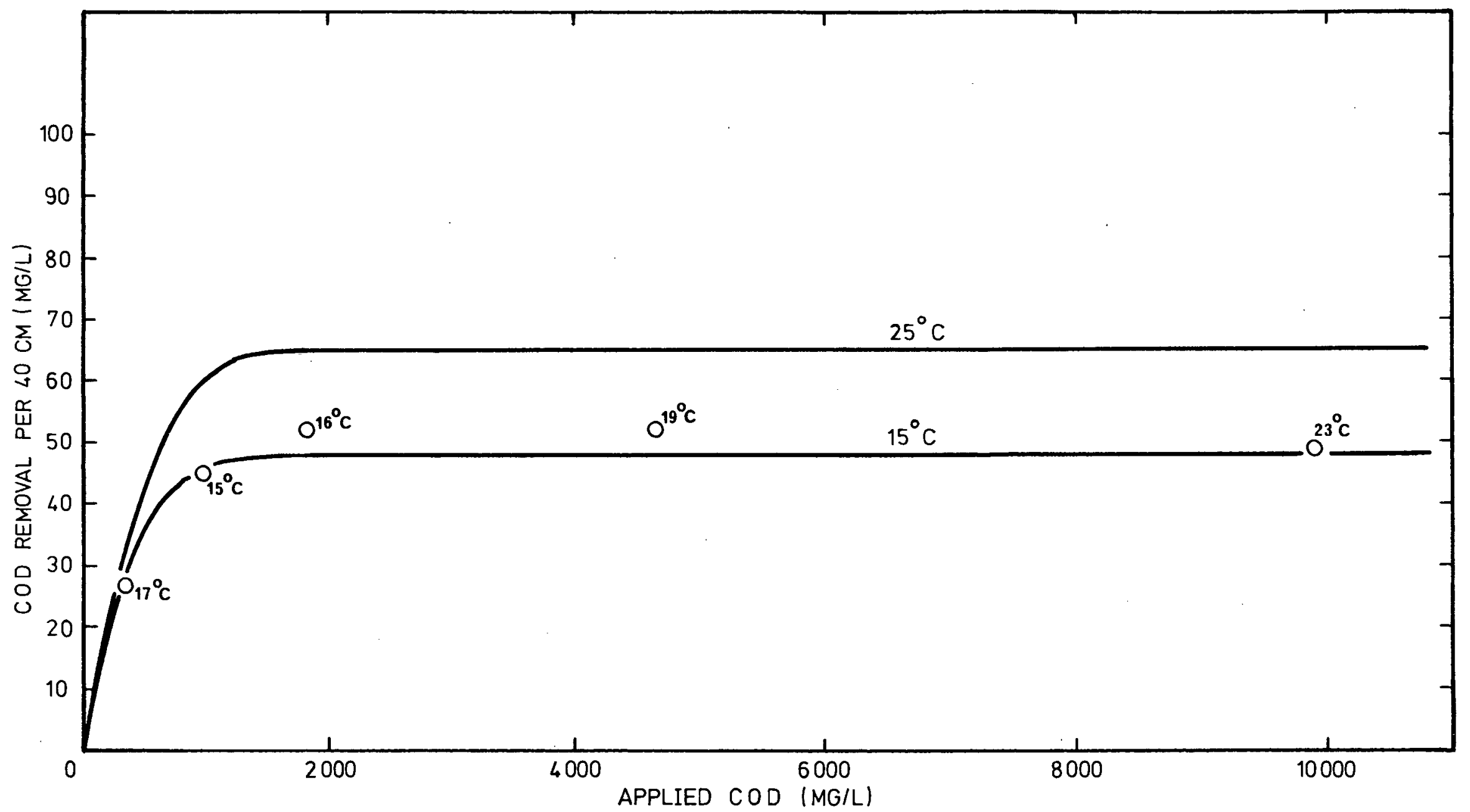

FIG. 4.6 - PREDICTED CURVES FOR 12 L/HR AT $15^{\circ} \mathrm{C}$ AND $25^{\circ} \mathrm{C}$ 


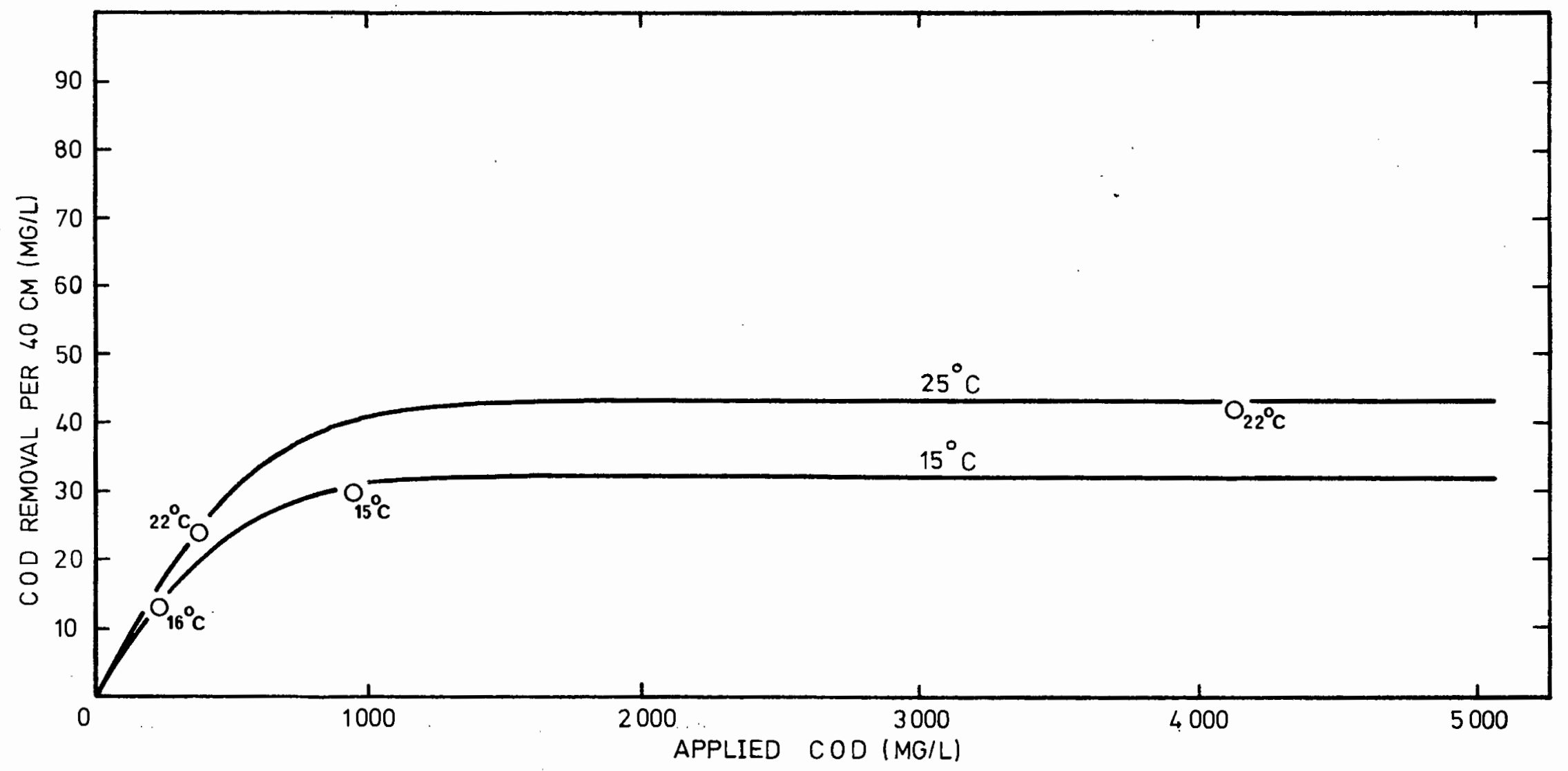

FIG. 4.7 -PREDICTED CURVES FOR 18 L/HR AT $15^{\circ} \mathrm{C}$ AND $25^{\circ} \mathrm{C}$ 


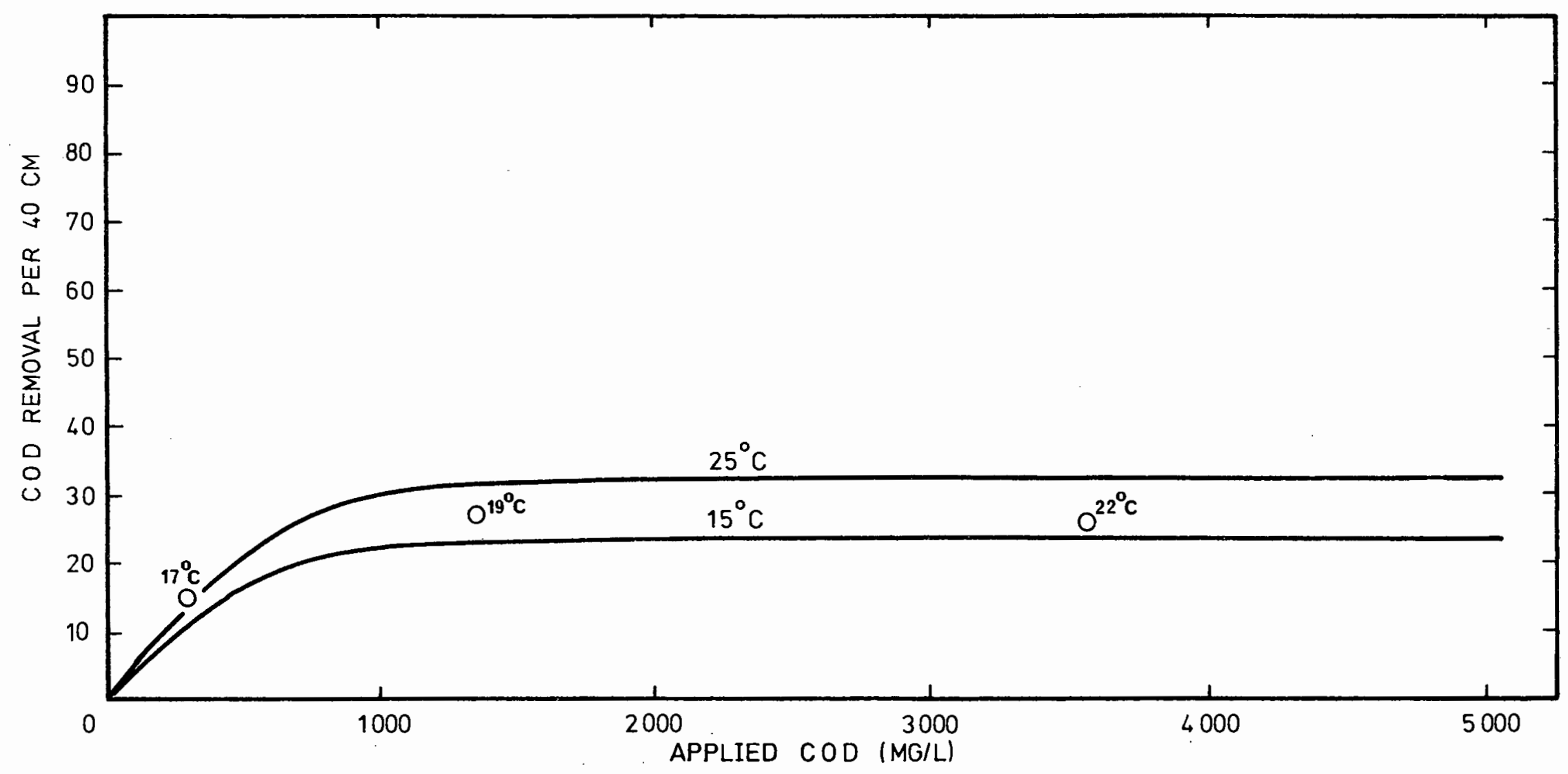

FIG. 4.8 - PREDICTED CURVES FOR 24 L/HR AT $15^{\circ} \mathrm{C}$ AND $25^{\circ} \mathrm{C}$ 
TABLE 4.1 - PARAMETER VALUES

\begin{tabular}{|l|c|}
\hline Parameter & Value \\
\hline$\hat{\mu}\left(15^{\circ} \mathrm{C}\right)$ & $0,0000834 \mathrm{sec}^{-1}$ \\
$\hat{\mu}\left(20^{\circ} \mathrm{C}\right)$ & $0,0001251 \mathrm{sec}^{-1}$ \\
$\hat{\mu}\left(25^{\circ} \mathrm{C}\right)$ & $0,0001668 \mathrm{sec}^{-1}$ \\
$\mathrm{Y}$ & 0,3 \\
$\mathrm{~K}_{\mathrm{S}}$ & $0,05 \mathrm{mg} / \mathrm{cm}^{3}$ \\
$\mathrm{~K}_{\mathrm{O}}$ & $0,000025 \mathrm{mg}^{\mathrm{c}} \mathrm{cm}^{3}$ \\
$\mathrm{~F}$ & $0,32 \mathrm{~g} \mathrm{oxygen} / \mathrm{g} \mathrm{COD}$ \\
$\mathrm{D}_{\mathrm{S}}$ & $0,0000069 \mathrm{~cm} / \mathrm{sec}$ \\
$\mathrm{D}_{\mathrm{O}}$ & $0,000025 \mathrm{~cm}^{2} / \mathrm{sec}$ \\
$\mathrm{X}^{2}$ & $90,0 \mathrm{mg} / \mathrm{cm}^{3}$ \\
$\mathrm{k}_{\mathrm{LS}}$ & $0,0004 \mathrm{~cm} / \mathrm{sec}$ \\
$\mathrm{k}_{\mathrm{LO}}$ & $0,04 \mathrm{~cm} / \mathrm{sec}$ \\
\hline
\end{tabular}

is good indicating that for flow rates greater than $6 \mathrm{l} / \mathrm{hr}$ the proposed theoretical model is an adequate description of the physical system. As pointed out in section 4.1.2, however, a high degree of scatter is expected at low flow rates. This may at least partially explain the observed trend although the possibility of a substrate removal mechanism different to the one described in this work occurring at low liquid flow rates should not be discounted. In any event since the recommended minimum wetting rate for plastic media filters is the equivalent of about $4,2 \mathrm{l} / \mathrm{hr}$ [62] on the experimental reactor, it is unlikely that full-scale industrial units would ever be operated in this low flow-rate regime and the problem therefore reduces to one of academic interest only.

\subsubsection{Active Depth; Oxygen and Substrate limitation}

Computed values of the active depth in the biological slime are plotted on figure 4.9 for each of the four hydraulic loading rates at applied COD concentrations ranging from 50 to $1900 \mathrm{mg} / \mathrm{l}$. The apparent scatter of points is not, however, predicted by the theory but is a 
consequence of the numerical solution technique. In this technique the substrate and oxygen concentration levels at which bio-oxidation ceased, and therefore which determined the active depth, were not, for computing reasons, defined to be exactly zero but were specified as ranges, zero to $1 \mathrm{mg} / \mathrm{l}$ for substrate and zero to $0,01 \mathrm{mg} / \mathrm{l}$ for oxygen. At these low concentrations the gradients of the substrate and oxygen profiles are almost zero and therefore, even though the above ranges are small, cutoff occurring at the upper limit will result in an active depth substantially different from that which would result if cutoff occurred at the lower limit.

At applied COD concentrations of greater than $500 \mathrm{mg} / \mathrm{l}$ the theory predicts that oxygen limits the operation of the biofilm reactor. This is shown by the oxygen concentration profile in the slime which falls to zero while the substrate profile remains positive. The active depth therefore becomes a function only of the dissolved oxygen concentration in the liquid which remains constant, hence the flattening of the curve. For applied COD concentrations below $300 \mathrm{mg} / \mathrm{l}$ the opposite is true with the substrate concentration profile aropping to zero while the oxygen profile remains positive. In this case the biofilm is substrate limited and the active depth is a function of the applied COD only. Within the applied COD range 300 to $500 \mathrm{mg} / \mathrm{l}$ both profiles fall to low levels leading to simultaneous substrate and oxygen limitation. This effectively causes a mutual reduction in the gradients of the profiles, thereby resulting in the occurrence of deeper active regions as shown in figure 4.9. Typical substrate and oxygen concentration profiles for the above three conditions are shown in figures $4.10 \mathrm{a}, \mathrm{b}$ and $c$. In their theoretical analysis of microbial slime performance Williamson and McCarty [40] derived the following inequality which, when satisfied, predicted that the slime would be substrate limited:- 


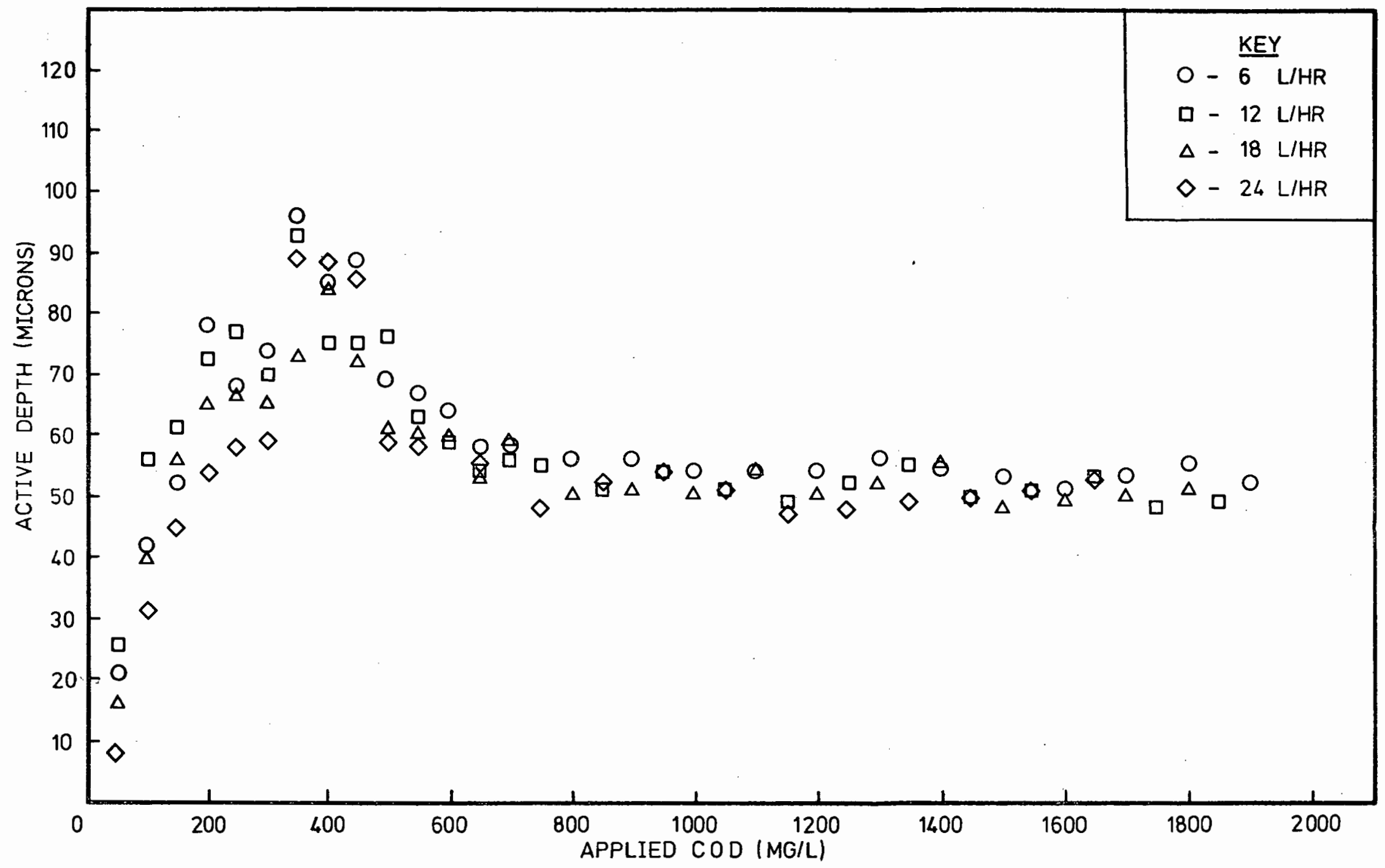

FIG. 4.9 - VARIATION IN ACTIVE DEPTH WITH APPLIED COD 
FIG.4-10-TYPICAL OXYGEN AND SUBSTRATE CONCENTRATION PROFILES IN THE BIOSLIME

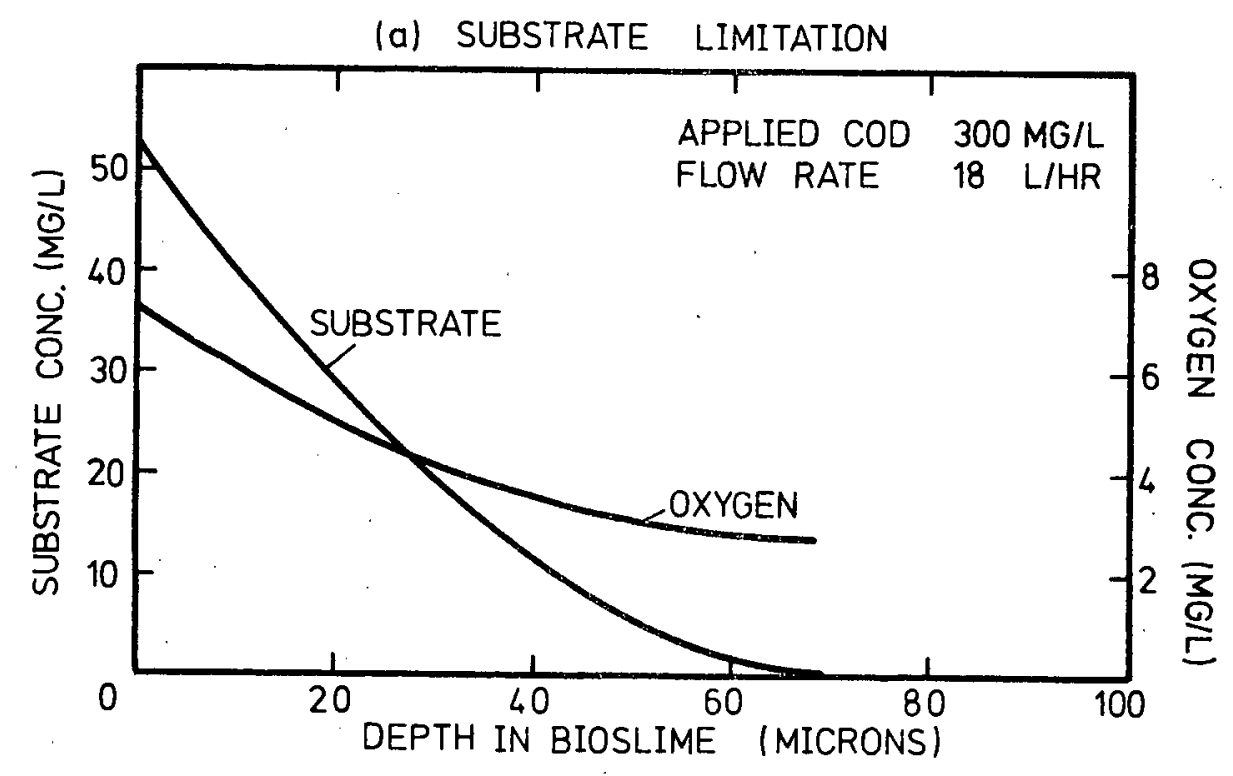

(b) SIMULTANEOUS SUBSTRATE AND OXYGEN LIMITATION
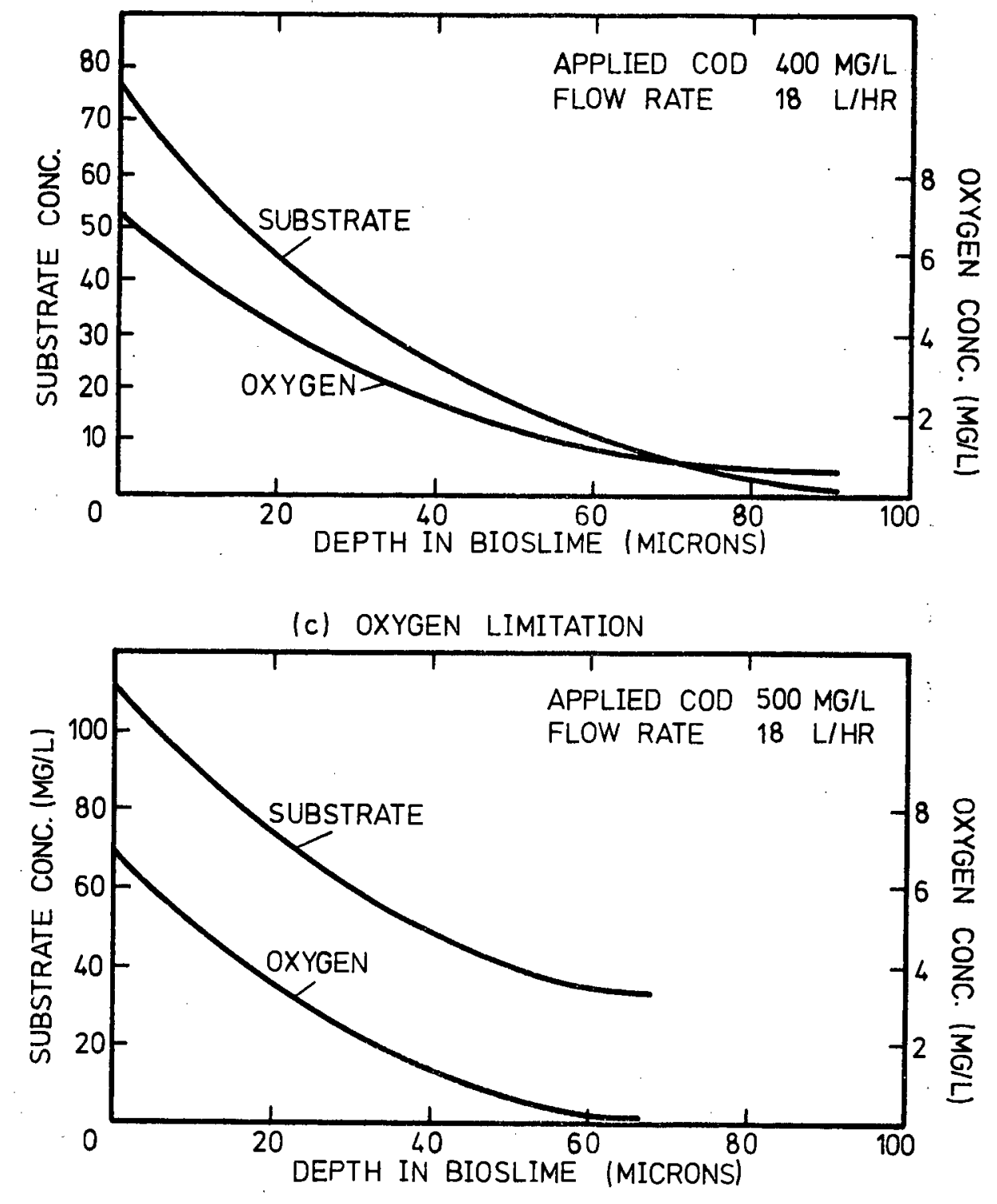


$$
0>\frac{\mathrm{K}_{\mathrm{O}}}{\mathrm{K}_{\mathrm{S}}} \cdot \mathrm{s}
$$

If it is assumed that for cases of substrate limitation oxygen concentrations do not fall below $0,2 \mathrm{mg} / \mathrm{l}$ at any point in the slime then the inequality predicts that $S$ should be greater than $400 \mathrm{mg} / \mathrm{l}$. This is in good agreement with the above figures which indicate a change from substrate to oxygen limitation occurring between applied COD's of 300 and $500 \mathrm{mg} / \mathrm{l}$.

The depth of the active region has been measured and reported values vary from 21 microns [43] to 150 microns [44]. These compare well with the theoretically predicted depths which range from 8 to 100 microns.

\subsubsection{Choosing filter design parameters}

By assuming an influent concentration to the reactor of $2000 \mathrm{mg} / \mathrm{l}$ COD theoretical curves were computed relating the residual $C O D$ in the liquid to the distance down the reactor for each liquid flow rate. These curves, plotted on figure 4.11, are useful if three of the four system parameters hydraulic load, influent COD, effluent COD, and length are known, as is the general case when designing industrial filters, and determination of the fourth is required.

Jank and Drynan [36], using their experimental data coupled with the theoretical equation derived by Kornegay and Andrews [23] for describing biological filter performance, plotted similar curves but did not extend them below a COD concentration of $200 \mathrm{mg} / \mathrm{l}$. They are therefore of limited use in the design of filters required to produce high quality effluents. 


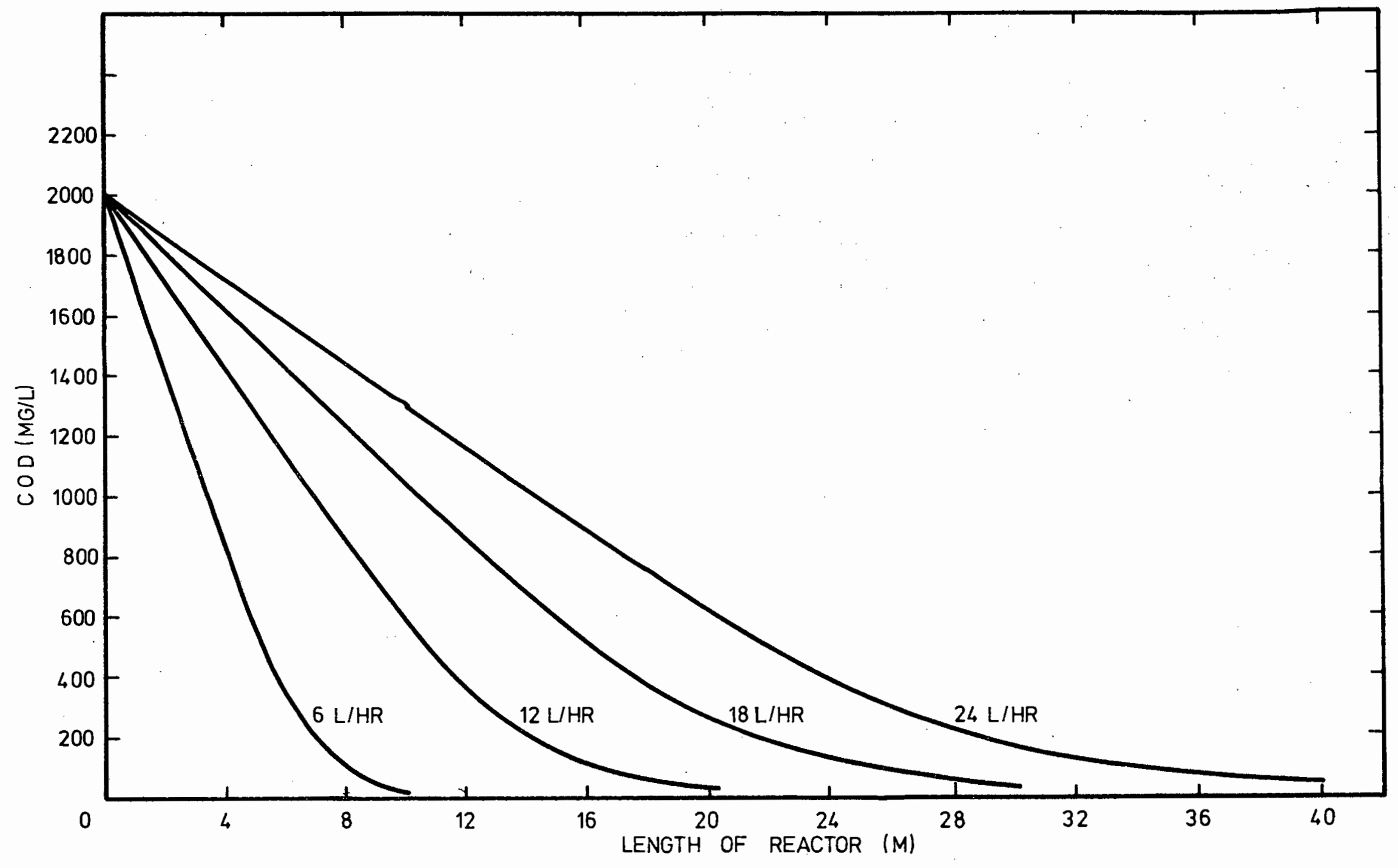

FIG, 4.11-COD DECREASE WITH REACTOR LENGTH 


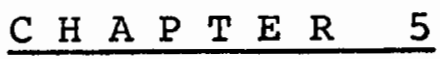

\section{CONCLUSIONS AND RECOMMENDATIONS}

The objectives with which this study was undertaken, as stated in section 1.2, have been realised insofar as a mathematical model has been developed describing the removal of substrate in a biological film reactor and experimental data have been obtained in support of it. The proposed theory was able to predict the COD removal capacity of a microbial slime subjected to flow rates and applied COD concentrations typical of industrial units using kinetic parameters which fell within ranges reported in the literature. It also indicated whether the operation of the film was limited by substrate, oxygen, or both simultaneously by calculating the substrate and oxygen profiles in the film and testing which one went to zero. Transition from substrate to oxygen limitation was shown to occur between applied COD concentrations of 300 to $500 \mathrm{mg} / \mathrm{l}$ which agreed well with the value of $400 \mathrm{mg} / \ell$ predicted by Williamson and McCarty [40].

From the results of the experimental part of this study several points emerged. These are:-

(i) As a result of uncertainty in the effects of temperature changes on biological slime performance the lack of temperature control was a serious arawback.

(ii) The data for $6 \mathrm{l} / \mathrm{hr}$ did not agree well with the theoretical predictions indicating that for this case the model was inadequate. An extension of the theoretical analysis to include hydrodynamic aspects of the liquid film may prove valuable in this respect.

(iii) The data for 12,18 and $24 \mathrm{l} / \mathrm{hr}$, although in good agreement with the theory, do not alone furnish sufficient evidence for acceptance of the model, firstly because of the large number of parameters involved, and secondly 
because only flow rates and applied COD concentrations were varied. Further experiments in which substrates other than glucose are used as well as tests in atmospheres with high oxygen concentrations would be valuable in either further substantiating the theory or exposing its shortcomings. 


\section{LITERATURE CITED}

(1) Lohmeyer, G.T., "Trickling filters and operation tips", Sewage and Ind. Wastes, 29, 1, 89 (1957).

(2) "Sewage treatment at military installations", National Research Council report, Sewage Wks. Journal, $\underline{18}, 787$ (1946).

(3) Velz, C.J., "A basic law for the performance of biological filters", Sewage Wks. Journal, 20, 607 (1948).

(4) Geber, B., "A new concept in trickling filter design", Sewage and Ind. Wastes, 26, 136 (1954).

(5) Fairall, J.M., "Correlation of trickling filter data", Sewage Wks., 28, 1067 (1956).

(6) Stack, V.R., "Theoretical performance of the trickling filtration process", Sewage and Ind. Wastes, 29, 987 (1957).

(7) Eckenfelder, W.W., "Trickling filtration design and performance", J. Sanit. Engng. Div. ASCE, 87, 33 (July 1961).

(8) Galler, W.S. and Gotaas, H.B., "Analysis of biological filter variables", J. Sanit. Engng. Div. ASCE, 90, 57 (Dec. 1964).

(9) Roberts, J., "Towards a better understanding of the high-rate biological film flow reactor theory", Water Research, 7, 1561 (1973).

(10) Baker, J.M. and Graves, Q.B., "Recent approaches for trickling filter design", J. Sanit. Engng. Div. ASCE, 94, SAl, 65 (1968).

(11) Bryan, E.H., "Moulded polystyrene for trickling filters", Ind. Wastes, 1,80 (1955).

(12) Schulze, K.L., "Experimental vertical screen trickling filter", Sewage and Ind. Wastes, 29, 458 (1957). 
(13) Schulze, K.I., "Load and efficiency of trickling filters", J. Wat. Pollut. Control Fed., 32 , 245 (1960).

(14) Germain, J.E., "Economical treatment of domestic waste by plastic medium trickling filters", J. Wat. Pollut. Control Fed., 38, 192 (1966).

(15) Eckenfelder, W.W., "Industrial Water pollution control", McGraw-Hill, N.Y. (1966).

(16) Gromiec, M.J.; Malina, J.F.; Eckenfelder, W.W., "Performance of plastic medium in trickling filters", Water Research, 6, 1321 (1972).

(17) Ames, W.F.; Behn, V.C.; Collings, W.Z., "Transient operation of the trickling filter", J. Sanit. Engng. Div. ASCE, 88, 21 (1962).

(18) Atkinson, B.; Busch, A.W.; Dawkins, G.C., "Recirculation, reaction kinetics and effluent quality in a trickling filter flow model". J.Wat. Pollut. Control Fed. , 35, 1307 (1963).

(19) Swilley, E.L.; Atkinson, B., "A mathematical model for trickling filters", Proc. 18th Ann. Ind. Waste Conf., Purdue University, Lafayette, Ind., 706 (1963).

(20) Maier, W.J.; Behn, V.C.; Gates, C.D., "Simulation of the trickling filter process", J. Sanit. Engng. Div. ASCE, 93, SA4, 91 (1967).

(21) Gulevich, W., "The role of diffusion in biological waste treatment", Ph.D. thesis, Johns Hopkins University, 1967 : Diss. Abstr., 28, B722 (1967).

(22) Kornegay, B.H. and Andrews, J.F., "Kinetics of fixed film biological reactors", Proc. 22nd Ind. Waste Conf., Purdue University, Lafayette; Ind., $620(1967)$.

(23) Kornegay, B.H. and Andrews, J.F., "Application of the continuous culture theory to the trickling filter process", Proc. 24th Ind. Waste Conf., Purdue university, Lafayette, Ind., 1398 (1969). 
(24) Atkinson, B.; Swilley, E.L.; Busch, A.W.; Williams, D.A., "Kinetics, mass transfer, and organism growth in a biological film reactor". Trans. Inst. Chem. Engrs. , 45, T257 (1967).

(25) Atkinson, B.; Daoud, I.S., "The analogy between microbiological 'ractions' and heterogenous catalysis", Trans. Inst. Chem. Engrs., 46, T19 (1968).

(26) Atkinson, B., Daoud, I.S.; Williams, D.A., "A theory for the biological film reactor", Trans, Inst. Chem. Engrs. , 46, T245 (1968).

(27) Atkinson, B.; Daoud, I.S., "Diffusion effects within microbial films", Trans. Inst. Chem. Engrs., 48, 245 (1970).

(28) Kehrberger, G.J. and Busch, A.W., "Effects of recirculation on the performance of trickling filter models", Proc. 24th Ann. Purdue Ind. Waste Conf., 37 (1969).

(29) Monadjemi, P., "Oxygen uptake and method of substrate purification in a model trickling filter", Ph.D. thesis, Cornell University, 1968 : Diss. Abstr., 29, B4206 (1969)。

(30) Lamb, R. and Owen (Mrs.) S.G.H., "A suggested formula for the process of biological filtration", Water Pollut. Control, 69, 209 (1970).

(31) Atkinson, B. and Williams, D.A., "The performance characteristics of a trickling filter with holdup of microbial mass controlled by periodic washing", Trans. Inst. Chem。Engrs., 49, 215 (1971).

(32) Mehta, D.S.; Davis, H.H.; Kińgsbury, R.P., "Oxygen theory in biological treatment plant design", J. Sanit. Engng. Div., ASCE, 98, SA3, 471 (1972).

(33) Quirk, T.P. "Scale-up and process design techniques for fixed film biological reactors", Water Research, 6, 1333 (1972). 
(34) Pirt, S.J., "Quantitative theory for the action of microbes attached to a packed column. Relevant to trickling filter effluent purification and to microbial action in soil", J.Appl. Chem. Biotechnol., $\underline{23}, 5,389$ (1973).

(35) Saunders, P.T. and Bazin, M.J., "Attachment of microorganisms in a packed column : metabolite diffusion through the microbial film as a limiting factor", J. Appl. Chem. Biotechnol. , 23, 11, 847 (1973).

(36) Jank, B.E. and Drynan, W.R., "Substrate removal mechanism of trickling filters", J. Environ. Engng. Div., ASCE, 99, EE3, 187 (1973).

(37) Vaughan, G.M.; Scott, P.H.; Holder, G.A., "Simulation of the trickling filtration process - studies of glucose removal and hydrodynamics", Journal of Chem. Eng. of Japan, 6, 6, 532 (1973).

(38) Atkinson, B. and Davies, I.J., "The overall rate of substrate uptake (reaction) by microbial films part 1 - A biological rate equation", Trans. Inst. Chem. Engrs., 52, 248 (1974).

(39) Atkinson, B. and How, S.Y., "The overall rate of substrate uptake (reaction) by microbial films part 2 - Effect of concentration and thickness with mixed microbial films", as for (38).

(40) Williamson; K.J. and McCarty, P.I., "A model of substrate utilization by bacterial films", submitted to J. Wat. Pollut. Control Fed., (1974).

(41) Williamson, K.J. and McCarty, P.I., "Verification studies of the biofilm model for bacterial substrate utilization", submitted to J. Wat. Pollut. Control Fed., (1974).

(42) Bungay, H.R.; Whalen, W.J., Sanders, W.M., "Microprobe techniques for determining diffusivities and respiration rates in microbial slime systems", Biotech. \& Bioeng., 11, 5, 765 (1969). 
(43) Sanders, W.M., "Oxygen utilization by slime organisms in continuous cultures", Int. Jour. Air and Water Poll. , 10, 253 (1966).

(44) Tomlinson, T.G. and Snaddon, D.H.M., "Biological oxidation of sewage by films of micro-organisms", Int. Jour. Air and Water Poll. , 10, 865 (1966).

(45) Hoehn, R.C., "The effects of thickness on the structure and metabolism of bacterial films", Ph.D. thesis, University of Missouri, Columbia 1970 : Diss. Abstr. , 31, B2728 (1970).

(46) Grieves, C.G., "Dynamic and steady state models for the rotating biological disk, reactor", Ph.D. thesis, Clemson University, 1972.

(47) Hansford, G.S. and Richter, H.I.H., "Anaerobic Digestion of Yeast Waste", Paper presented at the Seventh Int. Conf. on Wat. Pollut. Research, IAWPR, Paris (Sept. 1974).

(48) Monod, J., "The growth of Bacterial Cultures", A. Rev. Microbiol., 3, 371 (1949).

(49) Johnson, M.J., "Aerobic microbial growth at low oxygen concentrations", J. Bact., 94, 1, 101 (July 1967).

(50) Longmuir, I.S., "Respiration rate and oxygen consumption", Biochemistry J., 57, 81(954).

(51) Megee, III, R.D., "Interactions between dissimilar microbial populations and their environment", Ph.D. thesis, University of Minnesota, 1971.

(52) Bruce, A.M. and Merkens, J.C., "Recent studies of high-rate biological filtration", Wat. Pollut. Control, 69, 113 (1970).

(53) Mickley, H.S., Sherwood, T.K., Reed, C.E., "Applied mathematics in Chemical Engineering", 2nd edition, McGraw-Hill, Tokyo, 1957. 
(54) Mueller, J.A.; Boyle, W.C.; Lightfoot, E.N., "Oxygen diffusion through a pure culture floc of zoogloea Ramigera", Proc. 2lst Ind. Wast. Conf., Purdue University, Lafayette, Indiana, 964 (1966).

(55) Norman, W.S., "Absorbtion, Distillation and Cooling Towers", Longmans, 1961, pp 54.

(56) Perry, J.H., editor, "Chemical Engineers Handbook", 5th ed., pp 14-6.

(57) Johnstone, H.F. and Pigford, R.I., "Distillation in a Wetted-Wall Column", Trans. Am. Inst. Chem. Engrs., 38, 25 (1942).

(58) Treybal, R.E., "Mass Transfer Operations", 2nd ed., 1968 pp 45.

(59) Sherwood, T.K. and Pigford, R.L., "Absorbtion and Extraction", McGraw-Hi11, 1952, pp 267.

(60) Sanders, W.M.; Bungay, H.R.; Whalen, W.J.; "Oxygen microprobe studies of microbial slime films", Water 1970, A.I.Ch.E. Symp. Series, 107, 69 (1971).

(61) Chase, S.E., "Trickling Filters ... Past, Present and Future", Sew. Wks. Journal, 17, 929 (1945).

(62) Pamphlet published by Imperial Chemical Industries Ltd., Hyde, Cheshire in 1970 on the use of "Flocor" plastic medium.

(63) "'Flocor' process designs", published by Imperial Chemical Industries Ltd., Hyde, Cheshire.

(64) Heukelekian, H. and Rand, M.C., "Biochemical Oxygen Demand of pure Organic Compounds", Sewage and Ind. Wastes, 27, 9, 1040 (Sept. 1955).

(65) Ryder, D.N. and Sinclair, C.G., "Model for the Growth of Aerobic Micro-organisms Under Oxygen Limiting Conditions", Biotech. and Bioeng. , 14, 787 (1972). 
(66) Bird, R.B.; Stewart, W.E.; Lightfoot, E.N., "Transport Phenomena", John Wiley and Sons, Inc., N.Y.,1960

(67) McKinney, R.E., "Microbiology for Sanitary Engineers", McGraw-Hill, 1962 .

(68) Eckenfelder, W.W. and Barnhart, E.L., "Performance of a High Rate Trickling Filter Using Selected Media", J. Water Pollut. Control Fed., 35, 2, 1535 (1963).

(69) Aiba, S.; Humphrey, A.E.; Milis, N.F., "Biochemical Engineering", Academic Press, N.Y., 1965.

(70) Webb, F.C., "Biochemical Engineering", D. van Nostrand Co., London, 1964.

(71) Thimann, K.V., "The Life of Bacteria", 2nd ed., Macmillan, London, 1963.

(72) Bray, H.G. and White, K., "Kinetics and Thermodynamics in Biochemistry", 2nd ed., J.A. Churchill Ltd. , London, 1966.

(73) Gaffney, P.E. and Heukelekian, H., "Oxygen Demand Measurement Errors in pure Organic Compounds Nitrification studies", Sewage Ind. Wastes, 30, 4, 503 (April 1958). 
$\begin{array}{lllllllll}A & P & P & E & N & D & I & X & A\end{array}$

On Mass transfer of oxygen from the air to a falling film of liquid.

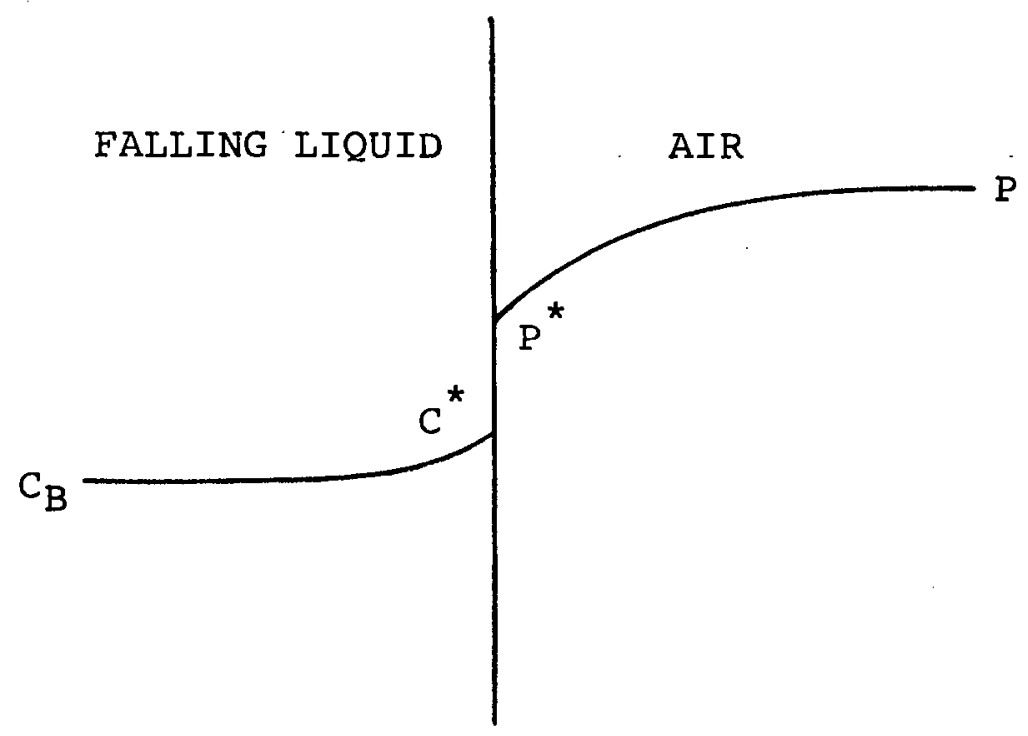

Consider the air-liquid interface illustrated above where

$$
\begin{aligned}
& \mathrm{P}=\text { partial pressure of oxygen in the air, } \\
& \mathrm{P}^{*}=\text { partial pressure of oxygen at the interface, } \\
& \mathrm{C}^{*}=\text { concentration of oxygen in the liquid at the } \\
& \quad \text { interface and } \\
& C_{B}=\text { bulk oxygen concentration in the liquid. }
\end{aligned}
$$

In this situation two overall mass transfer coefficients can be defined as follows:-

$$
\begin{array}{ll}
\text { (i) gas side i.e. } & K_{G}=\frac{N}{P-P_{B}} \\
\text { (ii) liquid side i.e. } & K_{L}=\frac{N}{C-C_{B}}
\end{array}
$$

where $N=$ mass flux of oxygen, $P_{B}$ is that partial pressure of oxygen which would be in equilibrium with $C_{B}$, i.e. $\mathrm{P}_{\mathrm{B}}=\mathrm{HC}_{\mathrm{B}}, \quad \mathrm{C}$ is that concentration of oxygen in the liquid 
which would be in equilibrium with $\mathrm{P}$, i.e. $\mathrm{C}=\mathrm{P} / \mathrm{H}$, and $H$ is the Henry's Law constant. Substituting into equations (1) and (2) gives

$$
\mathrm{K}_{\mathrm{G}}=\frac{\mathrm{N}}{\mathrm{P}-\mathrm{HC}_{\mathrm{B}}}
$$

and $\quad \mathrm{K}_{\mathrm{L}}=\frac{\mathrm{N}}{\mathrm{P} / \mathrm{H}^{-\mathrm{C}_{\mathrm{B}}}}$

Gases having low solubilities in water, such as carbon dioxide and oxygen, have such large Henry's Law constants that $K_{G}$ becomes negligible and mass transfer becomes dependent on the liquid film coefficient only [55]. Equation (4) may then be rearranged to

$$
C_{B}=\frac{P}{H}-\frac{N}{K_{L}}
$$

which gives the concentration of oxygen in the bulk of the liquid film for the general case where there is a flux of oxygen through the film. If there is no flux the concentration will be at its equilibrium value given by

$$
C_{B}=P / H
$$

Assuming air to contain 208 oxygen by volume the value of $\mathrm{H}$ for oxygen in the air-water system at $23^{\circ} \mathrm{C}$ is $4.2 \times 10^{4}$ [56]. This gives an equilibrium concentration of $8.96 \mathrm{mg} / \mathrm{l}$.

In order to determine whether oxygen transfer from the air to the falling liquid film represents a significant resistance to the aerobic degradation of organics in a biological film reactor the value of $\mathrm{N} / \mathrm{K}_{\mathrm{L}}$ must be calculated. If it is of the same order as $\mathrm{P} / \mathrm{H}$ then the resistance must be taken cognisance of but if it is very much less than $\mathrm{P} / \mathrm{H}$ the resistance may be assumed negligible, i.e. the liquid can be taken to be continuously saturated with oxygen. 
Estimation of $\mathrm{k}_{\mathrm{L}}$

For laminar falling films $\left(R_{e}<150\right)$ mass transfer occurs by molecular diffusion only and, since the flow conditions are mathematically definable, a theoretical value for the mass transfer coefficient may be calculated. This has been done by Johnstone and Pigford [57] who obtained a series solution relating the concentration of dissolved gas in the liquid to the gas-liquid contact time, and further developed by Treybal [58] who obtained the following equation for the mass transfer coefficient:-

$$
\mathrm{k}_{\mathrm{L}}=3,41 \frac{\mathrm{D}}{\delta}
$$

where $\mathrm{D}$ is the gas diffusivity in the liquid and $\delta$ is the liquid film thickness. Values of $\mathrm{k}_{\mathrm{L}}$ calculated with the above equation for the range of Reynold's numbers covered by the experimental programme, vary from $0,007 \mathrm{~cm} / \mathrm{sec}$ at a Reynold's number of 27 to 0,004 at a Reynold's number of 107. It is pointed out, however, by Sherwood and Pigford [59] as well as Treybal, that as a result of the onset of rippling at $R_{e}>20$ the actual coefficients can be expected to be several times larger than the theoretical predictions which do not account for surface purturbations. This is borne out by a comparison given by Sherwood and Pigford in which measured rates of oxygen absorbtion into falling films are shown to be up to seven times the predicted values. A value of $0,04 \mathrm{~cm} / \mathrm{sec}$ was, therefore, taken to represent a reasonable estimate of the actual value.

The maximum substrate utilization rate measured during the course of the experimental programme was about $0,5 \mathrm{mg}$ glucose $/ \mathrm{cm}^{2} \mathrm{hr}$. Assuming the rate of oxygen consumption to be directly related to that of substrate consumption by a proportionality constant of 0,32 (see section 2.3) the maximum mass flux of oxygen, $N$, is calculated to be $0,15 \mathrm{mg} / \mathrm{cm}^{2} \mathrm{hr}$. The value of $\mathrm{N} / \mathrm{K}_{\mathrm{L}}$ can now be calculated. 


$$
\begin{aligned}
\frac{\mathrm{N}}{\mathrm{K}_{L}} & =\frac{0,15 \times 1000}{0,04 \times 3600} \mathrm{mg} / \mathrm{l} \\
& =1,04 \mathrm{mg} / \mathrm{l}
\end{aligned}
$$

Substituting for $\mathrm{P} / \mathrm{H}$ and $\mathrm{N} / \mathrm{K}_{\mathrm{L}}$ into (5) yields

$$
C_{B}=8,96-1,04=7,92 \mathrm{mg} / \mathrm{l}
$$

i.e. under conditions of maximum flux the liquid film maintains a dissolved oxygen concentration level equal to $88 \%$ of the equilibrium solubility. 
\begin{tabular}{lllllllll} 
A & $\mathrm{P}$ & $\mathrm{P}$ & $\mathrm{E}$ & $\mathrm{N}$ & $\mathrm{D}$ & $\mathrm{I}$ & $\mathrm{X}$ & $\mathrm{B}$ \\
\hline
\end{tabular}

Fortran Program Listing and Sample Output

D!

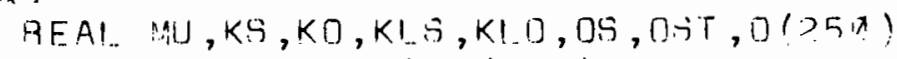

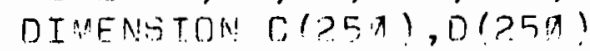

r.

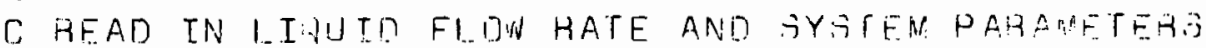

C

AEAD!9, $2 ! 1)$

READ $(0,1) M A I, X, Y, K S, K D, F, D S, D Z, K I S, K L O, D O$

WAITE (5, 11) MU, X, Y, KS, KD, F, D.S, DO , KI.S, KI.1), OZ

$\mathrm{J} 1=\sin$

$J ?=2,1: n: 4$

$73=? \cdot x \cdot x$

DO $35 \% J=J 1, J$, J?

C

C SET THF VALUE OF S1

$\mathrm{C}$

$S=J / 1 \ln : 1 / 1, \cdot 1$

QD-B*?5.9*3.6

WHITE $(5,21), 5$, ,, 0

$1991=5$

C

C INITIAI. GUESS DF S?

$\mathrm{C}$

S? $=51-9.91995$

$\mathrm{C}$

C CALCULATION DF INITIAL. CONDITTONS

$\mathrm{C}$

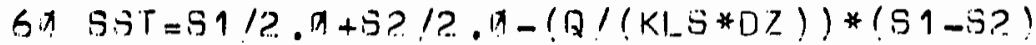

$O S=D .0$. An

OST $=0.5-($ G*F! (KI. D*DZ))*(S1-S? !

$C D N=? . x * M U * x ! Y$

COMP $=K() /(K D+0$ i $\Gamma)$

$B N=D S T+K() * A 1 . D F(C) M P$ )

$D S D X=-7 *(31-s ?)$ ? ( DS*DZ)

$D O D X=D S D X * F * D S / D 0$

$H=A . X 1$

AREA - . P

DENTH $=$ Q $\triangle$

$D(1)=1.1$

$N=1$

$C ! 1)=5: 3 T$

$0(1)=0.5 T$

$Y Y=D S D K$

$22=0017 x$

CDN!S $T=A A_{1} * x / Y$

C

C CAL_CU.ATTIN DF SIJATHATE AND OXYGEN PROFIIEG

C

$10 F N C=(C ! N) !(K B+C(N))) *(D(N) !(K D+O(N)))$

$A K 1=Y Y * H$

Al.. $1=K / * H$

C

C 
$c$

C

AM $1=$ ( CONSTT /DS ) *FNC*H

$A N 1=$ (CONST *F/DO) *FNC*H

$C C_{-}=C(N)+(A K 1 / 2 . X)$

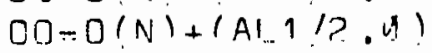

FNCI $=(C \Gamma * 00) /(K S+C C) *(K O+00)$ !

$A K ?=(Y Y+(A \cup 1) ? \cap) * \mathrm{H}$

Al. $2=(21+(A N 1 / 2 . A)) * H$

AM? = ( CINNST /DS $) * F N C A * H$

$A N ?=(C ! N i T * F ! D \cap) * F N C 1 * H$

$C C=C(N)+(A K) ! ? . M)$

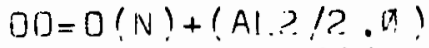

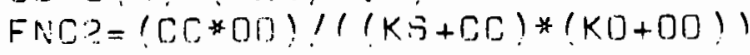

$A K ?=(Y Y+(A M 2 / 2 . A)) * H$

Al $3=(Z /+(A N ? / 2 . A)) * H$

AU3 $=$ (CONOT/DS! *FNC? *H

$A N 3=$ (CDNST *F! DO) *FNC? *H

$C \Gamma=C(N)+A K 3$

$\mathrm{OO}=0(\mathrm{~N})+\mathrm{Al} .3$

FNC $3=(C C * 0 O) !(K S+C C) *(K D+D O) !$

$A K A=(Y Y+A \cdot M) * H$

$A ! \wedge=(L \%+A N 3) * H$

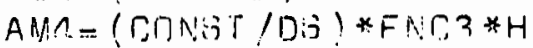

ANI $=($ CONST *F /DI) $* F N C 3 * H$

$D E I C=(A K 1+2 . A * A K ?+? . R * A K 3+A K 1) / 6 . !$

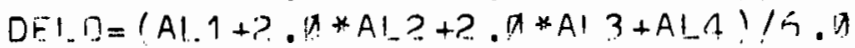

$D E L Y=(A M 1+2.0 * A M ?+2 . \emptyset * A 113+A M 4) ! / 5.4$

$D E L Z=(A N 1+? . A * A N ?+?$. D $* A N 3+A M n ! ! K . A$

$C(N+1)=C(N)+D F ! \cdot \Gamma$

$0(N+1)=D(N)+D=L O$

$Y Y=Y Y+D F I . Y$

$Z Z=Z \%+D F . . \%$

DENTH=DFPTH $+\mathrm{H}$

G1 $-(\Gamma) N) * n(N) ! /(K S+C(N)) *(K O+0 ! N) !$

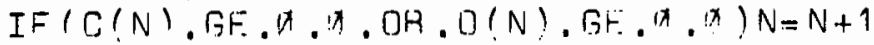

$D(N)=D(N-1 !+H$

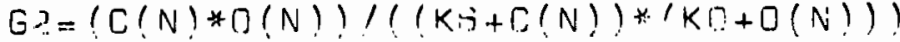

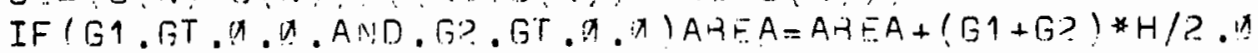

C

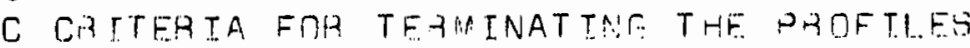

C

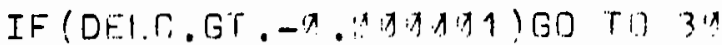

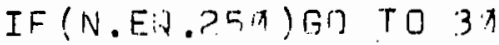

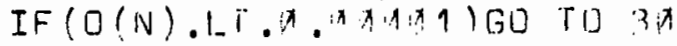

IF (C!N) . I.T. . . A 1 ! G! TO $3 ! x$

GD TI 1 II

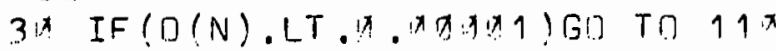

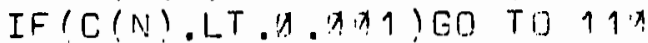

c.

C NEN EUJFSA FOH S?

C

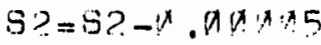

G1] TO $6: A$

$c$

C 


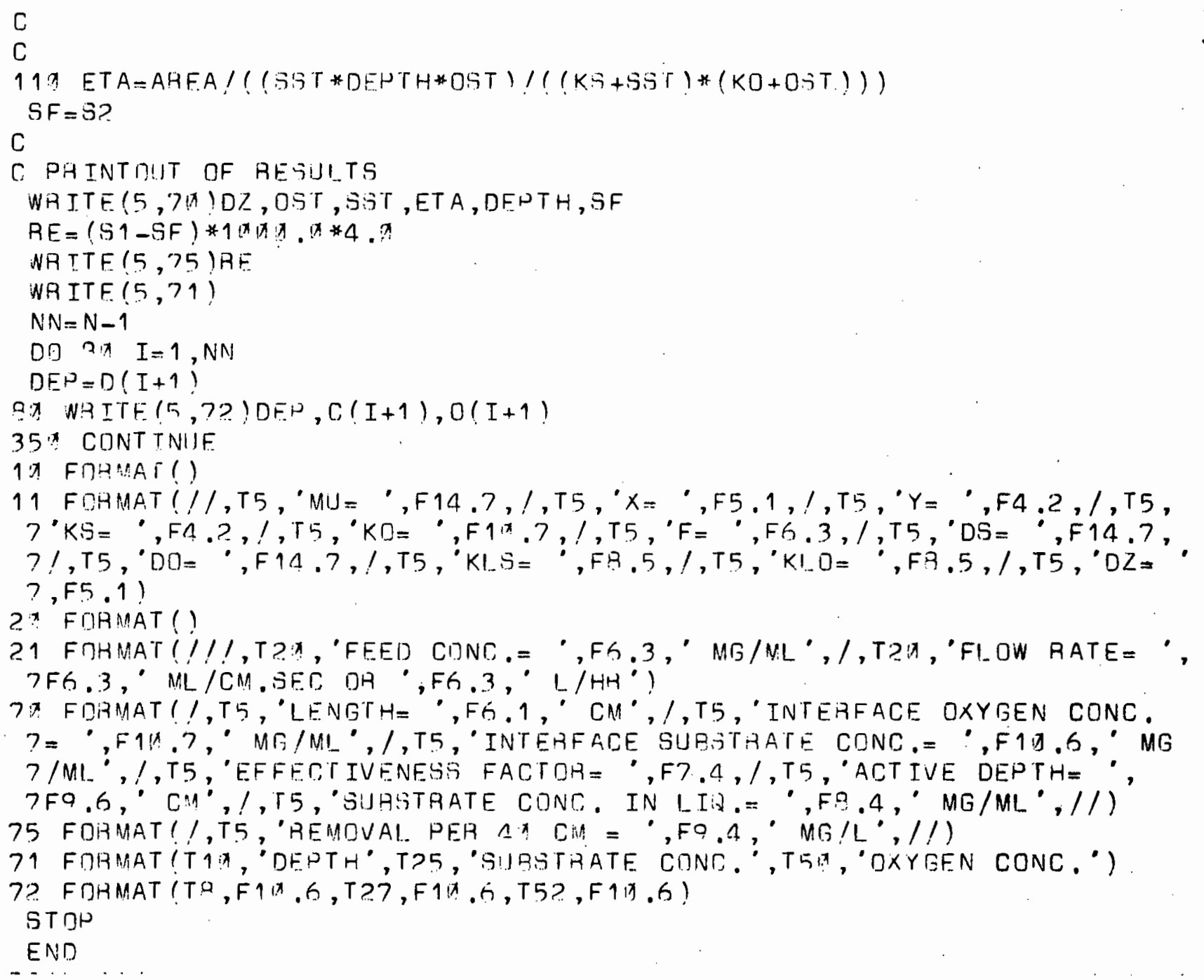

\section{Data Listing}

$\rho !$

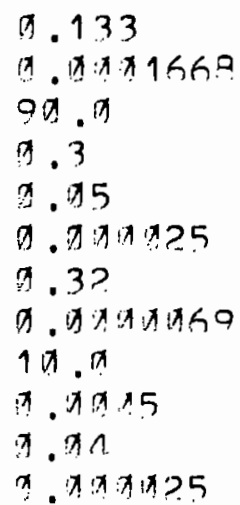




\section{Typical Output}

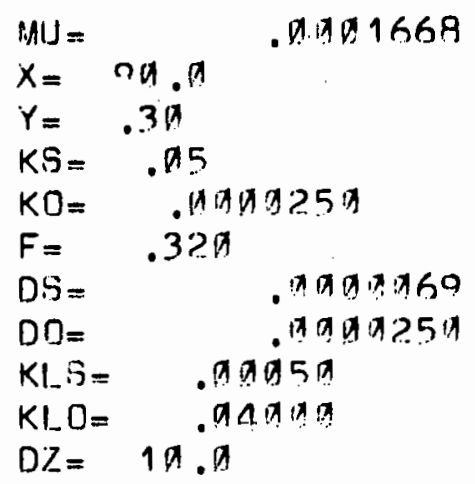

FEED CONC. $=$. . $\ M$ MG/ML

FLOW RATE $=.133 \mathrm{ML} /$ CM.SEC OH 11.971. L/HA

LENGTH= 19. CM

INTEAFACE OXYGEN CONC. = $1473563 \mathrm{MG} / \mathrm{ML}$

INTEHFACE SUASTHATE CONC. $=.36 \% 4 \mathrm{MG} / \mathrm{ML}$

EFFECT IVENESS FACTITR $=.4759$

ACTIVF DEPTH $=$. DGG2W CM

SUASTRATF CONE. IN LIQ.= .194A MG/ML

AEMOVAL. PEH AM CM $=24.1995 \mathrm{MG} / \mathrm{L}$

\begin{tabular}{|c|c|c|}
\hline DEPTH & SURSTQATE CONC. & OXYGEN CONE. \\
\hline .01010 & .034897 & .912255 \\
\hline . & .133776 & $.11 ? 156$ \\
\hline $.0 \sin 3$ & .732683 & .00795 \\
\hline $\ln \ln 4 x \sin$ & .931629 & . 19696 \\
\hline $.095 \times 10$ & $.93 \times 594$ & .90687 \\
\hline . & .1929576 & .09679 \\
\hline. $\operatorname{9an} 7 x$ & .1929594 & .09669 \\
\hline 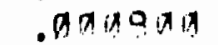 & .12276 .39 & .150651 \\
\hline $.9 \times 990$ & .026719 & .09653 \\
\hline 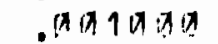 & .19259 .176 & .90645 \\
\hline$x \cap 11 \pi 9$ & .1924026 & .09637 \\
\hline $.012 \pi 0$ & $.1 \times 2.4 \times 7 \%$ & .00629 \\
\hline. $\sin 13 x$ & .123239 & $.0062 ?$ \\
\hline .901401 & .1222429 & .90615 \\
\hline . & $.02164 ?$ & .00609 \\
\hline $\operatorname{lng} 16 x$ & .129877 & .00601 \\
\hline $.017: x$ & .1921133 & .01595 \\
\hline. & $.91941 \%$ & .9058 \\
\hline $.01910 \pi$ & .918797 & $.105 B 2$ \\
\hline $.9120 x$ & .019024 & .00576 \\
\hline .91219 & .017360 & .00570 \\
\hline . 4 ดา? & .916715 & .99564 \\
\hline$. x \geqslant 23 x$ & $.016 \times 197$ & .99559 \\
\hline $.9024 x$ & .015479 & .09554 \\
\hline .4250 & .014885 & .00549 \\
\hline $.91 x \div 6 \times 1$ & .014309 & \\
\hline
\end{tabular}


A P P E N D I X C

Details of the Synthetic Feed Composition and Makeup

\section{Glucose Solution}

It was found that in order to prevent growth of microorganisms in the concentrated glucose solution, a minimum concentration of $100000 \mathrm{mg} / \mathrm{l}$ was required and this, therefore, was used as the lower concentration limit. Solutions were made up by weighing the required quantity of glucose in a clean 20 l bucket, adding sufficient distilled water to give a total volume of $10 \mathrm{l}$, and vigorously stirring until all the glucose had dissolved. This usually took between 12 and 24 hours, depending on the temperature. When high COD's (> $1000 \mathrm{mg} / \mathrm{l}$ ) were required in the feed to the reactor, the concentration of the glucose solution was increased up to $500000 \mathrm{mg} / \mathrm{l}$. . This was done to avoid using excessive volumes, thereby reducing the frequency of fresh solution makeup.

Nutrient Solution

The nutrient solution, also made up with distilled water in 10 \& quantities, consisted of dissolved inorganic salts containing nitrogen and phosphorus in sufficient quantities to ensure a COD : $N: P$ ratio in the diluted liquor of $100: 5: 1$ as recommended by Gaffney and Heukelekian [73]. Since the pH of the liquid in the reactor showed a tendency to drop as a result of organic acid synthesis and carbon dioxide production, sodium bicarbonate was added to the nutrient solution to offset this effect. The various trace elements required for organism growth were added by means of small quantities of previously prepared concentrated trace salt solution, the composition of which is given in table A4.1 below. These salts were dissolved in one litre of distllled water in the order presented [46]. 
TABLE A4.1 - COMPOSITION OF TRACE SALT SOLUTION

\begin{tabular}{|l|r|}
\hline \multicolumn{1}{|c|}{ Salt } & Quantity in Il \\
\hline & $20,23 \mathrm{~g}$ \\
$\mathrm{FeCl}_{2}$ & $4,25 \mathrm{~g}$ \\
$\mathrm{MnSO}_{4} \cdot \mathrm{H}_{2} \mathrm{O}$ & $3,40 \mathrm{~g}$ \\
$\mathrm{ZnCl}_{2}$ & $3,14 \mathrm{~g}$ \\
$\mathrm{CuSO}_{4} \cdot 5 \mathrm{H}_{2} \mathrm{O}$ & $3,00 \mathrm{~g}$ \\
$\mathrm{CoCl}_{2} \cdot 6 \mathrm{H}_{2} \mathrm{O}$ & $2,15 \mathrm{~g}$ \\
(NH $\left._{4}\right)_{6} \mathrm{MO}_{7} \mathrm{O}_{24} \cdot 4 \mathrm{H}_{2} \mathrm{O}$ & $1,19 \mathrm{~g}$ \\
$\mathrm{Na}_{2}{ }_{4} \mathrm{O}_{7} \cdot 1 \mathrm{OH}_{2} \mathrm{O}$ (Borax) & $189,0 \mathrm{~g}$ \\
Sodium Citrate & \\
\hline
\end{tabular}

The concentration of species in a typical feed solution of $1000 \mathrm{mg} / \mathrm{l}$ COD are listed in table A4.2.

\section{TABLE A4.2 - TYPICAL FEED SOLUTION COMPOSITION}

\begin{tabular}{|l|r|}
\hline \multicolumn{1}{|c|}{ Species } & Quantity \\
\hline $\mathrm{COD}$ (glucose) & $1000 \mathrm{mg}$ \\
$\left(\mathrm{NH}_{4}\right)_{2} \mathrm{SO}_{4}$ & $236 \mathrm{mg}$ \\
$\mathrm{K}_{2} \mathrm{HPO}_{4}$ & $55 \mathrm{mg}$ \\
$\operatorname{TraCe~Salt~Soln~}_{\mathrm{NaHCO}_{3}}$ & $0,2 \mathrm{ml}$ \\
\hline
\end{tabular}




\section{Temperature Measurements in the Falling Film}

Measurements were taken using thermocouples embedded at various levels down the length of the plate in order to establish whether the temperature of a falling water film changed significantly with distance from the top. These experiments were performed before seeding the plate with micro-organisms so that the measurements would be of the liquid temperature rather than the biological slime temperature. Flow rates of 10 and $18 \mathrm{l} / \mathrm{hr}$ were used and the results, tabulated below, showed that temperature profiles down the reactor were not significant.

TABLE A5.1 - RESULTS OF TEMPERATURE MEASUREMENTS

\begin{tabular}{|c|c|c|c|c|}
\hline Flow rate & 10 & $\ell / \mathrm{hr}$ & 18 & $\ell / \mathrm{hr}$ \\
\hline Wet bulb temp. $\left({ }^{\circ} \mathrm{C}\right)$ & 16.1 & 15.9 & 16.4 & 14.8 \\
\hline Air temp. & 20.0 & 20.0 & 19.9 & 18.9 \\
\hline Film temp at $0 \mathrm{~cm}$ & 25.0 & 18.4 & 25.7 & 17.7 \\
\hline Film temp at $1750 \mathrm{~mm}$ & 23.7 & $18: 2$ & 24.2 & 17.5 \\
\hline Temp. Change & 1.3 & 0.2 & 1.5 & 0.2 \\
\hline
\end{tabular}




\section{$\begin{array}{lllllllll}A & P & P & E & N & D & I & X & E\end{array}$}

Experimental Results

TABLE A6.1 - Flow rate $6 \mathrm{l} / \mathrm{hr}$

\begin{tabular}{|l|r|r|r|r|r|}
\hline Run no. & 1 & 2 & 3 & 4 & 5 \\
\hline COD in $(\mathrm{mg} / \mathrm{l})$ & 310 & 325 & 285 & 270 & 480 \\
COD out & 120 & 158 & 60 & 100 & 175 \\
$\Delta \mathrm{COD} / 40 \mathrm{~cm}$ & 42 & 37 & 50 & 38 & 68 \\
Temp. $\left({ }^{\circ} \mathrm{C}\right)$ & 18,2 & 17,5 & 16,9 & 16,4 & 17,0 \\
Yield & - & - & 0,32 & 0,40 & 0,29 \\
\hline
\end{tabular}

Mean $C O D=228 \mathrm{mg} / \mathrm{l}$

Mean $\triangle \mathrm{COD} / 40 \mathrm{~cm}=47 \mathrm{mg} / \mathrm{l}$

Mean temp. $=17,2^{\circ} \mathrm{C}$

Substrate removal rate $=2,82 \mathrm{~g} \mathrm{COD} / \mathrm{m}^{2} \mathrm{hr}$

Maximum deviation from mean $\triangle \mathrm{COD} / 40 \mathrm{~cm}=44 \%$

TABLE A6.2 - Flow rate $6 \mathrm{l} / \mathrm{hr}$

\begin{tabular}{|l|c|r|r|r|r|}
\hline \multicolumn{1}{|c|}{ Run no. } & 1 & 2 & 3 & 4 & 5 \\
\hline COD in (mg/l) & 1700 & 1520 & 1580 & 1580 & 1480 \\
COD out & 1093 & 1120 & 1063 & 1153 & 1120 \\
$\Delta$ COD/40 cm & 135 & 89 & 115 & 95 & 80 \\
Temp. $\left({ }^{\circ} \mathrm{C}\right)$ & 17,5 & 16,1 & 16,9 & 17,5 & 17,1 \\
Yield & 0,34 & - & - & 0,28 & - \\
\hline
\end{tabular}

Mean COD $=1341 \mathrm{mg} / \mathrm{l}$

Mean $\triangle C O D / 40 \mathrm{~cm}=103 \mathrm{mg} / \mathrm{l}$

Mean temp. $=17,0^{\circ} \mathrm{C}$

Substrate removal rate $=6,18 \mathrm{~g} \mathrm{COD} / \mathrm{m}^{2} \mathrm{hr}$

Maximum deviation from mean $\triangle \mathrm{COD} / 40 \mathrm{~cm}=318$ 
TABLE A6.3 - Flow rate $6 \mathrm{l} / \mathrm{hr}$

\begin{tabular}{|l|c|c|c|c|c|}
\hline \multicolumn{1}{|c|}{ Run no. } & 1 & 2 & 3 & 4 & 5 \\
\hline COD in (mg/l) & 4850 & 4810 & 5530 & 4570 & 5960 \\
COD out & 4121 & 4162 & 5031 & 4039 & 5479 \\
$\Delta$ COD $/ 40 \mathrm{~cm}$ & 162 & 144 & 111 & 118 & 107 \\
Temp. ( $\left.{ }^{\circ} \mathrm{C}\right)$ & 21,0 & 21,6 & 21,6 & 23,1 & 22,6 \\
Yield & - & 0,38 & - & 0,26 & - \\
\hline
\end{tabular}

Mean $\mathrm{COD}=4855 \mathrm{mg} / \mathrm{l}$

Mean $\triangle \mathrm{COD} / 40 \mathrm{~cm}=128 \mathrm{mg} / \mathrm{l}$

Mean temp. $=22,0^{\circ} \mathrm{C}$

Substrate removal rate $=7,68 \mathrm{~g} \mathrm{COD} / \mathrm{m}^{2} \mathrm{hr}$

Maximum deviation from mean $\triangle C O D / 40 \mathrm{~cm}=26,58$

TABLE A6.4 - Flow rate $12 \ell / \mathrm{hr}$

\begin{tabular}{|l|r|r|r|r|r|}
\hline \multicolumn{1}{|c|}{ Run no. } & 1 & 2 & 3 & 4 & 5 \\
\hline COD in (mg/l) & 400 & 313 & 423 & 447 & 377 \\
COD out & 263 & 217 & 323 & 320 & 225 \\
ACOD $40 \mathrm{~cm}$ & 30 & 21 & 22 & 28 & 34 \\
Temp. ( $\left.{ }^{\circ} \mathrm{C}\right)$ & 17,1 & 16,3 & 16,4 & 17,0 & 16,4 \\
Yield & - & 0,26 & - & 0,35 & - \\
\hline
\end{tabular}

Mean $C O D=331 \mathrm{mg} / \mathrm{l}$

Mean $\triangle \mathrm{COD} / 40 \mathrm{~cm}=27 \mathrm{mg} / \mathrm{l}$

Mean temp. $=16,6^{\circ} \mathrm{C}$

Substrate removal rate $=3,24 \mathrm{~g} \mathrm{COD} / \mathrm{m}^{2} \mathrm{hr}$

Maximum deviation from mean $\triangle \mathrm{COD} / 40 \mathrm{~cm}=268$ 
$\underline{\text { TABLE A6.5 }}-$ Flow rate $12 \mathrm{l} / \mathrm{hr}$

\begin{tabular}{|l|r|r|r|r|r|}
\hline \multicolumn{1}{|c|}{ Run no. } & 1 & 2 & 3 & 4 & 5 \\
\hline COD in (mg/l) & 1065 & 1125 & 1065 & 1050 & 1060 \\
COD out & 881 & 914 & 872 & 848 & 844 \\
$\Delta \mathrm{COD} / 40 \mathrm{~cm}$ & 41 & 47 & 43 & 45 & 48 \\
Temp. $\left({ }^{\circ} \mathrm{C}\right)$ & 15,8 & 16,0 & 15,0 & 14,8 & 14,5 \\
Yield & - & - & - & - & - \\
\hline
\end{tabular}

Mean $C O D=972 \mathrm{mg} / \mathrm{l}$

Mean $\triangle \mathrm{COD} / 40 \mathrm{~cm}=45 \mathrm{mg} / \mathrm{l}$

Mean temp. $=15,2{ }^{\circ} \mathrm{C}$

Substrate removal rate $=5,40 \mathrm{~g} \mathrm{COD} / \mathrm{m}^{2} \mathrm{hr}$

Maximum deviation from mean $\Delta \mathrm{COD} / 40 \mathrm{~cm}=8,98$

TABLE A6.6 - Flow rate $12 \mathrm{l} / \mathrm{hr}$

\begin{tabular}{|l|r|r|r|r|r|}
\hline \multicolumn{1}{|c|}{ Run no. } & 1 & 2 & 3 & 4 & 5 \\
\hline COD in (mg/l) & 1830 & 1860 & 2175 & 1890 & 1900 \\
COD out & 1601 & 1640 & 1851 & 1688 & 1702 \\
$\Delta$ COD $/ 40 \mathrm{~cm}$ & 51 & 49 & 72 & 45 & 44 \\
Temp. ( $\left.{ }^{\circ} \mathrm{C}\right)$ & 15,0 & 15,8 & 15,9 & 16,5 & 18,2 \\
Yield & - & 0,28 & - & - & 0,31 \\
\hline
\end{tabular}

Mean $\mathrm{COD}=1814 \mathrm{mg} / \mathrm{\ell}$

Mean $\triangle \mathrm{COD} / 40 \mathrm{~cm}=52 \mathrm{mg} / \mathrm{l}$

Mean temp. $=16,3^{\circ} \mathrm{C}$

Substrate removal rate $=6,24 \mathrm{~g} \mathrm{COD} / \mathrm{m}^{2} \mathrm{hr}$

Maximum deviation from mean $\Delta \mathrm{COD} / 40 \mathrm{~cm}=268$ 
TABLE $A 6.7$ - Flow rate $12 \ell / \mathrm{hr}$

\begin{tabular}{|l|r|r|r|r|r|}
\hline \multicolumn{1}{|c|}{ Run no. } & 1 & 2 & 3 & 4 & 5 \\
\hline COD in (mg/l) & 4517 & 4483 & 5017 & 5083 & 4628 \\
COD out & 4333 & 4384 & 4639 & 4818 & 4394 \\
$\Delta$ COD $/ 40 \cdot \mathrm{Cm}$ & 41 & 22 & 84 & 59 & 52 \\
Temp. ( $\left.{ }^{\circ} \mathrm{C}\right)$ & 19,8 & 18,8 & 19,1 & 19,6 & 19,2 \\
Yield & 0,34 & - & 0,23 & - & - \\
\hline
\end{tabular}

Mean $\mathrm{COD}=4630 \mathrm{mg} / \mathrm{l}$

Mean $\triangle \mathrm{COD} / 40 \mathrm{~cm}=52 \mathrm{mg} / \mathrm{l}$

Mean temp. $=19,3^{\circ} \mathrm{C}$

Substrate removal rate $=6,24 \mathrm{~g} \mathrm{COD} / \mathrm{m}^{2} \mathrm{hr}$

Maximum deviation from mean $\triangle \mathrm{COD} / 40 \mathrm{~cm}=38 \%$

TABLE A6.8 - Flow rate $18 \mathrm{l} / \mathrm{hr}$

\begin{tabular}{|l|c|c|c|c|c|}
\hline \multicolumn{1}{|c|}{ Run no. } & 1 & 2 & 3 & 4 & 5 \\
\hline COD in $(\mathrm{mg} / \mathrm{l})$ & 468 & 439 & 454 & 462 & 417 \\
COD out & 373 & 325 & 330 & 355 & 320 \\
$\Delta \mathrm{COD} / 40 \mathrm{~cm}$ & 21 & 25 & 28 & 24 & 22 \\
Temp. ( $\left.{ }^{\circ} \mathrm{C}\right)$ & 22,1 & 22,4 & - & 22,4 & 22,6 \\
Yield & - & - & - & - & - \\
\hline
\end{tabular}

Mean $\mathrm{COD}=395 \mathrm{mg} / \mathrm{l}$

Mean $\mathrm{COD} / 40 \mathrm{~cm}=24 \mathrm{mg} / \mathrm{l}$

Mean temp. $=22,4^{\circ} \mathrm{C}$

Substrate removal rate $=4,32 \mathrm{~g} \mathrm{COD} / \mathrm{m}^{2} \mathrm{hr}$.

Maximum deviation from mean $\Delta \mathrm{COD} / 40 \mathrm{~cm}=16,78$ 
TABLE A6.9 - Flow rate $18 \mathrm{l} / \mathrm{hr}$

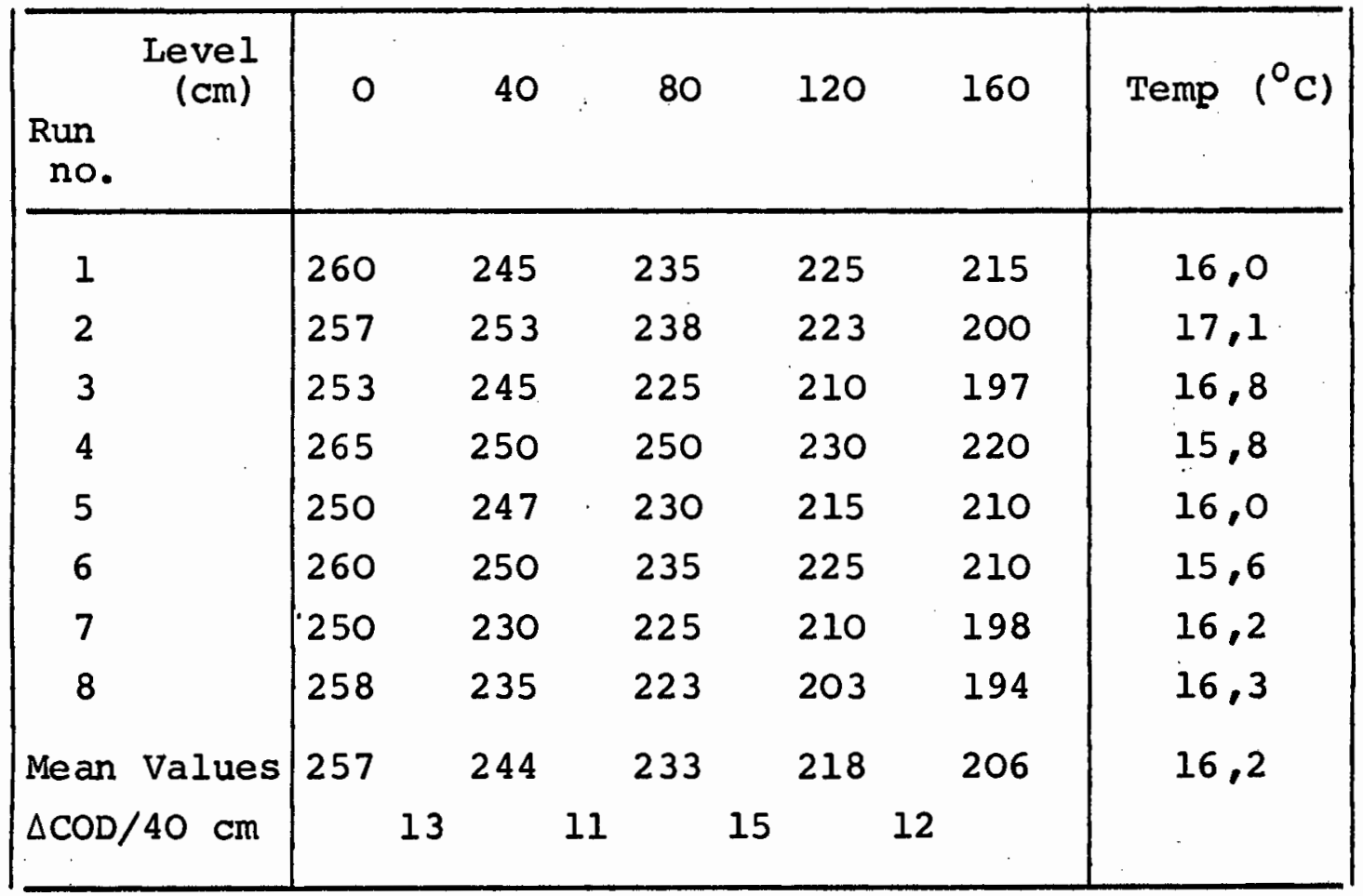

Mean $\operatorname{COD}=232 \mathrm{mg} / \mathrm{l}$

Mean $\triangle \mathrm{COD} / 40 \mathrm{~cm}=13 \mathrm{mg} / \mathrm{l}$

Mean temp. $=16,2^{\circ} \mathrm{C}$

Substrate removal rate $=2,34 \mathrm{~g} \mathrm{COD} / \mathrm{m}^{2} \mathrm{hr}$

Maximum deviation from mean $\Delta C O D / 40 \mathrm{~cm}=15,48$ 
TABLE A6.10 - Flow rate $18 \mathrm{l} / \mathrm{hr}$

\begin{tabular}{|c|c|c|c|c|c|c|}
\hline $\begin{array}{r}\begin{array}{r}\text { Level } \\
(\mathrm{cm})\end{array} \\
\text { Run } \\
\text { no. }\end{array}$ & 0 & 40 & 80 & 120 & 160 & Temp. $\left({ }^{\circ} \mathrm{C}\right)$ \\
\hline$I$ & 1040 & 1010 & 980 & 960 & 930 & 14,9 \\
\hline 2 & 950 & 930 & 910 & 900 & 850 & 14,0 \\
\hline 3 & 960 & 910 & 870 & 840 & 820 & 14,1 \\
\hline 4 & 1020 & 945 & 935 & 910 & 865 & 14,5 \\
\hline 5 & 1020 & 990 & 920 & 900 & 880 & 16,1 \\
\hline 6 & 1100 & 1070 & 1050 & 985 & 940 & 15,6 \\
\hline 7 & 995 & 950 & 930 & 885 & 860 & 14,9 \\
\hline 8 & 970 & 970 & 940 & 910 & 900 & 15,3 \\
\hline 9 & 1095 & 1070 & 1020 & 1010 & 1010 & 15,3 \\
\hline 10 & 960 & 940 & 905 & 900 & 855 & 15,8 \\
\hline Mean Values & 1010 & 979 & 946 & 920 & 891 & 15,1 \\
\hline$\triangle \mathrm{COD} / 40 \mathrm{~cm}$ & 32 & 33 & 26 & & & \\
\hline
\end{tabular}

Mean $\operatorname{COD}=949 \mathrm{mg} / \mathrm{l}$

Mean $\triangle \mathrm{COD} / 40 \mathrm{~cm}=30 \mathrm{mg} / \mathrm{l}$

Mean temp. $=15,1^{\circ} \mathrm{C}$

Substrate removal rate $=5,40 \mathrm{~g} \mathrm{COD} / \mathrm{m}^{2} \mathrm{hr}$

Maximum deviation from mean $\Delta \mathrm{COD} / 40 \mathrm{~cm}=13,4 \%$ 
TABLE A6.11 - Flow rate $18 \mathrm{l} / \mathrm{hr}$

\begin{tabular}{|l|r|r|r|r|r|}
\hline Run no. & 1 & 2 & 3 & 4 & 5 \\
\hline COD in (mg/l) & 4275 & 4125 & 4275 & 4150 & 4313 \\
COD out & 4095 & 3980 & 4075 & 3933 & 4106 \\
$\Delta$ COD $/ 40 \mathrm{~cm}$ & 40 & 32 & 44 & 48 & 46 \\
Temp. $\left({ }^{\circ} \mathrm{C}\right)$ & 22,4 & 21,0 & 22,3 & 22,3 & 21,5 \\
Yield & - & 0,40 & 0,26 & - & 0,30 \\
\hline
\end{tabular}

Mean $C O D=4133 \mathrm{mg} / \mathrm{\ell}$

Mean $\triangle \mathrm{COD} / 40 \mathrm{~cm}=42 \mathrm{mg} / \mathrm{l}$

Mean temp. $=21,9^{\circ} \mathrm{C}$

Substrate removal rate $=7,56 \mathrm{~g} \mathrm{COD} / \mathrm{m}^{2} \mathrm{hr}$

Maximum deviation from mean $\triangle C O D / 40 \mathrm{~cm}=23,8 \%$

TABLE A6.12 - Flow rate $24 \mathrm{l} / \mathrm{hr}$

\begin{tabular}{|l|r|r|r|r|r|}
\hline Run no. & \multicolumn{1}{|c|}{1} & 2 & 3 & 4 & \multicolumn{1}{c|}{5} \\
\hline COD in $(\mathrm{mg} / \mathrm{l})$ & 340 & 330 & 840 & 300 & 326 \\
COD out & 288 & 260 & 273 & 210 & 268 \\
$\Delta \mathrm{COD} / 40 \mathrm{~cm}$ & 12 & 16 & 15 & 20 & 13 \\
Temp. $\left({ }^{\circ} \mathrm{C}\right)$ & 16,3 & 17,2 & 17,7 & 16,9 & 16,4 \\
\hline
\end{tabular}

Mean $C O D=294 \mathrm{mg} / \mathrm{l}$

Mean $\triangle C O D / 40 \mathrm{~cm}=15 \mathrm{mg} / \mathrm{l}$

Mean temp. $=16,8^{\circ} \mathrm{C}$

Substrate removal rate $=3,60 \mathrm{~g} \mathrm{COD} / \mathrm{m}^{2} \mathrm{hr}$

Maximum deviation from mean $\triangle \mathrm{COD} / 40 \mathrm{~cm}=208$ 
TABLE A6.13 - Flow rate 24 l/hr

\begin{tabular}{|l|r|r|r|r|r|}
\hline Run no. & 1 & 2 & 3 & 4 & 5 \\
\hline COD in $(\mathrm{mg} / \ell)$ & 1560 & 1420 & 1560 & 1327 & 1200 \\
COD out & 1440 & 1300 & 1460 & 1200 & 1067 \\
$\triangle \mathrm{COD} / 40 \mathrm{~cm}$ & 27 & 27 & 22 & 28 & 30 \\
Temp. $\left({ }^{\circ} \mathrm{C}\right)$ & 18,5 & 17,8 & 18,5 & 18,8 & 19,4 \\
\hline
\end{tabular}

Mean $\mathrm{COD}=1353 \mathrm{mg} / \mathrm{l}$

Mean $\triangle \mathrm{COD} / 40 \mathrm{~cm}=27$

Mean temp. $=18,6^{\circ} \mathrm{C}$

Substrate removal rate $=6,48 \mathrm{~g} \mathrm{COD} / \mathrm{m}^{2} \mathrm{hr}$

Maximum deviation from mean $\triangle \mathrm{COD} / 40 \mathrm{~cm}=18,6 \%$

TABLE A6:14 - Flow rate $24 \mathrm{l} / \mathrm{hr}$

\begin{tabular}{|l|r|r|r|r|r|}
\hline \multicolumn{1}{|c|}{ Run no. } & 1 & 2 & 3 & 4 & \multicolumn{1}{c|}{5} \\
\hline COD in $(\mathrm{mg} / \mathrm{l})$ & 3650 & 3644 & 3369 & 3594 & 3806 \\
COD out & 3506 & 3538 & 3281 & 3413 & 3750 \\
$\Delta \mathrm{COD} / 40 \mathrm{~cm}$ & 32 & 24 & 20 & 40 & 12 \\
Temp. $\left({ }^{\circ} \mathrm{C}\right)$ & 21,6 & 22,4 & 22,2 & 21,3 & 21,0 \\
\hline
\end{tabular}

Mean $C O D=3555 \mathrm{mg} / \mathrm{l}$

Me an $\triangle \mathrm{COD} / 40 \mathrm{~cm}=26 \mathrm{mg} / \mathrm{l}$

Mean temp. $=21,5^{\circ} \mathrm{C}$

Substrate removal rate $=6,24 \mathrm{~g} \mathrm{COD} / \mathrm{m}^{2} \mathrm{hr}$

Maximum deviation from mean $\triangle \mathrm{COD} / 40 \mathrm{~cm}=54 \%$ 
RESULTS FOR SUBSTRATE REMOVAL AT HIGH COD VALUES

The results given below in tables $A 6.15$ and $A 6.16$ were obtained by measuring the mass of biological material produced over a fixed period of time and calculating, assuming a cell yield of 0,3 , the rate of substrate removal.

$\underline{\text { TABLE } A 6.15}-$ Flow rate $12 \mathrm{l} / \mathrm{hr}$

\begin{tabular}{|c|r|r|r|r|r|c|}
\hline Run no. & 1 & 2 & 3 & 4 & 5 & Mean Values \\
\hline COD in & 10 o0o & 10500 & 10000 & 9000 & 10000 & 9900 \\
Temp. $\left({ }^{\circ} \mathrm{C}\right)$ & 23,2 & 23,0 & 23,9 & 22,1 & 22,8 & 23,0 \\
$\Delta \mathrm{COD} / 40 \mathrm{~cm}$ & 33 & 61 & 50 & 57 & 45 & 49 \\
\hline
\end{tabular}

TABLE A6.16 - Flow rate $6 \mathrm{H} / \mathrm{hr}$

\begin{tabular}{|l|r|r|r|r|r|r|}
\hline$\therefore$ Run no. & 1 & 2 & 3 & 4 & 5 & Mean Values \\
\hline COD in & 11000 & 11000 & 10000 & 11000 & 11000 & 10800 \\
Temp. $\left({ }^{\circ} \mathrm{C}\right)$ & 22,8 & 22,5 & 21,9 & 23,0 & 21,8 & 22,4 \\
$\Delta \mathrm{COD} / 40 \mathrm{Cm}$ & 169 & 198 & 134 & 156 & 188 & 169 \\
\hline
\end{tabular}

